Chemosphere

Manuscript Draft

Manuscript Number: CHEM60158R2

Title: Nanopesticide based on botanical insecticide pyrethrum and its potential effects on honeybees

Article Type: Research paper

Section/Category: Toxicology and Risk Assessment

Keywords: Nanopesticide; Biocide; Sustainable agriculture, Solid lipid nanoparticles; Bees.

Corresponding Author: Dr. Leonardo Fernandes Fraceto, Ph.D

Corresponding Author's Institution: State University of São Paulo

First Author: Cristiane Ronchi de Oliveira, D.D.

Order of Authors: Cristiane Ronchi de Oliveira, D.D.; Caio Eduardo Domingues, D.D.; Nathalie de Melo, PhD; Thaisa Roat, PhD; Osmar Malaspina, Dr.; Monica Jones-Costa, Dr.; Elaine Silva-Zacarin, Dr.; Leonardo Fraceto, Dr.

Abstract: Nanotechnology has the potential to overcome the challenges of sustainable agriculture, and nanopesticides can control agricultural pests and increase farm productivity with little environmental impact. However, it is important to evaluate their toxicity on non-target organisms, such as honeybees (Apis mellifera) that forage on crops. The aims of this study were to develop a nanopesticide that was based on solid lipid nanoparticles (SLNS) loaded with pyrethrum extract (PYR) and evaluate its physicochemical properties and short-term toxicity on a nontarget organism (honeybee). SLN+PYR was physicochemically stable after 120 days. SLN+PYR had a final diameter of $260.8 \pm 3.7 \mathrm{~nm}$ and a polydispersion index of $0.15 \pm 0.02 \mathrm{~nm}$, in comparison with SLN alone that had a diameter of $406.7 \pm 6.7 \mathrm{~nm}$ and a polydispersion index of $0.39 \pm$ $0.12 \mathrm{~nm}$. SLN+PYR had an encapsulation efficiency of 99\%. The survival analysis of honeybees indicated that PYR10ng presented shorter longevity than those in the control group ( $\mathrm{P} \leq 0.01)$. Empty nanoparticles and PYRlOng caused morphological alterations in the bees' midguts, whereas pyrethrum-loaded nanoparticles had no significant effect on digestive cells, so are considered safer, at least in the short term, for honeybees. These results are important in understanding the effects of nanopesticides on beneficial insects and may decrease the environmental impacts of pesticides. 


\section{Can a nanopesticide based on solid lipid nanoparticles loaded with the botanical insecticide pyrethrum be toxic to honeybees?}

Cristiane R. Oliveira ${ }^{1,2}$; Caio E. C. Domingues ${ }^{3}$; Nathalie F. S. de Melo ${ }^{4}$; Thaisa C. Roat ${ }^{3}$; Osmar Malaspina $^{3}$; Monica Jones-Costa ${ }^{2}$; Elaine C. M. Silva-Zacarin ${ }^{2}$; Leonardo F. Fraceto ${ }^{1}$

1 - Universidade Estadual Paulista (UNESP), Instituto de Ciência e Tecnologia de Sorocaba, Laboratório de Nanotecnologia Ambiental, Av. Três de Março, 511, Alto da Boa Vista, 18087-180, Sorocaba, SP, Brazil. Email: cristianeronchi@hotmail.com; leonardo@sorocaba.unesp.br

2 - Universidade Federal de São Carlos (UFSCar), Campus Sorocaba, Departamento de Biologia (CCHB), Laboratório de Fisiologia da Conservação e Laboratório de Ecotoxicologia e Biomarcadores em Animais, Rodovia João Leme dos Santos km 110, Itinga, 18052-780, Sorocaba, SP, Brazil. Email: monica@ufscar.br; elaine@ufscar.br

3 -Universidade Estadual Paulista (UNESP) - "Júlio de Mesquita Filho", Campus Rio Claro, Departamento de Biologia, Centro de Estudos de Insetos Sociais (CEIS), Av. 24 A, 1515, Jardim Bela Vista, 13506-900, Rio Claro, SP, Brazil. Email: cecdomingues@gmail.com; thaisaroat@yahoo.com.br; malaspin@ rc.unesp.br

4 - Faculdade de Medicina São Leopoldo Mandic, Campus Araras. Av. Dona Renata, 71, Santa Cândida, 13600-001, Araras, SP, Brazil. Email: nathaliemelo@gmail.com

$01^{\text {th }}$ February 2019

\section{COVER LETTER}

Dear Editor of Chemosphere,

I am submitting the original article "Can a nanopesticide based on solid lipid nanoparticles loaded with the botanical insecticide pyrethrum be toxic to honeybees?" (Cristiane R. OLIVEIRA et al.) for the refereeing process, in order to publish it in the Chemosphere. Aiming to minimize the effects of pesticides on non-target beneficial insects, nanoparticles that act as carrier systems for agrochemicals are being developed by means of nanotechnology. The solid lipid nanoparticles encapsulated pyrethrum biocide releases small quantities over time and thereby reduces the amount of chemical compound bioavailable in the environment. Nevertheless, it is necessary to assess the adverse effects of nanopesticides in the terrestrial environment. In this sense, our study is pioneer in evaluating the toxicity of this system on a non-target pollinator insect, the honeybees.

We tried to follow precisely the journal's author guidelines, with the title page article, Introduction, Materials and Methods, Results and Discussion and Acknowledgment. Additional Information - Total number of words of the textual elements: 6117; Total number of Tables: 1; Total number of Figures: 4.

Sincerely,

\section{olaine Fo. m. Silva Zacarin}

Dra. Elaine C. M. Silva-Zacarin

Corresponding Author

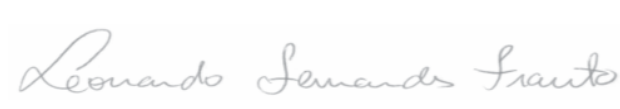

Dr. Leonardo Fernandes Fraceto

Corresponding Author 


\author{
Dear Prof. Willie J. G. M. Peijnenburg \\ Editor Chemosphere,
}

\title{
Ref. Chem60158
}

\section{RESPONSE TO EDITOR IN CHIEF AND REVIEWER}

\begin{abstract}
Reviewer comment: I thank you very much for submitting your revised manuscript. Having evaluated the responses to the comments made by the reviewers, there is one issue that I do not agree on and that is on the issue of the definition of nanoparticle. $100 \mathrm{~nm}$ is considered the upper limit of size in one dimension to allow a particle to be termed a nanoparticle. In your case, the particles are of a size of $260 \mathrm{~nm}$ and they should therefore not be termed 'nanoparticle' but they are 'submicron particles'. Throughout the manuscript, the term 'nano' therefore needs to be replaced by 'submicron', including in the title of the manuscript. This is depite the arguments raised in Nature Nanotechnology.
\end{abstract}

Answer: The authors are very thankful to the Reviewer for his(her) valuable comment regarding the nano definition. We really respect his(her) point of view, however, we disagree to change the term nanoparticles as well as nanopesticides in the manuscript to submicron particles. Our arguments are:

i) We can not use only size range to define a nanoparticle. In this way, the properties that we got with solid lipid nanoparticles in the range of size that we have in this study is totally different from the properties with bulk material. To support this statement, please look at A.D. Maynard, Don't define nanomaterials, Nature, 2011, 475, 31-31.

ii) It is clear in literature that nanoparticles prepared with polymeric and lipid materials showed a size distribution in the same range of the particles from our study and these particles are considered nanoparticles due its properties reached in the size range. Easily it is possible to find thousands of published papers in many different areas such as: cosmetics, food, medicine, pharmacy, agriculture that use particles with the same characteristics (lipid particles) and are considered by the scientific community as nanoparticles. 
iii) It is stated by the editorial from Nature Nanotechnology that in the case of nanopesticides authors showed that the size range threshold is higher for this kind of systems.

iv) European Food Safety Authority, a regulatory agency, described in recent guidance that nanomaterials definitions should be reconsidered for food and agriculture since they described that particles larger than $100 \mathrm{~nm}$ but retain properties typical of nanoparticles.

v) Food and Drug Administration - USA - definition (https://www.fda.gov/regulatoryinformation/search-fda-guidance-documents/considering-whether-fda-regulated-product-involvesapplication-nanotechnology\#_ftn6):

"At this time, when considering whether an FDA-regulated product involves the application of nanotechnology, FDA will ask:

1. Whether a material or end product is engineered to have at least one external dimension, or an internal or surface structure, in the nanoscale range (approximately $1 \mathrm{~nm}$ to $100 \mathrm{~nm}$ );

In addition, as we explain in more detail below, because materials or end products can also exhibit related properties or phenomena attributable to a dimension(s) outside the nanoscale range of approximately $1 \mathrm{~nm}$ to $100 \mathrm{~nm}$ that are relevant to evaluations of safety, effectiveness, performance, quality, public health impact, or regulatory status of products, we will also ask:

2. Whether a material or end product is engineered to exhibit properties or phenomena, including physical or chemical properties or biological effects, that are attributable to its dimension(s), even if these dimensions fall outside the nanoscale range, up to one micrometer $(1,000 \mathrm{~nm})$."

vi) Recently Nature Nanotechnology has published a series of papers that were written by worldwide specialists about the nanotechnology in agriculture (see below) and in all these papers there are a lot of citations of papers that showed size higher than $100 \mathrm{~nm}$ and they were considered nanomaterials/nanoparticles/nanopesticides/nanofertilizers.

- https://www.nature.com/articles/s41565-019-0464-4

- https://www.nature.com/articles/s41565-019-0468-0 
- https://www.nature.com/articles/s41565-019-0461-7

- https://www.nature.com/articles/s41565-019-0460-8

- https://www.nature.com/articles/s41565-019-0439-5

vii) If you look at the EU homepage below it is possible to find the definition:

“Upper size limit

Although $999 \mathrm{~nm}$ is still formally on the nanoscale, a very commonly used upper limit fornanomaterialsize is $100 \mathrm{~nm}$. This covers most nanomaterials, but there are exceptions. Nanomaterials clumped together can have outside dimensions larger than $100 \mathrm{~nm}$, as can those which have been modified by adding a coating or an unusually large chemical group such as a long-chain organic molecule. Such materials include liposomes - small fatty globules - which can be loaded with nanoparticles for drug delivery or use in cosmetic products."

https://ec.europa.eu/health/scientific_committees/opinions_layman/nanomaterials2012/en/l-2/3.htm

In this way, as our system is a solid lipid nanoparticles, this mean a structure formed by lipid covered by a surfactant it is like a liposomes, fatty globules and as mentioned below, in the area of cosmetics this is considered as nanoparticles.

vii) The Chemosphere Journal has published papers aiming pest control with particles with mean size distributions higher than $400 \mathrm{~nm}$ and they accepted the use of the term nanoparticles. Just as example, look at: https://doi.org/10.1016/j.chemosphere.2013.11.056

Also, based on all arguments above, we do not agree to change the term nanoparticles to submicron particles. We would like thank you so much the reviewer for this discussion, but from our point of view is really more than a question of size limit $(100 \mathrm{~nm})$ and by properties of the material. In addition, the application of polymeric and lipid materials in agriculture are well known nowadays and the community that develop systems for this kind of application really considered sizes in the range from the particles of our study as nanoparticles. 
Again, thank you for your comment that we really appreciate, but in this case, we can't agree with your suggestion to change the term in the manuscript since nowadays the scientific community has been accepted other definitions than a cut-off 100nm.

Sincerely yours

Dr. Leonardo Fraceto

Corresponding author

On-behalf of all authors. 


\title{
Nanopesticide based on botanical insecticide pyrethrum and its potential effects on honeybees
}

\author{
Cristiane R. Oliveira ${ }^{\mathrm{a}, \mathrm{b}}$; Caio E. C. Domingues ${ }^{\mathrm{c}}$; Nathalie F. S. de Melo ${ }^{\mathrm{d}}$; Thaisa C. Roat ${ }^{\mathrm{c}}$; Osmar \\ Malaspina $^{\mathrm{c}}$; Monica Jones-Costa ${ }^{\mathrm{b}}$; Elaine C. M. Silva-Zacarin ${ }^{\mathrm{b}}$ and Leonardo F. Fraceto ${ }^{\mathrm{a} *}$ \\ a Universidade Estadual Paulista (UNESP) - "Júlio de Mesquita Filho", Instituto de Ciência e Tecnologia de \\ Sorocaba, Laboratório de Nanotecnologia Ambiental, Av. Três de Março, 511, Alto da Boa Vista, 18087-180, \\ Sorocaba, SP, Brazil. \\ b Universidade Federal de São Carlos (UFSCar), Campus Sorocaba, Departamento de Biologia (CCHB), \\ Laboratório de Fisiologia da Conservação e Laboratório de Ecotoxicologia e Biomarcadores em Animais, \\ Rodovia João Leme dos Santos km 110, Itinga, 18052-780, Sorocaba, SP, Brazil. \\ " Universidade Estadual Paulista (UNESP) - "Júlio de Mesquita Filho", Campus Rio Claro, Departamento de \\ Biologia, Centro de Estudos de Insetos Sociais (CEIS), Av. 24 A, 1515, Jardim Bela Vista, 13506-900, Rio \\ Claro, SP, Brazil. \\ ${ }^{d}$ Faculdade de Medicina São Leopoldo Mandic, Campus Araras. Av. Dona Renata, 71, Santa Cândida, 13600- \\ 001, Araras, SP, Brazil.
}

\begin{abstract}
Nanotechnology has the potential to overcome the challenges of sustainable agriculture, and nanopesticides can control agricultural pests and increase farm productivity with little environmental impact. However, it is important to evaluate their toxicity on non-target organisms, such as honeybees (Apis mellifera) that forage on crops. The aims of this study were to develop a nanopesticide that was based on solid lipid nanoparticles (SLNs) loaded with pyrethrum extract (PYR) and evaluate its physicochemical properties and short-term toxicity on a non-target organism (honeybee). SLN+PYR was physicochemically stable after 120 days. SLN+PYR had a final diameter of $260.8 \pm 3.7 \mathrm{~nm}$ and a polydispersion index of $0.15 \pm 0.02 \mathrm{~nm}$, in comparison with SLN alone that had a diameter of $406.7 \pm 6.7 \mathrm{~nm}$ and a polydispersion index of $0.39 \pm 0.12 \mathrm{~nm}$. SLN+PYR had an encapsulation efficiency of $99 \%$. The survival analysis of honeybees indicated that PYR $10 \mathrm{ng}$ presented shorter longevity than those in the control group $(\mathrm{P} \leq 0.01)$. Empty nanoparticles and $\mathrm{PYR}_{10 \text { ng }}$ caused morphological alterations in the bees' midguts, whereas pyrethrum-loaded nanoparticles had no significant effect on digestive cells, so are considered safer, at least in the short term, for honeybees. These results are important in understanding the effects of nanopesticides on beneficial insects and may decrease the environmental impacts of pesticides.
\end{abstract}

KEYWORD: Nanopesticide; Biocide; Sustainable agriculture, Solid lipid nanoparticles; Bees.

\section{Corresponding Authors}

* Elaine C. M. Silva Zacarin - Universidade Federal de São Carlos (UFSCar), Campus Sorocaba, Departamento de Biologia (Dbio, CCHB), Laboratório de Fisiologia da Conservação e Laboratório de Ecotoxicologia e Biomarcadores em Animais, Rodovia João Leme dos Santos km 110, Itinga, 18052-780, Sorocaba, SP, Brazil. Email: elaine@ufscar.br

*Leonardo Fernandes Fraceto - Universidade Estadual Paulista (UNESP), Instituto de Ciência e Tecnologia de Sorocaba, Av. Três de Março, 511, Alto da Boa Vista, 18087-180, Sorocaba, SP, Brazil. Email leonardo.fraceto@unesp.br 


\section{INTRODUCTION}

Agri-food production and population growth are amongst the greatest challenges facing humanity. Agriculture is one of the primary drivers of the economy by providing food to the population and benefiting producing countries, but increased population growth has significantly increased humanity's global ecological footprint, surpassing the biocapacity of the Earth (SEKHON, 2014). Human populations increase exponentially over time, whereas food production increases in a linear manner. Conventional agricultural practices generally have negative impacts on the environment and biodiversity, as they require many resources such as energy, water, and soil, and large amounts of agrochemicals and fertilizers are used to improve productivity.

The U.S. Department of Agriculture's (USDA) National Institute of Food and Agriculture (NIFA, 2018) aims to find innovative solutions to issues related to agriculture, food, the environment, and communities. NIFA's priorities include global food security and hunger, food safety, plant health and production, and animal health and production (NANO, 2018). Many of these issues may be resolved using nanotechnology, which has demonstrated great potential in providing novel solutions to agricultural problems (SCOTT and CHEN, 2012; MUKHOPADHYAY, 2014). In the last few decades, nanoscience and nanotechnology have been at the forefront of the development of several nanomaterials for different medical and industrial purposes. Nanoparticles have been developed for a wide variety of applications in the biomedical and electronic fields, while research on nanoparticles as carriers of pesticides has only been conducted in the last decade, and there are still many variables to be investigated before their use on crops (LIU et al., 2008; ANJALI et al., 2010; GOPAL et al., 2012; KAH et al., 2014; SARLAK et al., 2014; MISHRA et al., 2017; KIM et al., 2018). 
Nanotechnology can deliver agricultural substances such as nanopesticides and

72 nanofertilizers that increase farm productivity, decrease the environmental impact and the

73 amount of resources used, improve pest control, and support sustainable agriculture,

74 particularly in developing countries. Furthermore, nanocarriers of pesticides and fertilizers

75 have economic advantages for agriculture, because their stability and controlled-release

76 mechanism increase efficiency and reduce the amount of chemicals required on crops

77 (PEREZ-DE-LUQUE and RUBIALES; 2009; CHEN and YADA, 2011; GRILLO et al.,

78 2016; PRASAD et al., 2017; WALKER et al., 2017).

79 However, the effects of nanoparticles should be fully evaluated before they are 80 incorporated into sustainable agriculture. The U.S. National Science Foundation (NSF) and

81 Environmental Protection Agency (EPA) encourage the investigation of various aspects of 82 nanomaterials, such as their toxicity to non-target organisms, their destination, transportation,

83 and safety in the environment, and their status in terms of food legislation, and support the 84 creation of a nanomaterial database and the maintenance of food regulations (SCOTT and 85 CHEN, 2012).

86 Pyrethrum extract is a natural botanical insecticide that is extracted from 87 chrysanthemum (Chrysanthemum cinerariaefolium and Chrysanthemum cineum) flowers, is 88 composed of pyrethrin types I and II and jasmolin, and can be used on crops to control pest 89 insects (PEAY et al., 2006). Natural pyrethrum (a.i.) is highly lipophilic, photodegradable, 90 has low water solubility $\left(<10 \mathrm{mg} . \mathrm{L}^{-1}\right)$, does not exhibit biomagnification (SCHLEIER and 91 PETERSON, 2011), and leaves no toxic residues in plants. However, it is more expensive 92 than synthetic pyrethroids (PEAY et al., 2006) and is highly toxic to insects, aquatic 93 invertebrates, and fish (USEPA, 2006). Pyrethroids are insecticides that were developed to 94 improve the photodegradation of natural pyrethrin, and thus be used as an insecticide in the 
95 field (SANTOS et al., 2007), and have great stability and target selectivity. Examples of 96 pyrethroids include deltamethrin, permethrin, and cypermethrin (MONTANHA and 97 PIMPÃO, 2012). However, for the use of pyrethrum extract in the field it is necessary, at first, to load

99 100 101 102 103 104 105 106 107 108 109 it into solid lipid nanoparticles (SLNs) to prevent its fast degradation, improving its stability and efficiency to allow its application on crops. Many benefits can be obtained by using SLNs, such as lower large-scale production costs, greater physicochemical stability, the possibility of hydrophilic and hydrophobic drug encapsulation, and the use of natural products in the formulation preparation (MULLER et al., 2000; MULLER et al., 2011; NASERI et al., 2015; SARANGI and PADHI et al., 2016).

Interactions between biological systems and nanomaterials are complex, so it is important to evaluate their toxicity to non-target organisms (JACQUES et al., 2017), particularly to beneficial insects such as honeybees (Apis mellifera), which play an important role in pollinating agricultural crops (GIANNINI et al., 2015). Honeybee populations are declining worldwide, and although multiple factors contribute to this decline (GOULSON et al., 2015), it is mainly caused by agrochemicals sprayed on crops visited by bees (POTTS et al., 2010). In this context, the physicochemical characterization of nanopesticides can enable their future use in organic farming and contribute to sustainable agriculture, because these carriers may have little effect on the environment and biodiversity (GRILLO et al., 2016; PRASAD et al., 2017). However, this carrier system must have low toxicity to honeybees and other beneficial insects.

The objectives of this study were to develop a nanopesticide that was based on SLNs loaded with pyrethrum extract biocide (nanobiocide), characterize its physicochemical properties, and evaluate its toxicity to honeybees (Africanized A. mellifera). We evaluated 
119 sublethal effects on the histopathology of the bee midgut, an organ that plays a central role

120 in food digestion and nutrient absorption. It is important to emphasize the fact that there are

121 gaps of information in the literature regarding the toxicity of nanopesticides to non-target

122 organisms, such as pollinator insects including honeybees. Our results can be applied in the 123 field, can contribute to nanopesticide regulation, and can improve both environmental and 124 food security.

125

126

2. MATERIALS AND METHODS

127

\subsection{Chemicals}

The pyrethrum extract Pestanal ${ }^{\circledR}$ (biocide, CAS 8003-34-7, analytical standard), 129 polyvinyl alcohol (PVA, 30-70 kDa, CAS 9002-89-5, hydrolyzed >99\%), and glyceryl 130 tripalmitate (tripalmitin, CAS 555-44-2, purity $\geq 99 \%$ ) were purchased from Sigma-Aldrich. Chloroform $\left(\mathrm{CHCl}_{3}, \mathrm{CAS} 67-66-3\right.$, purity $\left.\geq 99 \%\right)$ was purchased from a local supplier. All these products were used for the preparation of the nanoparticles. Acetone (CAS 67-64-1, purity $=100 \%$ ) was used as a solvent in the preparation of the pyrethrum solution.

\subsubsection{Solid lipid nanoparticles}

SLNs containing pyrethrum were prepared by the method of emulsification/solvent evaporation with some modifications (VITORINO et al., 2011; de MELO et al., 2018). Initially, $30 \mathrm{~mL}$ of an aqueous phase containing $1.25 \%$ PVA and distilled water was prepared and magnetically stirred (100 rpm). An organic phase with $250 \mathrm{mg}$ of glyceryl tripalmitate and $5 \mathrm{mg}$ of pyrethrum (active ingredient - a.i.) was then prepared, which was dissolved in

$1415 \mathrm{~mL}$ of chloroform. The organic phase was added to the aqueous phase, and this mixture 
143 ULTRA-TURRAX ${ }^{\mathrm{TM}}$ homogenizer at $14,000 \mathrm{rpm}$ for $7 \mathrm{~min}$. The organic solvent was then 144 removed using a rotating evaporator in order to create a concentrated emulsion with $10 \mathrm{~mL}$ 145 of nanoparticles. The final concentration of biocide was $0.05 \mathrm{mg} \cdot \mathrm{mL}^{-1}$. SLNs without 146 pyrethrum extract (control) were also prepared.

147

148

\subsection{Nanoparticles}

149

The purpose of the formulations was to achieve greater physicochemical stability and 150 better efficiency of pyrethrum encapsulation in the nanoparticles. In order to evaluate the

151 physicochemical stability as a function of time were used the maintenance of colloidal 152 parameters in formulation. The colloidal parameters were the mean diameter, polydispersity 153 index, zeta potential, besides the nanoparticle concentration and encapsulation efficiency of 154 the pyrethrum extract. All analyses were conducted for 120 days and the results were 155 expressed (mean \pm SEM).

156

157

\subsubsection{Nanoparticle characterization}

The mean diameter and polydispersion index were determined by dynamic light 159 scattering (DLS). Nanoparticle samples were diluted $(10 \mu \mathrm{L}: 1 \mathrm{~mL})$ in purified water and 160 analyzed using a Zetasizer Nano ZS90 analyzer (Malvern Panalytical, UK). Zeta potential 161 values (in $\mathrm{mV}$ ) were also determined using the ZS90 analyzer, with the same dilution process.

162 The $\mathrm{pH}$ of the nanoparticles was determined using a $\mathrm{pH}$ meter (Tecnal ${ }^{\circledR}$, Brazil). Further 163 details could be obtained in literature (VENKATRAMAN et al., 2005; de MELO et al., 2012; 164 OLIVEIRA et al., 2015). 
167

168

169

170

171

172

173

174

175

176

177

178

179

180

181

182

183

184

185

186

187

188

189

190

8

SLN size distributions and concentrations were analyzed using a nanoparticle tracking analysis (NTA) instrument (NanoSight LM10). Nanoparticle samples were diluted 10,000 times and analyzed by injecting $1 \mathrm{~mL}$ of the sample into the cell (more details in section 1.1 - Supplementary Material).

\subsubsection{Differential Scanning Calorimetry (DSC)}

A thermal analysis was performed to demonstrate that the pyrethrum was encapsulated in the nanocarriers using a DSC Q20 differential scanning calorimeter (TA Instruments). The samples of pyrethrum extract, lipid, SLNs, and SLNs loaded with pyrethrum were analyzed (Section 1.2 - Supplementary Material).

\subsubsection{Fourier-transform infrared spectroscopy (FTIR)}

FTIR was performed to investigate interactions between the biocide and the SLNs using an infrared spectrophotometer (Agilent). The pyrethrum extract, lipid, surfactant (PVA), physical mixture, SLNs, and SLNs loaded with pyrethrum were analyzed using an attenuated total reflectance accessory (POLLETO et al., 2007; WANG et al., 2010) (Section 1.3 - Supplementary Material).

2.3. Determination of encapsulation efficiency and quantification of pyrethrum by highperformance liquid chromatography $(H P L C)$

The total amount of pyrethrum extract present in the nanoparticle suspension was determined by the ultrafiltration/centrifugation method. After the suspension had been diluted with acetonitrile, it was filtered through a $0.22 \mu \mathrm{m}$ Millipore ${ }^{\mathrm{TM}}$ membrane filter and quantified by HPLC (Varian ProStar). The pyrethrum extract association rate was calculated 
191 as the difference between the non-associated fraction of biocide and the total amount initially

192 added to the nanoparticles (GAMISANS et al., 1999; SCHAFFAZICK et al., 2003; KILIC

193 et al., 2005) (Table 1S- Supplementary Material).

194

195

\subsection{Toxicological bioassay}

Operculated brood combs were collected from three healthy colonies of Africanized

197

198

199

200

201

202

203

204

205

206

207

208

209

210

211

212

213

214
Apis mellifera located in apiaries at Sao Paulo State, Brazil. The emergence of worker bees

was monitored in laboratory. Following emergence, the bees were transferred to plastic pots

lined with filter paper and fed ad libitum sugar-aqueous solution (50\%:50\% water:inverted sugar, v:v) to acclimatize for $24 \mathrm{~h}$.

Subsequently, the 1-day-old bees were divided into the following experimental groups in triplicate (each colony representing a replicate): I) Control (CTL) - sugar-aqueous solution (syrup); II) Sublethal dose (1 ng. $\left.\mu \mathrm{L}^{-1}\right)$ of pyrethrum extract (PYR $\left.{ }_{1 \mathrm{ng}}\right)$; III) Sublethal dose (10 ng. $\left.\mu \mathrm{L}^{-1}\right)$ pyrethrum extract (PYR $\left.\left.10 \mathrm{ng}\right) ; \mathrm{IV}\right) 1 \mathrm{ng} . \mu \mathrm{L}^{-1}$ of pyrethrum loaded in SLNs $\left.\left(\mathrm{SLNP}_{1 \mathrm{ng}}\right) ; \mathrm{V}\right) 10 \mathrm{ng} \cdot \mathrm{LL}^{-1}$ of pyrethrum loaded in SLNs (SLNP10ng); IV) Empty SLNs; V) Polyvinyl alcohol - surfactant control (PVA); VI) Acetone control (ACN) - vehicle/solvent control. The dose used per bee was based on the $\mathrm{LD} 0_{48 \mathrm{~h}}$ of pyrethrum for honeybees, i.e., 22 ng.bee ${ }^{-1}$ (USEPA, 1991).

Acute exposure was performed individually by oral administration, i.e., the corresponding solution of the experimental group was administrated to the bees $(1 \mu \mathrm{L}) \mathrm{using}$ a micropipette (per os administration). Two sublethal doses of $10 \mathrm{ng}$ or $1 \mathrm{ng}$ of biocide per bee were given of the pyrethrum extract (PYR) and pyrethrum loaded in nanoparticles (SLNs). The half the $\mathrm{LD}_{50}$ h value corresponded to a $1 / 2$ dilution $\left(\mathrm{LD} 50 / 2=10 \mathrm{ng} \cdot \mu \mathrm{L}^{-1}=10\right.$ ppm), and the other dose corresponded to a 1:20 dilution of the LD50 $48 \mathrm{~h}$ value (LD50/20 = 1 
215 ng. $\left.\mu \mathrm{L}^{-1}=1 \mathrm{ppm}\right)$, both being sublethal concentrations for honeybees. Concentrations of the

216 solutions, which were used for getting the sublethal doses offered to bees, were obtained by

217 serial dilution of stock solution.

218 After individually acute exposure, the bees were kept in plastic pots (cages), being

219 fed with $50 \%(\mathrm{w} / \mathrm{w})$ sucrose aqueous solution, in an incubator at a relative humidity of $70 \%$

$220 \pm 5$ and temperature of $32 \pm 2^{\circ} \mathrm{C}$, under dark conditions. Two bioassays were performed,

221 being the first one for survival analysis $(\mathrm{N}=12$ bees per pot in triplicate, per experimental

222 group, totalizing 36 individuals) and another one for histology analyzes ( $\mathrm{N}=15$ bees per pot

223 in triplicate per experimental group, totalizing 45 individuals).

224 In the first bioassay (survival analysis), the bees were monitored daily until the last

225 bee has died. Specifically for survival bioassay, the deltamethrin (DLT, 10 ng. $\mu \mathrm{L}^{-1}$ )

226 experimental group was added as positive control. In the second bioassay, the bees were

227 collected $48 \mathrm{~h}$ after the acute exposure ( $\mathrm{N}=6$ per group) and dissected for midguts' removal,

228 which were processed for resin embedding and histological analysis (section 2.4.1).

229

\subsubsection{Histology procedure}

The bee midguts were fixed in $4 \%$ buffered paraformaldehyde solution for $24 \mathrm{~h}$ and

232 immersed in phosphate-buffered saline $\left(0.1\right.$ mol. $\mathrm{L}^{-1}$ phosphate buffer, $\left.\mathrm{pH} 7.4\right)$. After, the material was dehydrated in an increasing ethanol series according to Silva-Zacarin et al. (2012). Subsequently, the material was embedded in historesin, and submitted to microtomy.

235 Slides containing 3- $\mu \mathrm{m}$ thick histological sections were stained with hematoxylin-eosin.

236 Posteriorly, the material was photodocumentated and both qualitative and semi-quantitative 237 histopathological analyses were performed using Leica Application Suite V3.8 coupled to 238 the light field photomicroscope (DM1000, Leica). For each bee from each experimental 
239 group $(\mathrm{N}=6)$, two slides were analyzed per individual and three non-sequential histological 240 sections were analyzed for each slide.

241

Other slides containing $3-\mu \mathrm{m}$ thick histological sections were submitted to

242 histochemical analysis for detection of proteins, lipids and neutral glycoconjugates (SILVA-

243 ZACARIN et al., 2012) (Section 1.4 - Supplementary Material and Figure 4S).

244

245

246

247

248

249

250

251

252

253

254

255

256

257

258 259 Material).

260

261

\subsubsection{Semi-quantitative analysis of midguts}

Parameters for semi-quantitative analysis were defined according to the Bernet et al. (1999) protocol, and histological alterations (lesions) in midgut of bees were based on Soares-Lima et al. (2018) protocol. To determine alterations in the bee midguts, the lesion index and the organ index, were calculated using two parameters: the importance factor and the score value (BERNET et al., 1999). Alterations were classified from 0 to 3, depending on their degree and extent: 0- no alteration, 1- slight alteration, 2- moderate alteration, and 3- severe alteration. The importance factor was established for each lesion observed (cells eliminated from the epithelium, increased apocrine secretions from the digestive cells, cellular vacuolization, changes in regenerative cells' nests, and the presence of pyknotic nuclei in cells of the epithelium) by a qualitative analysis based on pathological severity. This factor was categorized as (1) minimal pathological importance (repairable damage), (2) moderate pathological importance (damage was repairable in most cases), or (3) severe pathological importance (irreparable damage) (Table 2S and section 1.4 - Supplementary 
262

263

264

265

266

267

268

269

270

271

272

273

274

275

276

277

278

279

280

281

282

283

284

285

All data were previously subjected to homogeneity of variance (Bartlett's) and normality (Shapiro-Wilk and Kolmogorov-Smirnov) tests. The physicochemical characterization data were subjected to a Student's t-test followed by a Mann Whitney test. A semi-quantitative analysis of the bee midguts was performed using a Kruskal-Wallis test followed by Dunn's multiple comparison test. The significance level was set at $\alpha=0.05$. GraphPad Prism v.5.0 was used for these statistical analyses.

The survival curve of honeybees per each experimental group was analyzed by the Log-Rank test (Kaplan-Meier method), and comparison between survival time of the groups was performed by the Holm-Sidak test. The significance level was set at $\alpha=0.05$. SigmaPlot 13 software was used these analyze.

\section{RESULTS AND DISCUSSION}

\subsection{Nanoparticle characterization}

The SLNs were prepared using approved components that are generally recognized as safe (GRAS). Tripalmitin (glyceryl tripalmitate) was used as a solid lipid and PVA was used as a surfactant. Physicochemical stability of the empty and encapsulated biocide in SLNs were evaluated from maintenance measurements of the colloidal parameters (mean diameter, polydispersity and zeta potential), besides the concentration of nanoparticles and pyrethrum encapsulation efficiency, over time ( 0 to 120 days). Colloidal parameter values and other parameters are shown in Table 1.

The initial and final hydrodynamic diameters (mean \pm SEM) of the empty solid lipid nanoparticles (SLN) were $290.0 \pm 5.0$ and $406.7 \pm 6.7 \mathrm{~nm}$, respectively. For the SLNs loaded with pyrethrum (SLN+PYR) the initial and final hydrodynamic diameters were $264.9 \pm 2.8$ and $260.8 \pm 3.7 \mathrm{~nm}$, respectively. There was a significant difference between the empty 
286

287

288

289

290

291

292

293

294

295

296

297

298

299

300

301

302

303

304

305

306

307

308

309 nanoparticles and those loaded with pyrethrum in the initial $(\mathrm{P} \leq 0.0001$ and $\mathrm{T}=18.18)$ and final $(\mathrm{P} \leq 0.0001$ and $\mathrm{T}=48.51)$ analyses. The hydrodynamic diameter values of empty SLNs increased after 60 days of storage with significant differences between the timepoints $(\mathrm{P} \leq$ 0.0001 and $\mathrm{T}=54.60$ ), while these values remained stable for SLN+PYR over the experimental period (120 days) (Figure 1SA- Supplementary Material). The empty SLNs had a larger mean diameter and less physicochemical stability than SLN+PYR, indicating that active ingredient of pyrethrum can stabilize nanoparticle formulation and decrease aggregate formation.

The polydispersion index at 0 and 120 days was $0.12 \pm 0.01$ and $0.39 \pm 0.12 \mathrm{~nm}$, respectively, in empty SLNs, and $0.12 \pm 0.01$ and $0.15 \pm 0.02 \mathrm{~nm}$, respectively, in SLN+PYR (Table 1), and values below $0.2 \mathrm{~nm}$ in the initial analysis were considered indicative of good stability and a small distribution of particle diameters. The low values indicate that the nanoparticles were of similar size and without aggregates (MASARUDIN et al., 2015). Similar results were obtained by de Melo et al. (2016) in a 120-day experiment with 15dPGJ2-loaded SLNs, and by González et al. (2015) at the beginning of their experiment with poly (ethylene glycol)-nanoparticles containing geranium (an essential oil). However, the time-based analysis revealed that the SLN polydispersion index had increased after 60 days of storage (0.3 and $0.39 \mathrm{~nm}$; Figure 1SB - Supplementary Material), with significant differences between the timepoints $(\mathrm{P} \leq 0.005$ and $\mathrm{T}=0.0)$ and significant differences between $\mathrm{SLN}_{120}$ and $\mathrm{SLN}_{+} \mathrm{PYR}_{120}(\mathrm{P} \leq 0.005$ and $\mathrm{T}=0.0)$. These data indicate that there was a heterogeneous distribution of particle diameters, i.e., there was a greater aggregation of particles in the empty system (SLN). Particle aggregation and degradation occur in SLN formulations that increase and decrease particle size, respectively, due to the loss of a surfactant coating that protects the material (MULLER et al., 1996). 

0.4 and $-14 \pm 0.3 \mathrm{mV}$, respectively, for empty SLNs and $-9.7 \pm 0.2$ and $-18.2 \pm 0.3 \mathrm{mV}$, respectively, for SLN+PYR. There was a significant difference between the empty nanoparticles and those loaded with pyrethrum $\left(\mathrm{P} \leq 0.0001, \mathrm{~T}_{0 \mathrm{~d}}=8.989\right.$, and $\mathrm{T}_{120 \mathrm{~d}}=24.50$;

314 Table 1). After decreasing on the $30^{\text {th }}$ day $(-5.48 \pm 0.13 \mathrm{mV})$, the zeta potential of SLN+PYR 315 increased to $-12.2 \pm 0.18$ and $-18.2 \pm 0.35 \mathrm{mV}$ after 90 and 120 days, respectively (Figure 316 1SD- Supplementary Material). Similarly, the empty SLN zeta potential decreased after 15 $317(-4.85 \pm 0.19 \mathrm{mV})$ and $30(-6.27 \pm 0.18 \mathrm{mV})$ days, but increased on the $60^{\text {th }}$ day $(-15.43 \pm$ $3180.23 \mathrm{mV}$ ), indicating good stability until the end of the analysis time (Figure 1SD319 Supplementary Material). Zeta potential values greater than $30 \mathrm{mV}$ indicate excellent 320 electrostatic stabilization $(60 \mathrm{mV}$ is the ideal value), while values lower $15 \mathrm{mV}$ may result in 321 partial flocculation (SCHWARZ et al., 1994). Low zeta potentials were observed, but the 322 nanoparticle formulations were stable over time due to steric stabilization provided by the 323 PVA (LOURENÇO et al., 1996). Stabilizers can be used in nanoparticle formulations to 324 prevent particle aggregation (ABDELWAHED et al., 2006). In the present study, the 325 nonionic surfactant PVA was used to prepare the SLNs, which is absorbed onto surface 326 nanoparticles and promotes steric stabilization (ADITYA et al., 2013; OLIVEIRA et al., 327 2015). Therefore, unlike in previous studies, it was not superficial electrostatic repulsion that 328 provided stability to the system (PASQUOTO-STIGLIANI et al., 2017). Particles in 329 suspension are more stable if the zeta potential is greater than $20 \mathrm{mV}$, and $40 \mathrm{mV}$ indicates 330 excellent stability (ADITYA et al., 2013). Similar results were obtained by Oliveira et al. 331 (2018) in zein nanoparticles loaded with the essential oil citronella (geraniol and R332 citronellal), and by Kah et al. (2014) in a polymer-based nanoformulation of atrazine. 
Table 1: Characterization of empty SLN and SLN loaded with pyrethrum extract over a period from 0 to 120 days.

\begin{tabular}{|c|c|c|c|c|}
\hline PARAMETERS & $S L N_{0}$ & $S L N_{120}$ & $S L N+P Y R_{0}$ & $S L N+P Y R_{120}$ \\
\hline$M D_{D L S}(N M)$ & $290.0 \pm 5.0$ & $406.7 \pm 6.7^{\mathrm{a}, \mathrm{c}}$ & $264.9 \pm 2.8$ & $260.8 \pm 3.7$ \\
\hline$M D_{N T A}(N M)$ & $185.9 \pm 4.6^{\mathrm{c}}$ & $263.8 \pm 18.5^{\mathrm{a}, \mathrm{c}}$ & $161.5 \pm 2.7$ & $227.0 \pm 12.3^{\mathrm{b}}$ \\
\hline$P D I$ & $0.12 \pm 0.01$ & $0.39 \pm 0.12^{\mathrm{a}, \mathrm{c}}$ & $0.12 \pm 0.01$ & $0.15 \pm 0.02$ \\
\hline$Z P(-m V)$ & $13 \pm 0.4^{c}$ & $14 \pm 0.3^{c}$ & $9.7 \pm 0.2$ & $18.2 \pm 0.3^{b}$ \\
\hline $\begin{array}{c}C T\left(10^{13}\right. \\
\text { particles } / m L)\end{array}$ & $2.7 \pm 0.5$ & $3.8 \pm 0.2$ & $5.9 \pm 0.5$ & $2.0 \pm 0.1$ \\
\hline$p H$ & $4.9 \pm 0.04$ & $5,7 \pm 0.04^{\mathrm{a}, \mathrm{c}}$ & $5.0 \pm 0.02$ & $7.1 \pm 0.02^{\mathrm{b}}$ \\
\hline$E E(\%)$ & - & - & $>99 \%$ & $>99 \%$ \\
\hline
\end{tabular}

Legend - Mean diameter (MD) using dynamic light scattering (DLS) and nanoparticle tracking analysis (NTA) techniques; polydispersion index (PDI); zeta potential (ZP), concentration of nanoparticles(CT); hydrogenionic potential $(\mathrm{pH})$ and encapsulation efficiency (EE). The values are expressed as the mean \pm standard error of six measurements. ${ }^{a}$ Significant difference between SLN group and times; ${ }^{b}$ Significant difference between SLN+PYR group and times; ' ${ }^{c}$ Significant difference between SLN and SLN+PYR group. Paired T Test for parametric test, and Mann Whitney $\mathrm{U}$ test for nonparametric test.

SLNs showed good stability for the encapsulated a.i, evidencing that physicochemical properties not changed over time. According to Naseri et al. (2015), SLNs are good nanocarriers and can be used to deliver drugs and agrochemicals. Their properties include great physicochemical stability during production and storage, a good release profile, the ability to solubilize lipophilic actives, and low toxicity (NASERI et al., 2015).

There was a significant difference in the $\mathrm{pH}$ of the empty SLN suspension between 0 and 120 days $(4.9 \pm 0.04$ and $5.7 \pm 0.04$, respectively; $\mathrm{P} \leq 0.0001$ and $\mathrm{T}=16.08)$, and of SLN+PYR $(5.0 \pm 0.02$ and $7.1 \pm 0.02$, respectively; $\mathrm{P} \leq 0.0001$ and $\mathrm{T}=10.04$; Table 1$)$. Only at 120 days was there a significant difference in $\mathrm{pH}$ between the treatment groups $(\mathrm{P} \leq 0.0001$ and $\mathrm{T}=107.9$ ) with SLN+PYR having a pH of $7.16 \pm 0.02$ (Figure $1 \mathrm{SC}-$ Supplementary Material), indicating that hydrolytic processes occurred during this period. Similar results were obtained by Oliveira et al. (2015). 
The NTA revealed that the empty SLNs contained $2.7 \pm 0.5 \times 10^{13}$ particles per $\mathrm{mL}$

355 with an initial size of $185.9 \pm 4.6 \mathrm{~nm}$, and SLN+PYR contained $5.9 \pm 0.5 \times 10^{13}$ particles per

$356 \mathrm{~mL}$ with an initial size of $161.5 \pm 2.7 \mathrm{~nm}$. Table 1 shows that there was a significant

357 difference among timepoints for empty SLNs $(\mathrm{P} \leq 0.02$ and $\mathrm{T}=3.65)$ and $\mathrm{SLN}+\mathrm{PYR}(\mathrm{P} \leq$ 3580.007 and $\mathrm{T}=4.92)$, as well as between empty SLNs and SLN+PYR at $0(\mathrm{P} \leq 0.0004$ and T $359=10.68)$ and $120(\mathrm{P} \leq 0.007$ and $\mathrm{T}=5.23)$ days. NTA counts the number of particles per $\mathrm{mL}$ 360 and is a complementary technique in the analysis of hydrodynamic diameters, and DLS and 361 NTA did not provide similar diameter values and particle concentrations. This difference 362 may have been caused by sample dilution during the NTA, which could have caused some 363 aggregates to rupture in suspension and result in smaller particles than the DLS 364 (MARUYAMA et al., 2016).

The encapsulation efficiency of pyrethrum into the SLNs was evaluated using an analytical curve of pyrethrum determined by HPLC (Peak area (a.u.) $=4.69442+$ $3671952.15769 *$ [pyrethrum concentration], $\mathrm{r}=0.99341)$. The encapsulation efficiency was as 368 high as $99 \%$, suggesting that the pyrethrum extract was efficiently encapsulated in this carrier 369 system. Nevertheless, is important verify the release profile of pyrethrum in field conditions 370 and it is expected that due the high encapsulation efficiency that the particles protect the a.i.

371 in order to increase its shelf life in field conditions. A high encapsulation efficiency has also 372 been reported in polymeric nanocapsules and SLNs loaded with carbendazim and 373 tebuconazole (CAMPOS et al., 2015), in chitosan nanoparticles carrying the herbicides 374 imazapic and imazapyr (MARUYAMA et al., 2016), and in microcapsules containing 375 dementholized peppermint oil (ZHAO et al., 2016). The high encapsulation value indicates 376 the affinity of the biocide to the lipid matrix (de MELO et al., 2016) due to its low solubility 377 in water $\left(<10 \mathrm{mg} . \mathrm{L}^{-1}\right)$ and high solubility in organic solvents (USEPA, 2006). 
3.2. Differential scanning calorimetry (DSC)

381 are presented in Figure 1. The DSC analyzes in this study were carried out with the objective 382 of demonstrating that the pyrethrum interacts with nanocarriers components. There were no 383 endothermic peaks for the pyrethrum extract. Tripalmitin's lowest peak was observed at $38461^{\circ} \mathrm{C}$, which agrees with the melting point described in the literature (CHEN et al., 2006). 385 Analysis of the empty SLNs and SLN+PYR revealed that the melting points for tripalmitin 386 were 65 and $64^{\circ} \mathrm{C}$, respectively, indicating that tripalmitin in the SLNs was solid, and that 387 the pyrethrum did not change the lipid core organization of the SLNs. Similar results were 388 obtained by Oliveira et al. (2015), who found that the herbicides simazine and atrazine were 389 dispersed on a nanoparticle matrix; as well as, Nasseri et al. (2016), verified that SLNs 390 containing Zataria multiflora essential oil (ZEO) not showed DSC pick of Zanataria 391 multiflora, and authors suggested that essential oil was incorporated and dissolved in the lipid 392 matrix. Analysis of the empty and encapsulated SLNs revealed two peaks, one indicating a 393 tripalmitin peak and the other possibly indicating PVA. Thermal studies of PVA have 394 reported an $88.1^{\circ} \mathrm{C}$ peak, probably due to moisture evaporation (GUIRGUIS; MOSELHEY, 395 2012). 


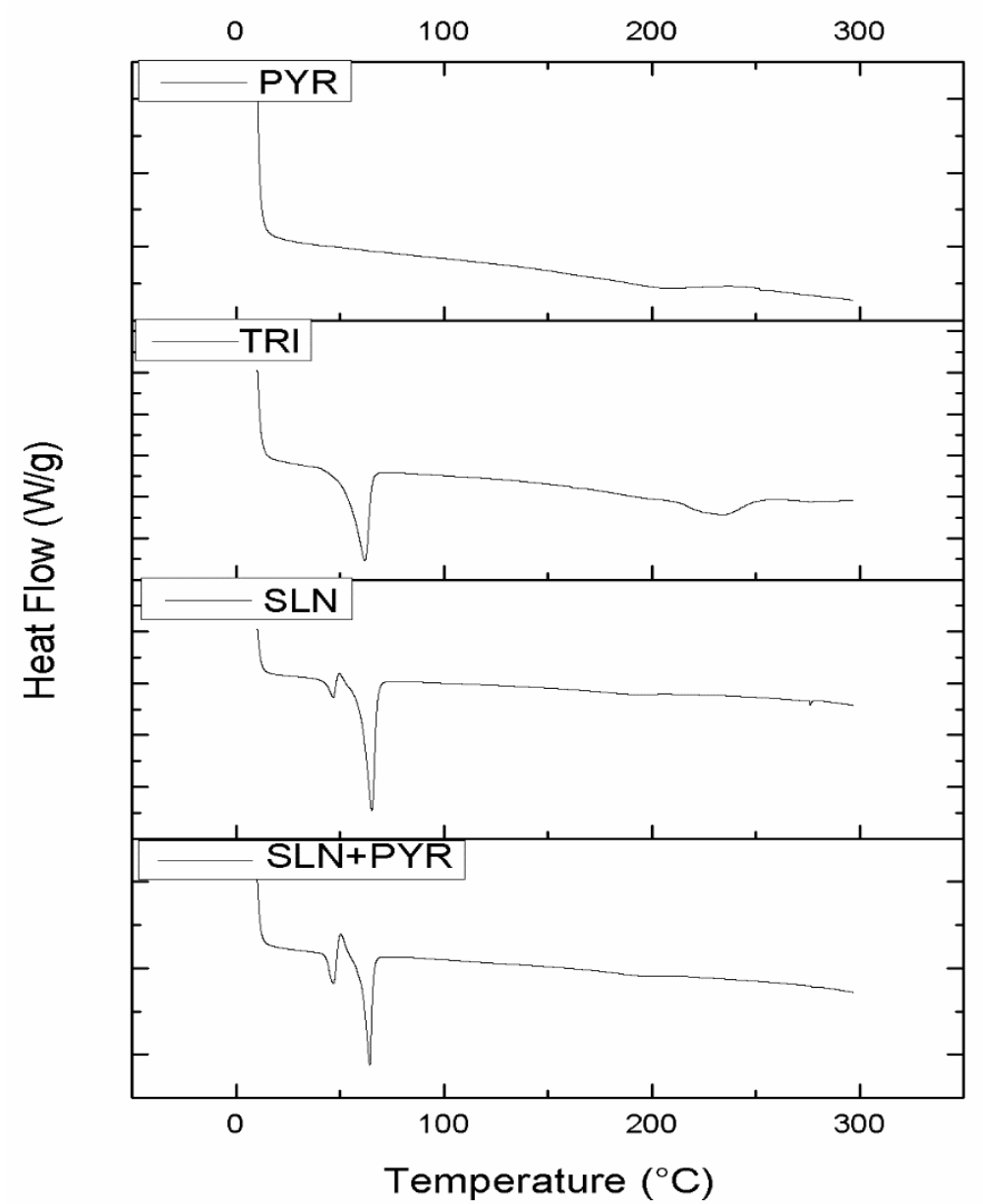

Figure 1 - Differential scanning calorimetry evaluation of interaction between pyrethrum extract and components of the SLN formulation: Thermograms for (PYR) Pyrethrum extract, (TRI) Tripalmitin, (SLN) Solid lipid nanoparticles, (SLN+PYR) Pyrethrum loaded in solid lipid nanoparticles. Conditions: $\mathrm{N}_{2}$ flow $-50 \mathrm{~mL} /$ minute, heating ramp of 10 to $300^{\circ} \mathrm{C}$ at a rate of $10^{\circ} \mathrm{C}$ per minute.

\subsection{Fourier Transform Infrared Spectroscopy (FTIR)}

The physical mixture had three specific bands at 2914, 2368, and $1654 \mathrm{~cm}^{-1}$ (Figure 2), which corresponded with tripalmitin $\left(2914 \mathrm{~cm}^{-1}\right)$; and pyrethrum extract bands at 2368 and $1654 \mathrm{~cm}^{-1}$, corresponding with peak $\mathrm{CO}_{2}$ (OLIVEIRA and PASSOS, 2013) and a stretching of the $-\mathrm{C}=\mathrm{C}$ group, respectively. The infrared spectra of PVA, empty SLNs, and SLN+PYR exhibited similar specific bands at $3335 \mathrm{~cm}^{-1}$ (Figure 2), which suggests the presence of an $-\mathrm{O}-\mathrm{H}$ group in the formulations. These groups were probably derived from the water and PVA used in the preparation of the nanoparticles (ZAIN et al., 2011). The 
411 specific bands at 2914 and $2848 \mathrm{~cm}^{-1}$ that were observed in the nanoparticles indicates a

412 stretching of the $-\mathrm{C}-\mathrm{H}$ group (Figure 2), corresponding to tripalmitin (CAMPOS et al., 2015).

413 It was also possible to observe bands at $1735 \mathrm{~cm}^{-1}$, corresponding to a stretching of the $414 \mathrm{C}=\mathrm{O}$ group, at $1470 \mathrm{~cm}^{-1}$, corresponding to a bending of the $-\mathrm{C}-\mathrm{H}_{2}$ group, and at $1178 \mathrm{~cm}^{-1}$, 415 corresponding to a stretching of the $-\mathrm{C}-\mathrm{O}$ group.

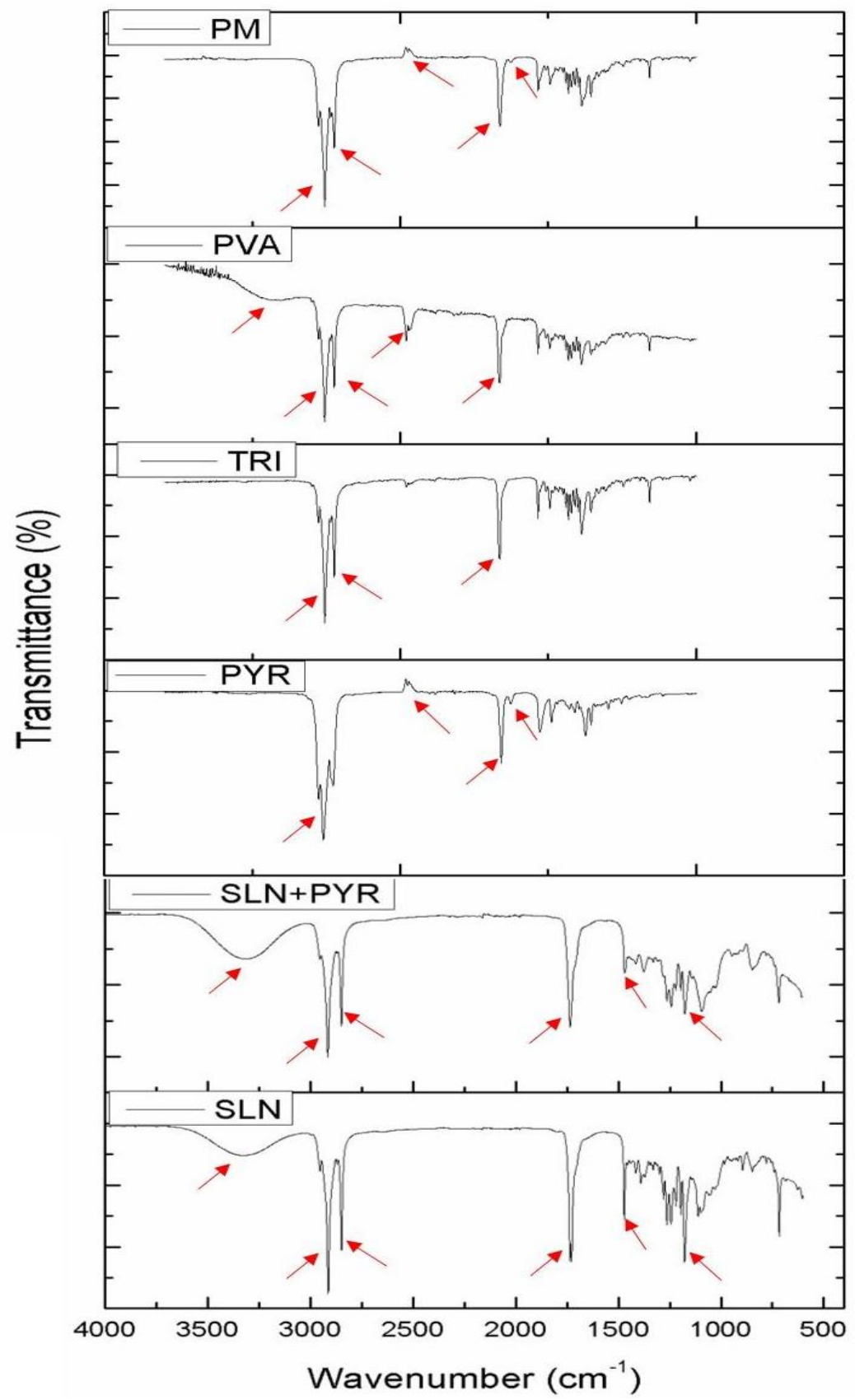


417 Figure 2 - Infrared spectroscopic evaluation of interaction between pyrethrum extract and 418 components of the SLN formulation: FTIR spectra for (PM) Physical mixture (PVA) 419 Surfactant - polyvinyl alcohol; (TRI) Tripalmitin; (PYR) Pyrethrum extract; (SLN+PYR) 420 Pyrethrum loaded in solid lipid nanoparticles; (SLN) Solid lipid nanoparticles. Arrows 421 indicate the main characteristic absorption bands in each spectrum. Conditions: infrared 422 spectrophotometer with a range of 400 to $4000 \mathrm{~cm}^{-1}, 128$ scans per sample and $2 \mathrm{~cm}^{-1}$ 423 resolutions.

424

425

426

427 bees, reducing their life span. Bees exposed to pyrethrum extract $(\mathrm{P}<0.01 ; 141.18 \pm 21.3$

428 hours $)$ and pyrethroid $(\mathrm{P}<0.001 ; 25.33 \pm 0.93 \mathrm{~h})$ presented shorter longevity than those in

429 the control group $(257.83 \pm 21.79 \mathrm{~h})$. There is not significant difference between control and

430 other experimental groups (ACN; PVA; SLN; SLNP 1 g; SLNP10ng and PYR 1 ng; P > 0.05).

431 The $\mathrm{ACN}(252.7 \pm 25.03 \mathrm{~h})$ data was similar to control group, as well as $\mathrm{SLNP}_{1 \mathrm{ng}}(256.24 \pm$ 432 $21.00 \mathrm{~h})$ and $\mathrm{SLNP}_{10 \mathrm{ng}}(241.33 \pm 18.81 \mathrm{~h})$. The mean survival time of PVA $(171.16 \pm 18.09$ h), SLN (196.54 \pm 11.38 h) and PYR 1ng $(175.33 \pm 28.12$ h) groups was lower than the control 434 group, but not significant $(\mathrm{P}>0.05)$. The data of survival analysis were showed in 435 Supplementary Material (Figure 2S).

Pyrethroids can be dangerous to honeybees (JOHNSON et al., 2010), for example,

437 they interfere in the behavior (PALMQUIST et al., 2012), learning and memory performance

438 (LIAO et al., 2018). In addition, exposure to Lambda-Cyhalothrin negatively affects the life 439 span (LIAO et al., 2018; DOLEZAL et al., 2016). In line with these data, the pyrethrum 440 extract and deltamethrin also reduced survival of Africanized Apis mellifera.

441 The sublethal doses of $1 \mathrm{ng} \cdot \mu \mathrm{L}^{-1}(1 \mathrm{ppm})$ and $10 \mathrm{ng} \cdot \mu \mathrm{L}^{-1}$ (10 ppm) of biocide free or 442 encapsulated that were administered to the bees, induced short-term responses, at 443 morphological level, in the midguts of newly emerged workers. 
444

445

446

447 448

The bee midgut is mainly responsible for food digestion and nutrient absorption, and is composed of three cell types: digestive, endocrine, and regenerative cells. Digestive cells are responsible for the production of digestive enzymes and nutrient absorption, endocrine cells produce hormones, and regenerative cells, which are within nests, are responsible for cell renewal of the epithelium (MARTINS et al., 2006).

Histological analysis of the bee midguts revealed morphological alterations in the epithelium (Figure 3), specifically in the digestive cells, whereas the regenerative cell nests maintained their normal morphological pattern. An increase in the elimination of digestive cells to the intestinal lumen was observed in some treatment groups (empty SLNs, SLNP ${ }_{1 \mathrm{ng}}$, and $\mathrm{PYR}_{10 \mathrm{ng}}$; Figure $3 \mathrm{D}, 3 \mathrm{E}$, and $\left.3 \mathrm{H}\right)$ in comparison to the control groups (CTL, ACN, and PVA), which was significant in the empty SLN group (Figure 4A and Table 3S Supplementary Material).

Therefore, sublethal concentrations of pyrethrum extract in both non-encapsulated and encapsulated form in nanoparticles, as well as in empty nanoparticles (SLN), caused changes in digestive cells. Digestive cells have many microvilli close to the peritrophic matrix in the lumen, and among these cells, nests of small regenerative cells are in the intestinal epithelium (NEVES et al., 2002). These undifferentiated cells that remain in the nest are a source for cell renewal in epithelium of bee midgut (CAVALCANTE and CRUZLANDIM, 2004). Thus, regenerative cells replace dead digestive cells, which were released into the lumen, for new epithelial digestive cells by differentiation process (CRUZ et al., 2011). In this study, regenerative nests were observed in midgut epithelium, but histological alterations indicative of cytotoxicity were not found in these cells, such as pyknotic nuclei. If the regenerative cells from nests had presented nuclear pyknosis, which is an indicative of cell death in undifferentiated cells, this alteration would have a "severe pathological 
468 importance" because regenerative cells in adults does not suffer mitosis (CRUZ et al., 2011),

469 and consequently epithelial renewal of midgut would be compromised, resulting to partial or 470 total loss of the organ function.

471 Digestive cells are eliminated by cell degeneration under natural conditions, 472 meanwhile this process can be accelerated and/or intensified in response to xenobiotic 473 exposure (e.g., SLNs; Table 3S - Supplementary Material). Therefore, cell renewal is an 474 important process in maintaining the organ function, because the differentiation process from 475 regenerative cells can replace dead digestive cells and to renew the midgut epithelium.

476 There was less elimination of digestive cells to the intestinal lumen in bees exposed 477 to pyrethrum-loaded nanoparticles than in those exposed to empty nanoparticles (SLN). 478 Probably, the reduced cell-to-lumen liberation has been due to the interaction of the 479 pyrethrum with the active sites in the nanoparticle, providing greater stability of the colloidal 480 system over the time (0-120d) and high encapsulation efficiency (> 99\% along 120d), as 481 evidenced in the physicochemical characterization data. On the contrary, empty SLNs are 482 more reactive and form aggregates more easily over time. Therefore, reactive empty SLNs 483 could interact with the epithelial cells of the midgut (oral exposure) and induce cytotoxicity 484 in digestive cells, which would trigger their elimination to the organ's lumen. The compounds 485 used in nanoparticle formulations, and the colloidal instability of the system, can affect 486 interactions with cell membranes and trigger cytotoxicity (NAFEE et al., 2009). Whereas 487 the worker honeybee has lifetime of 45 days, and considering the acute exposure to the 488 nanopesticide during its application, probably the whole SLNP will remain stable during its 489 life span. Associating this information with the survival analysis, it can be noted that 490 encapsulated pyrethrum kept the survival time $(256.24 \pm 21.00 \mathrm{~h}$ and $241.33 \pm 18.81 \mathrm{~h}$, $491 \mathrm{SLNP}_{1 \mathrm{ng}}$ and $\mathrm{SLNP}_{1 \mathrm{ng}}$, respectively) of the bees similar to the control group $(257.83 \pm 21.79$ 
492 h). Given that $10 \mathrm{ng}$ of pyrethrum extract and pyrethroid (deltamethrin) reduced life span of

493 the bees, it may be noted that pyrethrum-loaded in nanoparticle is more safe for honeybees,

494 probably because of the stability of the encapsulated pyrethrum and its release as a function 495 of time.

496 Another important process that we observed was increased apocrine secretions from 497 the midgut epithelium onto the apical surfaces of midgut digestive cells (Figure 3SD and 3SE 498 - Supplementary Material). These epithelial cells secrete digestive enzymes and peritrophic 499 matrix substances normally by means of apocrine secretion. Therefore, an increase in 500 secretion may be a protective compensatory response to xenobiotic exposure. Increased 501 apocrine secretion occurred in both the empty nanoparticle-exposed and $1 \mathrm{ng} . \mu \mathrm{L}^{-1}$ of 502 pyrethrum-loaded nanoparticle-exposed groups (SLN and $\mathrm{SLNP}_{1 \mathrm{ng}}$; Table 3S and Figure 503 4B). A previous study reported an increase in apocrine secretion of midgut digestive cells in 504 bees exposed to sublethal doses of thiamethoxam insecticide $\left(0.428 \mathrm{ng} \cdot \mu \mathrm{L}^{-1}\right.$ and 0.0428 505 ng. $\mu \mathrm{L}^{-1}$ per day for 18 days), as well as the increase in both cell vacuolization and cell 506 elimination from the epithelium to the midgut lumen over the exposure period (OLIVEIRA 507 et al., 2014). Higher frequency of eliminated digestive cells and release of apocrine secretion

509 (Figure 4) were considered reversible alterations in the bee midgut and that did not affect 510 survival of bees in empty SLNs or encapsulated pyrethrum (SLNPs) groups. In normal 511 physiological situations, there is low frequency of senescent or dead cells eliminated to the 512 lumen (CAVALCANTE; CRUZ-LANDIM, 1999), and releasing of digestive enzymes from 513 cells to the peritrophic matrix in the lumen, usually by apocrine secretion (TERRA; 514 FERREIRA, 2012). Therefore, these alterations were classified as importance factor 1 in the 515 semi-quantitative analysis, because normally they are reversible, i.e., damage recovery in 
516 epithelium occurs through the differentiation of regenerative cells from their nests in order

517 to have new digestive cells. Thus, there is a compensatory response to the potential 518 physiological stress triggered by agrochemicals or nanocarriers that can lead to the 519 elimination of cells and/or intensification of apocrine secretion. Soares et al. (2012) reported 520 an elimination of cells into the lumen, increased apocrine secretion, and pyknotic nuclei in

521 the epithelial cells of the Scaptotrigona postica midgut after applying sublethal doses of the 522 insecticide imidacloprid. Similarly, Rossi et al. (2011) exposed Africanized A. mellifera to 523 sublethal doses of imidacloprid and observed an increase in both cell elimination and 524 apocrine secretion in the midgut.

Aljedani (2017) evaluated the effects of acute exposure to deltamethrin on foraging 526 worker honeybees (A. mellifera jemenatica). The bees that were fed a sugary solution 527 containing $2.5 \mathrm{ppm}$ of pyrethroid presented morphological changes in the midgut. In our 528 study, sublethal concentrations of pyrethrum extract (1 and $\left.10 \mathrm{ng} . \mu \mathrm{L}^{-}\right)$did not induce 529 histopathological effects on midguts' honeybees when the cell biomarkers were analyzed 530 separately, but the total organ index analysis showed alterations in $10 \mathrm{ng} \cdot \mu \mathrm{L}^{-1}$ pyrethrum 531 extract that could potentially impair midgut function, since there was a decrease in the 532 longevity of the bees, demonstrating the relevance of evaluation of total organ index in bees 533 exposed to pesticides coupled to survival analysis. 

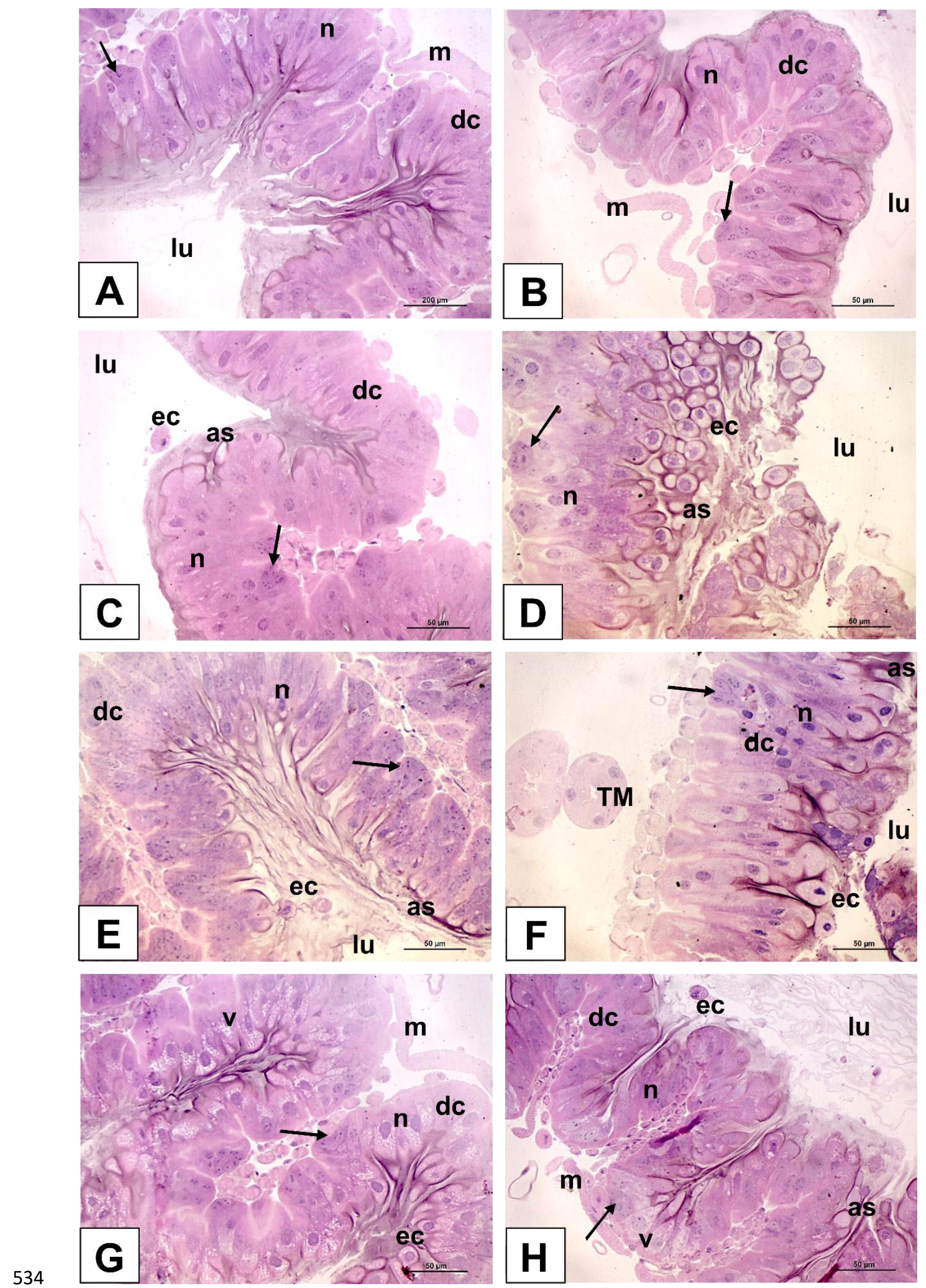
535

536

537

538

539

540

541

542

543

544

545

546

547

548

549

550

551

552

553

554

555

556 557 formed from early endosomes due to an inward budding of its membrane resulting in

558

559

560

561

562

Figure 3 - Honeybees (Africanized A. mellifera) midguts after $48 \mathrm{~h}$ of acute exposure. A) CTL - syrup control; B) ACN - acetone control; C) PVA - surfactant control; D) SLN - Solid lipid nanoparticles; E) SLNP ${ }_{1 n g}-1$ ng. $\mu \mathrm{L}^{-1}$ of pyrethrum loaded in solid lipid nanoparticles; F) SLNP $_{10 n g}-10$ ng. $\mu L^{-1}$ of pyrethrum loaded in solid lipid nanoparticles G) PYR Rng $_{1}-1$ ng. $\mu \mathrm{L}^{-1}$ of pyrethrum extract; H) PYR $10 \mathrm{ng}-10 \mathrm{ng} . \mu \mathrm{L}^{-1}$ of pyrethrum extract. Legend: $\mathrm{dc}=$ digestive cell; $\mathrm{ec}=$ eliminated cell in the lumen; $\mathrm{l}=$ lumen; $\mathrm{n}=$ nucleus, $\mathrm{v}=$ vacuolization; as $=$ apocrine secretion; Black arrow $=$ Regenerative cell; $\mathrm{TM}=$ Malpighi's tubes; $\mathrm{m}=$ muscle. Staining: Hematoxylin-Eosin. Bars: $50 \mu \mathrm{m}$.

Although vacuolization can be present in bee midgut cells as a physiological process of autophagy for intracellular turnover, their increased level frequently has been associated to side-effects of xenobiotics, especially in bees exposed to pesticides. For example, Cruz et al. (2010) reported cytoplasmic vacuolization and cell elimination in A. mellifera larvae midguts exposed to fipronil $\left(0.1\right.$ and $\left.1 \mu \mathrm{g} \cdot \mathrm{g}^{-1}\right)$ and boric acid $\left(1.0,2.5\right.$, and $\left.7.5 \mathrm{mg} \cdot \mathrm{g}^{-1}\right)$. Kakamand et al. (2008) observed an increase in the vacuolization of midgut cells in honeybees exposed to deltamethrin $\left(1,2.5,5\right.$, and $\left.10 \mathrm{mg} \cdot \mathrm{L}^{-1}\right)$ and the degeneration of the midgut epithelium of bees exposed to the highest concentration of this compound.

Histochemical analysis of vacuolization areas in digestive cells (Figure 4S Supplementary Material) showed that they are negative for proteins or neutral glycoconjugates, but had positive labelling for lipids that could indicate multivesicular bodies, because newly emerged honeybees have no spherocrystals yet. Multivesicular bodies are frequently found in midgut cells of insects (SERRAO; CRUZ-LANDIM, 1996), and are intralumenal vesicles whose main function is "collecting" plasma membrane receptors to be degraded into the lysosomes. Multivesicular bodies and autophagy are closely related (FADER; COLOMBO, 2009).

At the present study, intensification of cytoplasm vacuolization was considered a morphological alteration indicative of cytoplasmic loss, which is of greater pathological 
563 importance than the other alterations analyzed because, especially in insects, autophagy may 564 act as a pro-death process at the cellular/organ level (MALAGOLI et al., 2010), although its 565 effects at the organismal level can still be considered as fundamental for survival.

566 Cell vacuolization increased in both groups exposed to pyrethrum extract (Figure 3G 567 and $3 \mathrm{H}$, Figure $3 \mathrm{SG}$ and $3 \mathrm{SH}$, and Table $3 \mathrm{~S}$ ), but there was no significant difference due to 568 the highly variable degree of vacuolization among individuals exposed to pyrethrum extract 569 (Figure 4C). However, when the organ index was calculated, vacuolization accounted for a 570 higher total index under $10 \mathrm{ng} \cdot \mu \mathrm{L}^{-1}$ of pyrethrum extract (Figure 4D), as this alteration was 571 classified as importance factor 2 in the semi-quantitative analysis (Table 3S) because of the 572 loss of cytoplasmic material and the severity level.

573 In the total organ index analysis, the empty nanoparticles and $10 \mathrm{ng} \cdot \mathrm{LL}^{-1}$ of pyrethrum 574 extract caused more significant changes than the other experimental groups (Table 3S). In 575 contrast, nanoparticles loaded with 1 ng. $\mu \mathrm{L}^{-1}$ pyrethrum extract did not increase cell 576 alterations more than the other groups (nanoparticles and pyrethrum extract). The SLNP 577 groups exhibited a decrease in short-term cell alterations, so in this respect was considered 578 safer for bees over short exposure times. 

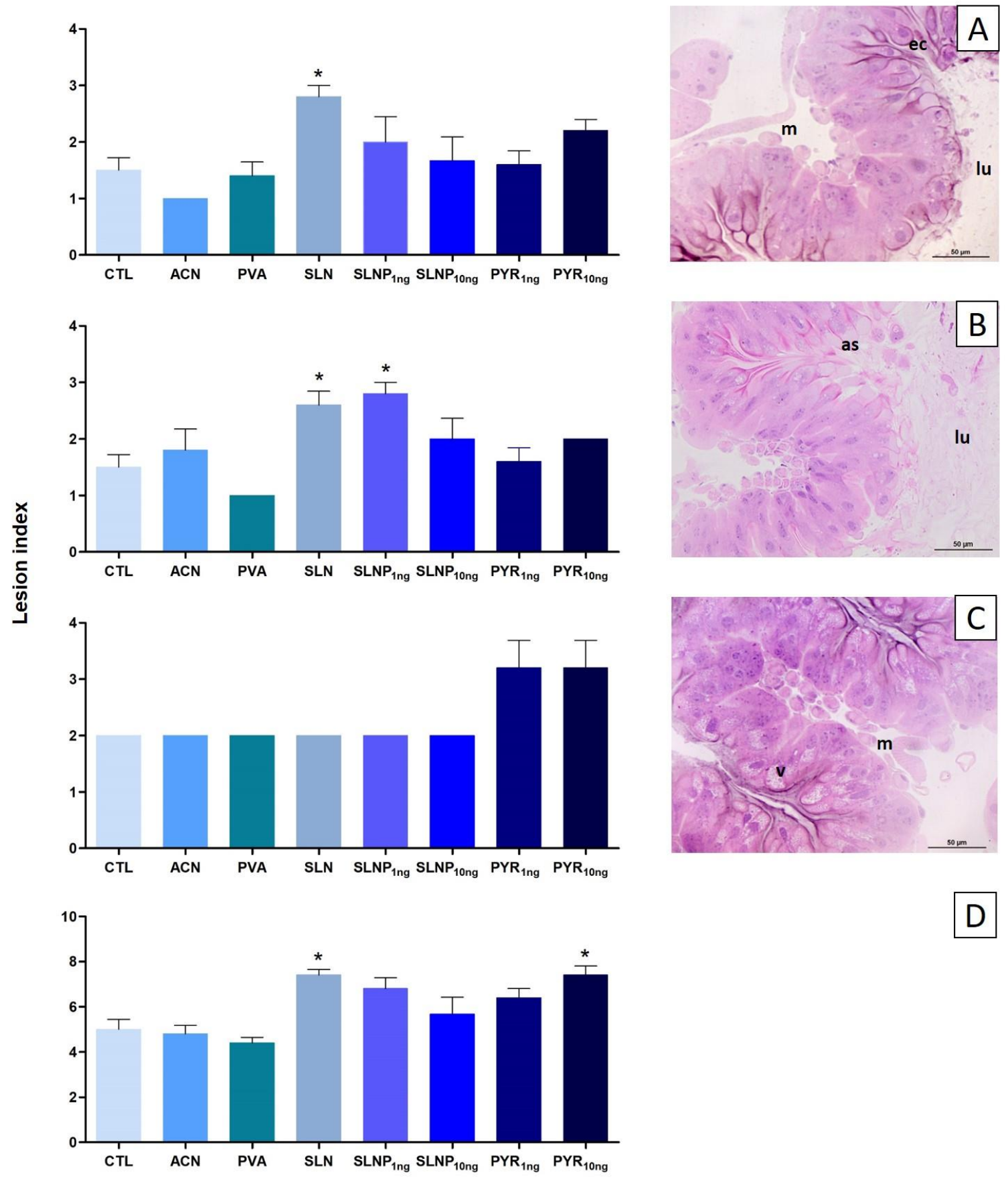

\section{Treatments}

Figure 4 - Alterations and organ index in honeybee (Africanized A. mellifera) midguts. a) Eliminated cell index; b) Apocrine secretion index; c) Vacuolization index; d) Total organ index. Legend: CTL - syrup control; ACN - acetone control; PVA - surfactant control; SLN - Solid lipid nanoparticles; SLNP 1 ng -1 ng. $\mu L^{-1}$ of pyrethrum loaded in solid lipid nanoparticles; $\mathrm{SLNP}_{10 \mathrm{ng}}-10 \mathrm{ng} . \mu \mathrm{L}^{-1}$ of pyrethrum loaded in solid lipid nanoparticles PYR $1 \mathrm{ng}$ -1 ng. $\mu L^{-1}$ of pyrethrum extract; PYR $10 \mathrm{ng}-10 \mathrm{ng} \cdot \mu \mathrm{L}^{-1}$ of pyrethrum extract. Kruskal Wallis One-way ANOVA, followed by Dunn's multiple comparison test. *represent significant differences between groups. 
At the lowest sublethal doses $\left(1 \mathrm{ng} . \mu \mathrm{L}^{-1}\right)$, the biocide did not evidence significant

589 histopathological changes in the total lesion index, indicating that could be applied on crops.

590 A carrier system could be developed to improve pyrethrum extract stability, thus allowing its

591 use as nanopesticides. Besides, when the pyrethrum extract was encapsulated in nanocarriers

592 and demonstrated lower toxicity when compared with pyrethrum only. Therefore,

593 nanocarriers are an alternative to conventional pesticide applications. Nanotechnology

594 applied in the agricultural sector could increase agricultural production and crop protection,

595 contribute to sustainable agriculture and eco-friendly carrier systems, and reduce

596 environmental effects and toxicity to organisms (GRILLO et al., 2016). Oliveira et al. (2018)

597 found that zein nanoparticles loaded with citronella effectively controlled the pest species

598 Tetranychus urticae with low toxicity.

599 The empty SLNs showed effects onto honeybee, for example, in the total lesion index,

600 with the increase the eliminated cells and apocrine secretion. Therefore, nanocarrier system

601 itself may have reactive sites capable of changing their biological system because it has no

602 active ingredient encapsulated. These reactive sites could interact with organic molecules of

603 the organism, inducing negative effects that indirectly decreased the mean survival time of

604 the bees $(196.54 \pm 11.38 \mathrm{~h} ; \mathrm{P}>0.05)$. By the way, further studies need to be performed in

605 order to evaluate these hypotheses.

606 Nanopesticides can be able to increase the efficiency of agrochemicals and biocides,

607 because it is possible that in the field low doses of the active ingredients can be used.

608 However, in the case of pyrethrum and SLNs this fact will be confirmed with biological 609 assays in target organisms that will be run in the future. In addition, they increase production 610 and reduce damage to the environment (PRASAD et al., 2017). However, there are still many 611 gaps in information to be filled, normative instructions to be written, and legislation to be 
612 made before they can be extensively and safely employed in agriculture (KAH; HOFMANN,

613 2014; KOOKANA et al., 2014). According Kah et al. (2018), further studies that investigate

614 the efficacy of nanopesticides in crop farming are needed, in order to elucidate their effects

615 on biodiversity and human health, and their benefits and costs compared with conventional 616 formulations.

617

618

\section{CONCLUSION}

It is important to develop and analyze carrier systems as they have many potential benefits in comparison to synthetic and natural agrochemicals, such as reducing the amount 621 of biocide in the environment and greater stability. However, nanotoxicological studies 622 should be undertaken to evaluate the effects of nanoparticles on non-target organisms. In 623 conclusion, this study demonstrates that nanoparticles loaded with pyrethrum extract at 624 sublethal dose (1 or $\left.10 \mathrm{ng} \cdot \mathrm{LL}^{-1}\right)$ are relatively safe for honeybees, because they do not cause 625 morphological changes in digestive cells. In contrast, empty nanoparticles and $10 \mathrm{ng} . \mu \mathrm{L}^{-1} \mathrm{of}$ 626 pyrethrum extract caused changes in digestive cells during acute exposure. The concentration 627 of $1 \mathrm{ng} \cdot \mu \mathrm{L}^{-1}$ of pyrethrum extract could be used for pest control. These data reflect the effects 628 of a sublethal and acute exposure, and more studies are needed to check if a chronic exposure 629 to these compounds would have different effects on bees. Our results added information for 630 subsidizing future decision making, regulatory framework creation, risk assessments, and 631 legislation development, and improve food security. In addition, based on the results we are 632 planning to run biological assays in order to investigate the efficacy of the nanopesticide 633 against target organisms. 
673

674

675

676

677

\section{ACKNOWLEDGMENTS}

Authors would like to thank the grant of São Paulo Research Foundation (\#2017/21004-5). Hellen Maria Soares-Lima and Rafaela Tadei for assisting in the toxicity bioassays, and Edson Sampaio keeping the colonies of honeybees for experiments. Authors thanks Profa. Dra. Leticia S. Souto from LADIVE by the availability of the microtome (FAPESP 2015/01424-4).

\section{CONFLICT OF INTEREST}

The authors declare there are no conflicts of interest in the present study.

\section{REFERENCES}

Abdelwahed, W.; Degobert, G.; Stainmesse, S.; Fessi, H. 2006. Freeze-drying of nanoparticles: formulation, process and storage considerations. Adv. Drug Delivery Rev. 58 (15), 1688-1713. https://doi.org/10.1016/j.addr.2006.09.017

About NIFA, 2018. National Institute of Food and Agriculture (NIFA) - United States Department of Agriculture (USDA). White House Office of Science and Technology Policy: Alexandria, VA, 2018. https://nifa.usda.gov/about-nifa (accessed Mar 04, 2018).

Aditya, N.P.; Shim, M.; Lee, I.; Lee, Y.; Im, M.H.; Ko, S. 2013. Curcumin and gnistein coloaded nanostructured lipid carriers: in vitro digestion and antiprostate cancer activity. $J$. Agri. Food Chem. 61 (8), 1878-1883. doi: 10.1021/jf305143k.

Aljedani, D.M. 2017. Effects of Abamectin and Deltamethrin to the foragers honeybee workers of Apis mellifera jemenatica (Hymenoptera: Apidae) under laboratory conditions. Saudi J. Biol. Sci. 24 (5), 1007-1015. doi: http://dx.doi.org/10.1016/j.sjbs.2016.12.007.

Anderson, W.; Kozak, D.; Coleman, V.A.; Jämting, Å.K.; Trau, M. 2013. A comparative study of submicron particle sizing platforms: Accuracy, precision and resolution analysis of polydisperse particle size distributions. J. Colloid Interface Sci. 405, 322-330. https://doi.org/10.1016/j.scienta.2007.11.013

Anjali, C.H.; Sudheer Khan, S.; Margulis-Goshen, K.; Magdassi, S.; Mukherjee, A.; Chandrasekaran, N. 2010. Formulation of water-dispersible nanopermethrin for larvicidal applications. Ecotoxicol. Environ. Saf. $73 \quad$ (8), 1932-1936. doi: 10.1016/j.ecoenv.2010.08.039.

Bernet, D.; Schmidt, H.; Meier, W.; Burkhardt-Holm, P.; Wahli, T. 1999. Histopathology in fish: Proposal for a protocol to assess aquatic pollution. J. Fish Dis., 22 (1), 25-34. https://doi.org/10.1046/j.1365-2761.1999.00134.x 
678

679

680

681

682

683

684

685

686

687

688

689

690

691

692

693

694

695

696

697

698

699

700

701

702

703

704

705

706

707

708

709

710

711

712

713

714

715

716

717

718

719

720

721

722

723
Campos, E.V.R.; de Oliveira, J.L.; da Silva, C.M.; Pascoli, M.; Pasquoto, T.; Lima, R.; Abhilash, P.C.; Fraceto, L.F. 2015. Polymeric and Solid Lipid Nanoparticles for Sustained Release of Carbendazim and Tebuconazole in Agricultural Applications. Sci Rep. 5, 13809. doi: $10.1038 /$ srep13809

Cavalcante, V.M.; C. Cruz-Landim. 1999. Types of cells present in the midgut of the insects: A review. Naturalia (Rio Claro) 24, 19-40.

Cavalcante, V.M.; Cruz-Landim, C. 2004. Padrão eletroforético de proteínas e atividade de fosfatase ácida em extratos do intestino médio de Apis mellifera L. durante a metamorfose. Neotrop. $\quad$ Entomol. $33 \quad$ (2), 169-172. http://dx.doi.org/10.1590/S1519$566 \times 2004000200007$.

Chen, H; Chang, X.; Du, D.; Liu, W.; Liu, J.; Weng, T.; Yang, Y.; Xu, H.; Yang, X. 2006. Podophyllotoxin-loaded solid lipid nanoparticles for epidermal targeting. J. Controlled Release 110 (2), 296 - 306. doi: 10.1016/j.jconrel.2005.09.052

Chen, H., Yada, R. 2011. Nanotechnologies in agriculture: new tools for sustainable development. Trends Food Sci. Technol 22, 585-594. https://doi.org/10.1016/j.tifs.2011.09.004

Cruz, A.S.; da Silva-Zacarin, E.C.; Bueno, O.C.; Malaspina, O. 2010. Morphological alterations induced by boric acid and fipronil in the midgut of worker honeybee (Apis mellifera L.) larvae. Cell Biol. Toxicol. 26 (2), 165-176. doi: 10.1007/s10565-009-9126-X.

Cruz, L.C.; Araújo, V.A.; Dolder, H.; Araújo, A.P.; Serrão, J.E.; Neves, C.A. 2011. Morphometry of the midgut of Melipona quadrifasciata anthidioides (Lepeletier) (Hymenoptera: Apidae) during metamorphosis. Neotrop. Entomol. 40 (6), 677-681. http://dx.doi.org/10.1590/S1519-566X2011000600007.

de Melo, N.F.S.; Araújo, D.R.; Grillo, R.; Moraes, C.M.; Matos, A.P.; Paula, E.; Rosa, A.H.; Fraceto, L.F. 2012. Benzocaine-loaded polymeric nanocapsules: Study of the anesthetic activities. J. Pharm. Sci. 101, 1157-1165.

de Melo, N.F.; de Macedo, C.G.; Bonfante, R.; Abdalla, H.B.; da Silva, C.M.; Pasquoto, T.; de Lima, R.; Fraceto, L.F.; Clemente-Napimoga, J.T.; Napimoga, M.H. 2016. 15d-PGJ $2^{-}$ Loaded Solid Lipid Nanoparticles: Physicochemical Characterization and Evaluation of Pharmacological Effects on Inflammation. PLoS One 11 (8), e0161796. https://doi.org/10.1371/journal.pone.0161796

Dolezal, A.G.; Carrillo-Tripp, J.; Miller, W.A.; Bonning, B.C.; Toth, A.L. 2016. Pollen Contaminated with Field-Relevant levels of Cyhalothrin affects Honey Bee Survival, Nutritional Physiology, and Pollen Consumption Behavior. J. Econ, Entomol. 109 (1), 41-8. https://doi.org/10.1093/jee/tov301. 
Fader, C.M.; Colombo, M.I. 2009. Autophagy and multivesicular bodies: two closely related partners. Cell Death Differ. 16 (1), p. 70-78. doi: 10.1038/cdd.2008.168.

Gamisans, F.; Lacoulonche, F.; Chauvet, A.; Espina, M.; García, M.L.; Egea, M.A. 1999. Flurbiprofen-loaded nanospheres: analysis of the matrix structure by thermal methods. Int. J. Pharm. 179 (1), 37-48. https://doi.org/10.1016/S0378-5173(98)00381-0

Giannini, T.C.; Cordeiro, G.D.; Freitas, B.M.; Saraiva, A.M. Imperatriz-Fonseca, V.L. 2015. The dependence of crops for pollinators and the economic value of pollination in Brazil. $J$. Econ. Entomol. 108, 1-9. doi: 10.1093/jee/tov093.

Gopal, M.; Kumar, R.; Goswami, A. 2012. Nano-pesticides - A recent approach for pest control. The J. Plant Protec. Sci. 4 (2), 1-7.

Goulson, D.; Nicholls, E.; Botías, C.; Rotheray, E.L. 2015.Bee declines driven by combined stress from parasites, pesticides, and lack of flowers. Science. 347 (6229), 1255957. Doi: $10.1126 /$ science. 1255957

Grillo, R.; Abhilash, P.C.; Fraceto, L.F. 2016. Nanotechnology applied to Bio-encapsulation of pesticides. J. Nanosci. Nanotechnol. 16, 1231-1234. https://doi.org/10.1166/jnn.2016.12332

Guirguis, O.W.; Moselhey, M.T.H. 2012. Thermal and structural studies of poly(vinyl alcohol) and hydroxypropyl cellulose blends. Natural Sci. 4 (1), 57-67. http://dx.doi.org/10.4236/ns.2012.41009

Jacques, M.T.; Oliveira, J.L.; Campos, E.V.; Fraceto, L.F.; Ávila, D.S. 2017. Safety assessment of nanopesticides using the roundworm Caenorhabditis elegans. Ecotoxicol. Environ. Saf. 139, 245-253. doi: 10.1016/j.ecoenv.2017.01.045

Johnson, R.M.; Ellis, M. D.; Mullin, C. A.; Frazier, M. 2010. Pesticides and honey bee toxicity - USA. Apidologie 41, 312-331. doi: 10.1051/apido/2010018

Kah, M.; Machinski, P.; Koerner, P.; Tiede, K.; Grillo, R.; Fraceto, L.F. 2014. Hofmann T.Analysing the fate of nanopesticides in soil and the applicability of regulatory protocols using a polymer-based nanoformulation of atrazine. Environ. Sci. Pollut. Res. 21 (20), 11699707. doi: 10.1007/s11356-014-2523-6.

Kah, M.; Hofmann, T. 2014. Nanopesticide research: Current trends and future priorities. Environ. Int. 63, 224-235. doi: 10.1016/j.envint.2013.11.015.

Kah, M.; Kookana, R.S.; Gogos, A.; Bucheli, T.D. 2018. A critical evaluation of nanopesticides and nanofertilizers against their conventional analogues. Nat. Nanotechnol. 13, 677-684. doi: 10.1038/s41565-018-0131-1. 
Kakamand, F.A.K.; Mahmoud, T. T.; Amin, A.M. 2008. The role of three insecticides in disturbance the midgut tissue in honey bee Apis mellifera L. Workers. J. Dohuk Univ. 11 (1), 144-151.

Kearns, C.A.; Inouye, D. W. 1997. Pollinators, Flowering Plants, and Conservation Biology. BioScience 47 (5), 297-307.

Kilic, A. C.; Capan, Y.; Vural, I.; Gursoy, R.N.; Dalkara, T.; Cuine, A.; Hincal, A.A. 2005. Preparation and characterization of PLGA nanospheres for the targeted delivery of NR2Bspecific antisense oligonucleotides to the NMDA receptors in the brain. $J$. Microencapsulation 22, 633-641.

Kim, D.Y.; Kadam, A.; Shinde, S.; Saratale, R.G.; Patra, J.; Ghodake, G. 2018. Recent developments in nanotechnology transforming the agricultural sector: a transition replete with opportunities. J. Sci. Food Agric. 98 (3), 849-864. doi: 10.1002/jsfa.8749.

Kookana, R.S.; Boxall, A.B.; Reeves, P.T.; Ashauer, R.; Beulke, S.; Chaudhry, Q.; Cornelis, G.; Fernandes, T.F.; Gan, J.; Kah, M.; Lynch, I.; Ranville, J.; Sinclair, C.; Spurgeon, D.; Tiede, K.; Van den Brink, P.J. 2014. Nanopesticides: guiding principles for regulatory evaluation of environmental risks. J. Agric. Food. Chem. 62 (19), 4227-4240. doi: $10.1021 /$ jf500232f

Liao, C.H.; He, X.J.; Wang, Z.L.; Barron, A.B.; Zhang, B.; Zeng, Z.J.; Wu, X.B. 2018. ShortTerm Exposure to Lambda-Cyhalothrin Negatively Affects the Survival and MemoryRelated Characteristics of Worker Bees Apis mellifera. Arch. Environ. Contam. Toxicol. 75 (1), 59-65. doi: 10.1007/s00244-018-0514-1.

Liu, Y.; Tong, Z.; Prud'homme, R.K. 2008. Stabilized polymeric nanoparticles for controlled and efficient release of bifenthrin. Pest. Manag. Sci. 64 (8), 808-812. doi: 10.1002/ps.1566.

Lourenço, C.; Teixeira, M.; Simões, S.; Gaspar, R. 1996. Steric stabilization of nanoparticles: Size and surface properties. Int. J. Pharm. 138 (1), 1-12. https://doi.org/10.1016/03785173(96)04486-9

Malagoli, D.; Abdalla, F.C.; Cao, Y.; Feng, Q.; Fujisaki, K.; Gregorc, A.; Matsuo, T.; Nezis, I.P.; Papassideri, I.S.; Sass, M.; Silva-Zacarin, E.C.; Tettamanti, G.; Umemiya-Shirafuji, R. 2010. Autophagy and its physiological relevance in arthropods: current knowledge and perspectives. Autophagy. 6 (5), 575-88. doi: 10.4161/auto.6.5.11962.

Martins, G.F.; Neves, C.A.; Campos, L.A.; Serrão, J.E. 2006. The regenerative cells during the metamorphosis in the midgut of bees. Micron 37 (2), 161-168. https://doi.org/10.1016/j.micron.2005.07.003

Maruyama, C.R.; Guilger, M.1.; Pascoli, M.; Bileshy-José, N.; Abhilash, P.C.; Fraceto, L.F.; de Lima, R. 2016. Nanoparticles Based on Chitosan as Carriers for the Combined Herbicides Imazapic and Imazapyr. Sci. Rep. 6 (19768). Doi: 10.1038/srep19768 
816

817

818

819

820

821

822

823

824

825

826

827

828

829

830

831

832

833

834

835

836

837

838

839

840

841

842

843

844

845

846

847

848

849

850

851

852

853

854

855

856

857

858

859

860

861

862
Masarudin, M.J.; Cutts, S.M.; Evison, B.J.; Phillips, D.R.; Pigram, P. J. 2015. Factors determining the stability, size distribution, and cellular accumulation of small, monodisperse chitosan nanoparticles as candidate vectors for anticancer drug delivery: application to the passive encapsulation of $\left[{ }^{14} \mathrm{C}\right]$-doxorubicin. Nanotechnol. Sci. Appl. 8, 67-80. http://doi.org/10.2147/NSA.S91785

Mishra, S.; Keswani, C.; Abhilash, P.C.; Fraceto, L.F.; Singh, H.B. 2017. Integrated Approach of Agri-nanotechnology: Challenges and Future Trends. Front. Plant. Sci. 8, 1-12.

Montanha, F.P.; Pimpão, C.T. 2012. Efeitos toxicológicos de piretróides (cipermetrina e deltametrina) em peixes. Rev. Cient. Elet. Med. Vet. 9 (18), 1-58.

Mukhopadhyay, S.S. 2014. Nanotechnology in agriculture: prospects and constraints. Nanotechnol., Sci. Appl. 7, 63-71. doi: 10.2147/NSA.S39409

Muller, R. H.; Rühl, D.; Runge, S.A. 1996. RungeBiodegradation of solid lipid nanoparticles as a function of lipase incubation time. Int. J. Pharm. 144 (1), 115-121.

Muller, H.R.; Mäder, K.; Gohla, S. 2000. Solid lipid nanoparticles (SLN) for controlled drug delivery: a review of the state of the art. Eur. J. Pharm. Biopharm. 50 (1), 161-177. https://doi.org/10.1016/S0939-6411(00)00087-4

Muller, H.; Shegokar, R.; Keck, C.M. 2011. 20 Years of Lipid Nanoparticles (SLN \& NLC): Present State of Development \& Industrial Applications. Curr. Drug. Discov. Technol. 8, 207-227. https://doi.org/10.2174/157016311796799062

Nafee, N.; Schneider, M.; Schaefer, U.F.; Lehr, C.M. 2009. Relevance of the colloidal stability of chitosan/PLGA nanoparticles on their cytotoxicity profile. Int. J. Pharm. 381 (2, 3), 130-139. https://doi.org/10.1016/j.ijpharm.2009.04.049

Naseri, N.; Valizadeh, H.; Zakeri-Milani, P. 2015. Solid Lipid Nanoparticles and Nanostructured Lipid Carriers: Structure, Preparation and Application. Adv. Pharm. Bull. 5 (3), 305-313. http://doi.org/10.15171/apb.2015.043

Nasseri, M.; Golmohammadzadeh, S.; Arouiee, H.; Jaafari, M.R.; Neamati, H. 2016. Antifungal activity of Zataria multiflora essential oil-loaded solid lipid nanoparticles in-vitro condition. Iran. J. Basic Med. Sci. 19 (11), 1231-1237. Doi: 10.22038/ijbms.2016.7824

Neves, C.A.; Bhering, L.L.; Serrão, J.E.; Gitirana, L.B. 2002. FMRFamide-like midgut endocrine cells during the metamorphosis in Melipona quadrifasciata anthidioides (Hymenoptera Apidae). Micron 33 (5), 453-460. https://doi.org/10.1016/S09684328(01)00043-9

Oliveira, J.L.; Campos, E.V.; Gonçalves da Silva, C.M.; Pasquoto, T.; Lima, R.; Fraceto, L.F. 2015. Solid Lipid Nanoparticles Co-loaded with Simazine and Atrazine: Preparation, Characterization, and Evaluation of Herbicidal Activity. J. Agric. Food Chem. 63, 422-432. Doi: $10.1021 /$ jf5059045 
863

864

865

866

867

868

869

870

871

872

873

874

875

876

877

878

879

880

881

882

883

884

885

886

887

888

889

890

891

892

893

894

895

896

897

898

899

900

901

902

903

904

905

906

907

908

909
Oliveira, J.L.; Campos, E.V.R.; Pereira, A.E.S.; Pasquoto, T.; Lima, R.; Grillo, R.; Andrade, D.J.; Santos, F.A.D.; Fraceto, L.F. 2018. Zein Nanoparticles as Eco-Friendly Carrier Systems for Botanical Repellents Aiming Sustainable Agriculture. J. Agric. Food Chem. 66, 13301340. doi: 10.1021/acs.jafc.7b05552.

Oliveira, R.A.; Roat, T.C.; Carvalho, S.M.; Malaspina, O. 2014. Side-effects of thiamethoxam on the brain and midgut of the africanized honeybee Apis mellifera (Hymenopptera: Apidae). Environ. Toxicol. 29 (10), 1122-33. doi: 10.1002/tox.21842.

Oliveira, R.L.; Passos, F.B. 2013. Estudo da oxidação parcial do etanol em catalisadores de Rh por DRIFTS. Quim. Nova 36 (3), 375-381.

Palmquist, K.; Salatas, J.; Fairbrother, A. 2012. Pyrethroid insecticides: use, environmental fate, and ecotoxicology, in: Perveen, F. (Ed.), Insecticides: Advances in Integrated Pest Management, InTech, Rijeka: Croatia, cap. 11, pp. 251-278.

Pasquoto-Stigliani, T.; Campos, E.V.R.; Oliveira, J.L.; Silva, C.M.G.; Bilesky-José, N.; Guilger, M.; Troost, J.; Oliveira, H.C.; Stolf-Moreira, R.; Fraceto, L.F.; de Lima, R. 2017. Nanocapsules Containing Neem (Azadirachta Indica) Oil: Development, Characterization, And Toxicity Evaluation. Sci. Rep. 7 (5929). doi:10.1038/s41598-017-06092-4

Peay, S.; Hiley, P.D.; Collen, P.; Martin, I. 2006. Biocide treatment of ponds in Scotland to eradicate signal crayfish. Bull. Fr. Pêche Piscic. 380-381, 1363-1379. https://doi.org/10.1051/kmae:2006041

Perez-de-Luque, A.; Rubiales, D. 2009. Nanotechnology for parasitic plant control. Pest Manage. Sci. 65 (5), 540-545. https://doi.org/10.1002/ps.1732

Polleto, F.S.; Jäger, E.; Ré, M.I.; Guterres, S.S.; Pohlmann, A.R. 2007. Rate modulating PHBHV/PCL microparticles containing weak acid model drugs. Int. J. Pharm. 345, 70-80. https://doi.org/10.1016/j.ijpharm.2007.05.040

Potts, S.G.; Biesmeijer, J.C.; Kremen, C.; Neumann, P.; Schweiger, O.; Kunin, W.E. 2010. Global pollinator declines: trends, impacts and drivers. Trends Ecol. Evol. 25 (6), 345-353. https://doi.org/10.1016/j.tree.2010.01.007

Prasad, R., Bhattacharyya, A.; Nguyen, Q.D. 2017. Nanotechnology in Sustainable Agriculture: Recent Developments, Challenges, and Perspectives. Front. Microbiol. 20; 8:1014. https://doi.org/10.3389/fmicb.2017.01014

Rossi, C.A., Roat, T.C.; Tavares, D.A.; Cintra-Socolowski, P.; Malaspina, O. 2011. Effects of sublethal doses of imidacloprid in malpighian tubules of africanized Apis mellifera (Hymenoptera, Apidae). Microsc. Res. Tech. 76 (5), 552-558. https://doi.org/10.1002/jemt.22199 
910

911

912

913

914

915

916

917

918

919

920

921

922

923

924

925

926

927

928

929

930

931

932

933

934

935

936

937

938

939

940

941

942

943

944

945

946

947

948

949

950

951

952

953

954

955

956
Santos, M.A.T.; Areas, M.A.; Reyes, F.G. 2007. Piretróides - uma visão geral. Alim. Nutr. 18 (3), 339-349.

Sarangi, M.J.; Padhi, S. Solid lipid nanoparticles - A Review. J. Crit. Rev. 2016, 3 (3), 5-12.

Sarlak, N.; Taherifar, A.; Salehi, F. 2014. Synthesis of Nanopesticides by Encapsulating Pesticide Nanoparticles Using Functionalized Carbon Nanotubes and Application of New Nanocomposite for Plant Disease Treatment._J. Agric. Food Chem 62 (21), 4833-483. doi.10.1021/jf404720d

Schaffazick, S.R.; Guterres, S.S.; Freitas, L.L.; Pohlmann, A.R. 2003. Caracterização e estabilidade físico-química de sistemas poliméricos nanoparticulados para administração de fármacos. Quím. Nova $26 \quad$ (5), 726-737. http://dx.doi.org/10.1590/S010040422003000500017.

Schleier, J.J.; Peterson, R.K.D. 2011. Pyrethrins and Pyrethroid Insecticides, in: López, O.; Fernández-Bolaños, J.G. (Eds.), Green Trend. Insect Cont, J. Publishing. London: Burlington House, cap. 3, pp. 94-131.

Schwarz, C.; Mehnert, W.; Lucks, J.S.; Müller, R.H. 1994. Solid lipid nanoparticles (SLN) for controlled drug delivery. I. Production, characterization and sterilization. J. Controlled Release. 30 (1), 83-96. https://doi.org/10.1016/0168-3659(94)90047-7

Serrão, J. E., C. Cruz-Landim. 1996. Ultrastructure of digestive cells in stingless bees of various ages (Hymenoptera, Apidae, Meliponinae). Cytobios 88, 161-171.

Scott, N.; Chen, H. 2012. Nanoscale Science and Engineering for Agriculture and Food Systems. Ind. Biotechnol. 9 (1), 17-18. https://doi.org/10.1089/ind.2013.1555

Sekhon, B.S. 2014. Nanotechnology in agri-food production: an overview. Nanotechnol., Sci. Appl. 7, 31-53. http://doi.org/10.2147/NSA.S39406

Silva-Zacarin, E.C.M.; Chauzat, M.P.; Zeggane, S.; Drajnudel, P.; Schurr, F.; Faucon, J.P.; Malaspina, O.; Engler, J.A. 2012. Protocol for optimization of histological, histochemical and immunohistochemical analyses of larval tissues: application in histopathology of honey bee. In: Méndez-Vilas, A. (Ed.), Current microscopy contributions to advances in science and technology, Formatex Research Center: Badajoz, 5. ed., v. 1, pp. 696-703.

Silva, M. dos S. Cocenza, D. S. Grillo, R. de Melo, N. F. S. Tonello, P. S. Oliveira, L. C. de Cassimiro, D. L. Rosa, A. H. Fraceto, L. F. 2011. Paraquat-loaded alginate/chitosan nanoparticles: preparation, characterization and soil sorption studies. J. Hazard. Mater. 190 (1-3), 366-374.

Soares, H.M. Avaliação dos efeitos do inseticida imidacloprido para abelhas sem ferrão Scaptotrigona postica Latreille, 1807 (Hymenoptera, Apidae, Meliponini). Dissertação de Mestrado, Universidade Estadual Paulista - campus Rio Claro/SP, 2012. 
957

958

959

960

961

962

963

964

965

966

967

968

969

970

971

972

973

974

975

976

977

978

979

980

981

982

983

984

985

986

987

988

989

990

991

992

993

994

995

996

997

998

999

1000

1001

1002

1003
Soares-Lima, H.M.; Silva-Zacarin, E.C.M.; Camargo, I; Nocelli, R.C.F.; Malaspina, O. Histopathological alterations on honeybees midgut infected by Nosema ceranae and exposed to imidacloprid. In: Society of Environmental Toxicology and Chemistry Asia-Pacific Conference, Daegu, Korea, Sep 16-19, 2018; SETAC AP, Eds.; SETAC: Korea, 2018.

Terra, W.R.; Ferreira, C. 2012. Biochemistry and molecular biology of digestion. In, Gilbert, L.I. (Ed.), Insect Molecular Biology and Biochemistry, Academic Press: San Diego, pp. 365418. https://doi.org/10.1016/C2009-0-62118-8

U.S. Department of Agriculture, National Institute of Food and Agriculture (USDA/NIFA) 2018; National Nanotechnology Initiative (NANO). White House Office of Science and Technology Policy: Alexandria, VA, 2018. https://www.nano.gov/node/137 (accessed Mar 04, 2018).

Data Evaluation Record - Pyrethrum extract 1991; U.S. Environmental Protection Agency (USEPA). White House Office of Science and Technology Policy: Philadelphia, PA, 1991. https://www3.epa.gov/pesticides/chem_search/cleared_reviews/csr_PC-069001_3-Sep-

91_a.pdf (accessed Mar 14, 2018).

Reregistration Eligibility Decision for Pyrethrins 2006; U.S. Environmental Protection Agency (USEPA). White House Office of Science and Technology Policy: Philadelphia, PA, 2006. http://www.epa.gov/oppsrrd1/REDs/pyrethrins_red.pdf (accessed Mar 14, 2018).

Venkatraman, S. S. 2005. Micelle-like nanoparticles of PLA-PEG-PLA triblock copolymer as chemotherapeutic carrier. Int. J. Pharm. 298, 219-232. https://doi.org/10.1016/j.ijpharm.2005.03.023

Vitorino, C.; Carvalho, F.A.; Almeida, A.J.; Sousa, J.J.; Pais, A.A. 2011. The size of solid lipid nanoparticles: An interpretation from experimental design. Colloids Surf., B. 84 (1), 117-130. https://doi.org/10.1016/j.colsurfb.2010.12.024

Walker, G.W.; Kookana, R.S.; Smith, N.E.; Kah, M.; Doolette, C.L.; Reeves, P.T.; Lovell, W.; Anderson, D.J.; Turney, T.W.; Navarro, D.A. 2017. Ecological risk assessment of nanoenabled pesticides: A perspective on problem formulation. J. Agric. Food Chem. 66 (26), 6480-6486. https://doi: 10.1021/acs.jafc.7b02373

Wang, Q.; Guan, Y.X.; Yao, S.J.; Zhu, Z.Q. 2010. Microparticle formation of sodium cellulose sulfate using supercritical fluid assisted atomization introduced by hydrodynamic cavitation mixer. Chem. Eng. J. 159(1-3), 220-229. https://doi.org/10.1016/j.cej.2010.02.004

Zain, N.A.M.; Suhaimi, M.S.; Idris, A. 2011. Development and modification of PVAalginate as a suitable immobilization matrix. Process Biochem. 46 (11), 2122-2129. https://doi.org/10.1016/j.procbio.2011.08.010

Zhao, D.; Jiao, X.; Zhang, M.; Ye, K.; Shi, X.; Xihua, Lu. Qiu, G.; Sheac, K.J. 2016. Preparation of high encapsulation efficiency fragrance microcapsules and their application in textiles. $R S C A d v$. 84, 80924-80933. doi: 10.1039/C6RA16030A 
1004

1005 Zhou, T.; Zhou, W.; Wanga, Q.; Dai, P.L.; Feng, L.; Zhang, Y.L; Sun, J.H. 2011. Effects of 1006 pyrethroids on neuronal excitability of adult honeybees Apis mellifera. Pestic. Biochem. 1007 Physiol. 100 (1), 35-40. https://doi.org/10.1016/j.pestbp.2011.02.001

1008 
${ }^{*}$ Highlights ( 3 to 5 bullet points (maximum 85 characters including spaces per bullet point)

\section{HIGHLIGHTS}

Nanoparticles showed good properties to be used as pyrethrum carrier system Pyrethrum extract in nanocarrier and sublethal concentrations is safer for honeybees Pyrethrum and nanotechnology showed promising results aiming agriculture applications 


\title{
Nanopesticide based on botanical insecticide pyrethrum and its potential effects on honeybees
}

\author{
Cristiane R. Oliveira ${ }^{\mathrm{a}, \mathrm{b}}$; Caio E. C. Domingues ${ }^{\mathrm{c}}$; Nathalie F. S. de Melo ${ }^{\mathrm{d}}$; Thaisa C. Roat ${ }^{\mathrm{c}}$; Osmar \\ Malaspina $^{\mathrm{c}}$; Monica Jones-Costa ${ }^{\mathrm{b}}$; Elaine C. M. Silva-Zacarin ${ }^{\mathrm{b}}$ and Leonardo F. Fraceto ${ }^{\mathrm{a} *}$ \\ a Universidade Estadual Paulista (UNESP) - "Júlio de Mesquita Filho", Instituto de Ciência e Tecnologia de \\ Sorocaba, Laboratório de Nanotecnologia Ambiental, Av. Três de Março, 511, Alto da Boa Vista, 18087-180, \\ Sorocaba, SP, Brazil. \\ b Universidade Federal de São Carlos (UFSCar), Campus Sorocaba, Departamento de Biologia (CCHB), \\ Laboratório de Fisiologia da Conservação e Laboratório de Ecotoxicologia e Biomarcadores em Animais, \\ Rodovia João Leme dos Santos km 110, Itinga, 18052-780, Sorocaba, SP, Brazil. \\ " Universidade Estadual Paulista (UNESP) - "Júlio de Mesquita Filho", Campus Rio Claro, Departamento de \\ Biologia, Centro de Estudos de Insetos Sociais (CEIS), Av. 24 A, 1515, Jardim Bela Vista, 13506-900, Rio \\ Claro, SP, Brazil. \\ ${ }^{d}$ Faculdade de Medicina São Leopoldo Mandic, Campus Araras. Av. Dona Renata, 71, Santa Cândida, 13600- \\ 001, Araras, SP, Brazil.
}

\begin{abstract}
Nanotechnology has the potential to overcome the challenges of sustainable agriculture, and nanopesticides can control agricultural pests and increase farm productivity with little environmental impact. However, it is important to evaluate their toxicity on non-target organisms, such as honeybees (Apis mellifera) that forage on crops. The aims of this study were to develop a nanopesticide that was based on solid lipid nanoparticles (SLNs) loaded with pyrethrum extract (PYR) and evaluate its physicochemical properties and short-term toxicity on a non-target organism (honeybee). SLN+PYR was physicochemically stable after 120 days. SLN+PYR had a final diameter of $260.8 \pm 3.7 \mathrm{~nm}$ and a polydispersion index of $0.15 \pm 0.02 \mathrm{~nm}$, in comparison with SLN alone that had a diameter of $406.7 \pm 6.7 \mathrm{~nm}$ and a polydispersion index of $0.39 \pm 0.12 \mathrm{~nm}$. SLN+PYR had an encapsulation efficiency of $99 \%$. The survival analysis of honeybees indicated that $\mathrm{PYR}_{10 \mathrm{ng}}$ presented shorter longevity than those in the control group $(\mathrm{P} \leq 0.01)$. Empty nanoparticles and $\mathrm{PYR}_{10 \text { ng }}$ caused morphological alterations in the bees' midguts, whereas pyrethrum-loaded nanoparticles had no significant effect on digestive cells, so are considered safer, at least in the short term, for honeybees. These results are important in understanding the effects of nanopesticides on beneficial insects and may decrease the environmental impacts of pesticides.
\end{abstract}

KEYWORD: Nanopesticide; Biocide; Sustainable agriculture, Solid lipid nanoparticles; Bees.

\section{Corresponding Authors}

* Elaine C. M. Silva Zacarin - Universidade Federal de São Carlos (UFSCar), Campus Sorocaba, Departamento de Biologia (Dbio, CCHB), Laboratório de Fisiologia da Conservação e Laboratório de Ecotoxicologia e Biomarcadores em Animais, Rodovia João Leme dos Santos km 110, Itinga, 18052-780, Sorocaba, SP, Brazil. Email: elaine@ufscar.br

*Leonardo Fernandes Fraceto - Universidade Estadual Paulista (UNESP), Instituto de Ciência e Tecnologia de Sorocaba, Av. Três de Março, 511, Alto da Boa Vista, 18087-180, Sorocaba, SP, Brazil. Email leonardo.fraceto@unesp.br 


\section{INTRODUCTION}

Agri-food production and population growth are amongst the greatest challenges facing humanity. Agriculture is one of the primary drivers of the economy by providing food to the population and benefiting producing countries, but increased population growth has significantly increased humanity's global ecological footprint, surpassing the biocapacity of the Earth (SEKHON, 2014). Human populations increase exponentially over time, whereas food production increases in a linear manner. Conventional agricultural practices generally have negative impacts on the environment and biodiversity, as they require many resources such as energy, water, and soil, and large amounts of agrochemicals and fertilizers are used to improve productivity.

The U.S. Department of Agriculture's (USDA) National Institute of Food and Agriculture (NIFA, 2018) aims to find innovative solutions to issues related to agriculture, food, the environment, and communities. NIFA's priorities include global food security and hunger, food safety, plant health and production, and animal health and production (NANO, 2018). Many of these issues may be resolved using nanotechnology, which has demonstrated great potential in providing novel solutions to agricultural problems (SCOTT and CHEN, 2012; MUKHOPADHYAY, 2014). In the last few decades, nanoscience and nanotechnology have been at the forefront of the development of several nanomaterials for different medical and industrial purposes. Nanoparticles have been developed for a wide variety of applications in the biomedical and electronic fields, while research on nanoparticles as carriers of pesticides has only been conducted in the last decade, and there are still many variables to be investigated before their use on crops (LIU et al., 2008; ANJALI et al., 2010; GOPAL et al., 2012; KAH et al., 2014; SARLAK et al., 2014; MISHRA et al., 2017; KIM et al., 2018). 
Nanotechnology can deliver agricultural substances such as nanopesticides and

72 nanofertilizers that increase farm productivity, decrease the environmental impact and the

73 amount of resources used, improve pest control, and support sustainable agriculture,

74 particularly in developing countries. Furthermore, nanocarriers of pesticides and fertilizers

75 have economic advantages for agriculture, because their stability and controlled-release

76 mechanism increase efficiency and reduce the amount of chemicals required on crops

77 (PEREZ-DE-LUQUE and RUBIALES; 2009; CHEN and YADA, 2011; GRILLO et al.,

78 2016; PRASAD et al., 2017; WALKER et al., 2017).

79 However, the effects of nanoparticles should be fully evaluated before they are 80 incorporated into sustainable agriculture. The U.S. National Science Foundation (NSF) and

81 Environmental Protection Agency (EPA) encourage the investigation of various aspects of 82 nanomaterials, such as their toxicity to non-target organisms, their destination, transportation, 83 and safety in the environment, and their status in terms of food legislation, and support the 84 creation of a nanomaterial database and the maintenance of food regulations (SCOTT and 85 CHEN, 2012).

86 Pyrethrum extract is a natural botanical insecticide that is extracted from 87 chrysanthemum (Chrysanthemum cinerariaefolium and Chrysanthemum cineum) flowers, is 88 composed of pyrethrin types I and II and jasmolin, and can be used on crops to control pest 89 insects (PEAY et al., 2006). Natural pyrethrum (a.i.) is highly lipophilic, photodegradable, 90 has low water solubility $\left(<10 \mathrm{mg} . \mathrm{L}^{-1}\right)$, does not exhibit biomagnification (SCHLEIER and 91 PETERSON, 2011), and leaves no toxic residues in plants. However, it is more expensive 92 than synthetic pyrethroids (PEAY et al., 2006) and is highly toxic to insects, aquatic 93 invertebrates, and fish (USEPA, 2006). Pyrethroids are insecticides that were developed to 94 improve the photodegradation of natural pyrethrin, and thus be used as an insecticide in the 
field (SANTOS et al., 2007), and have great stability and target selectivity. Examples of pyrethroids include deltamethrin, permethrin, and cypermethrin (MONTANHA and PIMPÃO, 2012).

However, for the use of pyrethrum extract in the field it is necessary, at first, to load it into solid lipid nanoparticles (SLNs) to prevent its fast degradation, improving its stability and efficiency to allow its application on crops. Many benefits can be obtained by using SLNs, such as lower large-scale production costs, greater physicochemical stability, the possibility of hydrophilic and hydrophobic drug encapsulation, and the use of natural products in the formulation preparation (MULLER et al., 2000; MULLER et al., 2011; NASERI et al., 2015; SARANGI and PADHI et al., 2016).

Interactions between biological systems and nanomaterials are complex, so it is important to evaluate their toxicity to non-target organisms (JACQUES et al., 2017), particularly to beneficial insects such as honeybees (Apis mellifera), which play an important role in pollinating agricultural crops (GIANNINI et al., 2015). Honeybee populations are declining worldwide, and although multiple factors contribute to this decline (GOULSON et al., 2015), it is mainly caused by agrochemicals sprayed on crops visited by bees (POTTS et al., 2010). In this context, the physicochemical characterization of nanopesticides can enable their future use in organic farming and contribute to sustainable agriculture, because these carriers may have little effect on the environment and biodiversity (GRILLO et al., 2016; PRASAD et al., 2017). However, this carrier system must have low toxicity to honeybees and other beneficial insects.

The objectives of this study were to develop a nanopesticide that was based on SLNs loaded with pyrethrum extract biocide (nanobiocide), characterize its physicochemical properties, and evaluate its toxicity to honeybees (Africanized A. mellifera). We evaluated 
119 sublethal effects on the histopathology of the bee midgut, an organ that plays a central role

120 in food digestion and nutrient absorption. It is important to emphasize the fact that there are

121 gaps of information in the literature regarding the toxicity of nanopesticides to non-target

122 organisms, such as pollinator insects including honeybees. Our results can be applied in the 123 field, can contribute to nanopesticide regulation, and can improve both environmental and 124 food security.

125

126

2. MATERIALS AND METHODS

127

\subsection{Chemicals}

The pyrethrum extract Pestanal ${ }^{\circledR}$ (biocide, CAS 8003-34-7, analytical standard), 129 polyvinyl alcohol (PVA, 30-70 kDa, CAS 9002-89-5, hydrolyzed >99\%), and glyceryl 130 tripalmitate (tripalmitin, CAS 555-44-2, purity $\geq 99 \%$ ) were purchased from Sigma-Aldrich. Chloroform $\left(\mathrm{CHCl}_{3}, \mathrm{CAS} 67-66-3\right.$, purity $\left.\geq 99 \%\right)$ was purchased from a local supplier. All these products were used for the preparation of the nanoparticles. Acetone (CAS 67-64-1, purity $=100 \%$ ) was used as a solvent in the preparation of the pyrethrum solution.

\subsubsection{Solid lipid nanoparticles}

SLNs containing pyrethrum were prepared by the method of emulsification/solvent evaporation with some modifications (VITORINO et al., 2011; de MELO et al., 2018). Initially, $30 \mathrm{~mL}$ of an aqueous phase containing $1.25 \%$ PVA and distilled water was prepared and magnetically stirred (100 rpm). An organic phase with $250 \mathrm{mg}$ of glyceryl tripalmitate and $5 \mathrm{mg}$ of pyrethrum (active ingredient - a.i.) was then prepared, which was dissolved in

$1415 \mathrm{~mL}$ of chloroform. The organic phase was added to the aqueous phase, and this mixture 
143 ULTRA-TURRAX ${ }^{\mathrm{TM}}$ homogenizer at $14,000 \mathrm{rpm}$ for $7 \mathrm{~min}$. The organic solvent was then

144 removed using a rotating evaporator in order to create a concentrated emulsion with $10 \mathrm{~mL}$

145 of nanoparticles. The final concentration of biocide was $0.05 \mathrm{mg} \cdot \mathrm{mL}^{-1}$. SLNs without

146 pyrethrum extract (control) were also prepared.

147

148

\subsection{Nanoparticles}

149

The purpose of the formulations was to achieve greater physicochemical stability and 150 better efficiency of pyrethrum encapsulation in the nanoparticles. In order to evaluate the

151 physicochemical stability as a function of time were used the maintenance of colloidal 152 parameters in formulation. The colloidal parameters were the mean diameter, polydispersity 153 index, zeta potential, besides the nanoparticle concentration and encapsulation efficiency of 154 the pyrethrum extract. All analyses were conducted for 120 days and the results were 155 expressed (mean \pm SEM).

156

\subsubsection{Nanoparticle characterization}

The mean diameter and polydispersion index were determined by dynamic light scattering (DLS). Nanoparticle samples were diluted $(10 \mu \mathrm{L}: 1 \mathrm{~mL})$ in purified water and analyzed using a Zetasizer Nano ZS90 analyzer (Malvern Panalytical, UK). Zeta potential 161 values (in $\mathrm{mV}$ ) were also determined using the ZS90 analyzer, with the same dilution process.

162 The $\mathrm{pH}$ of the nanoparticles was determined using a $\mathrm{pH}$ meter $\left(\right.$ Tecnal $^{\circledR}$, Brazil). Further 163 details could be obtained in literature (VENKATRAMAN et al., 2005; de MELO et al., 2012; 164 OLIVEIRA et al., 2015). 
167

168

169

170

171

172

173

174

175

176

177

178

179

180

181

182

183

184

185

186

187

188

189

190

\section{7}

8

.

SLN size distributions and concentrations were analyzed using a nanoparticle tracking analysis (NTA) instrument (NanoSight LM10). Nanoparticle samples were diluted 10,000 times and analyzed by injecting $1 \mathrm{~mL}$ of the sample into the cell (more details in section 1.1 - Supplementary Material).

\subsubsection{Differential Scanning Calorimetry (DSC)}

A thermal analysis was performed to demonstrate that the pyrethrum was encapsulated in the nanocarriers using a DSC Q20 differential scanning calorimeter (TA Instruments). The samples of pyrethrum extract, lipid, SLNs, and SLNs loaded with pyrethrum were analyzed (Section 1.2 - Supplementary Material).

\subsubsection{Fourier-transform infrared spectroscopy (FTIR)}

FTIR was performed to investigate interactions between the biocide and the SLNs using an infrared spectrophotometer (Agilent). The pyrethrum extract, lipid, surfactant (PVA), physical mixture, SLNs, and SLNs loaded with pyrethrum were analyzed using an attenuated total reflectance accessory (POLLETO et al., 2007; WANG et al., 2010) (Section 1.3 - Supplementary Material).

2.3. Determination of encapsulation efficiency and quantification of pyrethrum by highperformance liquid chromatography (HPLC)

The total amount of pyrethrum extract present in the nanoparticle suspension was determined by the ultrafiltration/centrifugation method. After the suspension had been diluted with acetonitrile, it was filtered through a $0.22 \mu \mathrm{m}$ Millipore ${ }^{\mathrm{TM}}$ membrane filter and quantified by HPLC (Varian ProStar). The pyrethrum extract association rate was calculated 
191 as the difference between the non-associated fraction of biocide and the total amount initially

192 added to the nanoparticles (GAMISANS et al., 1999; SCHAFFAZICK et al., 2003; KILIC

193 et al., 2005) (Table 1S- Supplementary Material).

194

195

\subsection{Toxicological bioassay}

Operculated brood combs were collected from three healthy colonies of Africanized

Apis mellifera located in apiaries at Sao Paulo State, Brazil. The emergence of worker bees

was monitored in laboratory. Following emergence, the bees were transferred to plastic pots

lined with filter paper and fed ad libitum sugar-aqueous solution (50\%:50\% water:inverted sugar, v:v) to acclimatize for $24 \mathrm{~h}$.

Subsequently, the 1-day-old bees were divided into the following experimental groups in triplicate (each colony representing a replicate): I) Control (CTL) - sugar-aqueous solution (syrup); II) Sublethal dose $\left(1 \mathrm{ng} . \mu \mathrm{L}^{-1}\right)$ of pyrethrum extract ( $\left.\mathrm{PYR}_{1 \mathrm{ng}}\right)$; III) Sublethal 204 dose $\left(10 \mathrm{ng} \cdot \mu \mathrm{L}^{-1}\right)$ pyrethrum extract $\left.\left(\mathrm{PYR}_{10 \mathrm{ng}}\right) ; \mathrm{IV}\right) 1 \mathrm{ng} \cdot \mu \mathrm{L}^{-1}$ of pyrethrum loaded in SLNs 205 (SLNP 1 g $) ; \mathrm{V}) 10$ ng. $\mu \mathrm{L}^{-1}$ of pyrethrum loaded in SLNs (SLNP10ng); IV) Empty SLNs; V) 206 Polyvinyl alcohol - surfactant control (PVA); VI) Acetone control (ACN) - vehicle/solvent 207 control. The dose used per bee was based on the LD5048h of pyrethrum for honeybees, i.e., 20822 ng.bee ${ }^{-1}$ (USEPA, 1991).

Acute exposure was performed individually by oral administration, i.e., the corresponding solution of the experimental group was administrated to the bees $(1 \mu \mathrm{L})$ using

211 a micropipette (per os administration). Two sublethal doses of $10 \mathrm{ng}$ or $1 \mathrm{ng}$ of biocide per

212 bee were given of the pyrethrum extract (PYR) and pyrethrum loaded in nanoparticles

213 (SLNs). The half the $\mathrm{LD}_{40} \mathrm{~h}$ value corresponded to a $1 / 2$ dilution $\left(\mathrm{LD} 50 / 2=10 \mathrm{ng} \cdot \mu \mathrm{L}^{-1}=10\right.$ $214 \mathrm{ppm})$, and the other dose corresponded to a 1:20 dilution of the LD50 $48 \mathrm{~h}$ value $(\mathrm{LD} 50 / 20=1$ 
215 ng. $\left.\mu \mathrm{L}^{-1}=1 \mathrm{ppm}\right)$, both being sublethal concentrations for honeybees. Concentrations of the

216 solutions, which were used for getting the sublethal doses offered to bees, were obtained by

217 serial dilution of stock solution.

218 After individually acute exposure, the bees were kept in plastic pots (cages), being 219 fed with $50 \%(\mathrm{w} / \mathrm{w})$ sucrose aqueous solution, in an incubator at a relative humidity of $70 \%$ $220 \pm 5$ and temperature of $32 \pm 2^{\circ} \mathrm{C}$, under dark conditions. Two bioassays were performed, 221 being the first one for survival analysis $(\mathrm{N}=12$ bees per pot in triplicate, per experimental 222 group, totalizing 36 individuals) and another one for histology analyzes $(\mathrm{N}=15$ bees per pot 223 in triplicate per experimental group, totalizing 45 individuals). In the first bioassay (survival analysis), the bees were monitored daily until the last 225 bee has died. Specifically for survival bioassay, the deltamethrin (DLT, 10 ng. $\mu \mathrm{L}^{-1}$ ) 226 experimental group was added as positive control. In the second bioassay, the bees were collected $48 \mathrm{~h}$ after the acute exposure ( $\mathrm{N}=6$ per group) and dissected for midguts' removal, 228 which were processed for resin embedding and histological analysis (section 2.4.1).

\subsubsection{Histology procedure}

The bee midguts were fixed in $4 \%$ buffered paraformaldehyde solution for $24 \mathrm{~h}$ and immersed in phosphate-buffered saline $\left(0.1\right.$ mol.L $\mathrm{L}^{-1}$ phosphate buffer, $\left.\mathrm{pH} 7.4\right)$. After, the material was dehydrated in an increasing ethanol series according to Silva-Zacarin et al. (2012). Subsequently, the material was embedded in historesin, and submitted to microtomy.

235 Slides containing 3- $\mu \mathrm{m}$ thick histological sections were stained with hematoxylin-eosin. 236 Posteriorly, the material was photodocumentated and both qualitative and semi-quantitative 237 histopathological analyses were performed using Leica Application Suite V3.8 coupled to 
239 group $(\mathrm{N}=6)$, two slides were analyzed per individual and three non-sequential histological 240 sections were analyzed for each slide.

241 Other slides containing $3-\mu \mathrm{m}$ thick histological sections were submitted to 242 histochemical analysis for detection of proteins, lipids and neutral glycoconjugates (SILVA243 ZACARIN et al., 2012) (Section 1.4 - Supplementary Material and Figure 4S).

\subsubsection{Semi-quantitative analysis of midguts}

Parameters for semi-quantitative analysis were defined according to the Bernet et al.

247 (1999) protocol, and histological alterations (lesions) in midgut of bees were based on

248 Soares-Lima et al. (2018) protocol. To determine alterations in the bee midguts, the lesion

249 index and the organ index, were calculated using two parameters: the importance factor and 250 the score value (BERNET et al., 1999). Alterations were classified from 0 to 3, depending 251 on their degree and extent: 0- no alteration, 1- slight alteration, 2- moderate alteration, and 252 3- severe alteration. The importance factor was established for each lesion observed (cells 253 eliminated from the epithelium, increased apocrine secretions from the digestive cells, 254 cellular vacuolization, changes in regenerative cells' nests, and the presence of pyknotic 255 nuclei in cells of the epithelium) by a qualitative analysis based on pathological severity. This 256 factor was categorized as (1) minimal pathological importance (repairable damage), (2) 257 moderate pathological importance (damage was repairable in most cases), or (3) severe 258 pathological importance (irreparable damage) (Table 2S and section 1.4 - Supplementary 259 Material). 
All data were previously subjected to homogeneity of variance (Bartlett's) and normality (Shapiro-Wilk and Kolmogorov-Smirnov) tests. The physicochemical characterization data were subjected to a Student's t-test followed by a Mann Whitney test. A semi-quantitative analysis of the bee midguts was performed using a Kruskal-Wallis test followed by Dunn's multiple comparison test. The significance level was set at $\alpha=0.05$. GraphPad Prism v.5.0 was used for these statistical analyses.

The survival curve of honeybees per each experimental group was analyzed by the Log-Rank test (Kaplan-Meier method), and comparison between survival time of the groups was performed by the Holm-Sidak test. The significance level was set at $\alpha=0.05$. SigmaPlot 13 software was used these analyze.

\section{RESULTS AND DISCUSSION}

\subsection{Nanoparticle characterization}

The SLNs were prepared using approved components that are generally recognized as safe (GRAS). Tripalmitin (glyceryl tripalmitate) was used as a solid lipid and PVA was used as a surfactant. Physicochemical stability of the empty and encapsulated biocide in SLNs were evaluated from maintenance measurements of the colloidal parameters (mean diameter, polydispersity and zeta potential), besides the concentration of nanoparticles and pyrethrum encapsulation efficiency, over time ( 0 to 120 days). Colloidal parameter values and other parameters are shown in Table 1.

The initial and final hydrodynamic diameters (mean \pm SEM) of the empty solid lipid nanoparticles (SLN) were $290.0 \pm 5.0$ and $406.7 \pm 6.7 \mathrm{~nm}$, respectively. For the SLNs loaded with pyrethrum (SLN+PYR) the initial and final hydrodynamic diameters were $264.9 \pm 2.8$ and $260.8 \pm 3.7 \mathrm{~nm}$, respectively. There was a significant difference between the empty 
286

287

288

289

290

291

292

293

294

295

296

297

298

299

300

301

302

303

304

305

306

307

308

309 nanoparticles and those loaded with pyrethrum in the initial $(\mathrm{P} \leq 0.0001$ and $\mathrm{T}=18.18)$ and final $(\mathrm{P} \leq 0.0001$ and $\mathrm{T}=48.51)$ analyses. The hydrodynamic diameter values of empty SLNs increased after 60 days of storage with significant differences between the timepoints $(\mathrm{P} \leq$ 0.0001 and $\mathrm{T}=54.60$ ), while these values remained stable for SLN+PYR over the experimental period (120 days) (Figure 1SA- Supplementary Material). The empty SLNs had a larger mean diameter and less physicochemical stability than SLN+PYR, indicating that active ingredient of pyrethrum can stabilize nanoparticle formulation and decrease aggregate formation.

The polydispersion index at 0 and 120 days was $0.12 \pm 0.01$ and $0.39 \pm 0.12 \mathrm{~nm}$, respectively, in empty SLNs, and $0.12 \pm 0.01$ and $0.15 \pm 0.02 \mathrm{~nm}$, respectively, in SLN+PYR (Table 1), and values below $0.2 \mathrm{~nm}$ in the initial analysis were considered indicative of good stability and a small distribution of particle diameters. The low values indicate that the nanoparticles were of similar size and without aggregates (MASARUDIN et al., 2015). Similar results were obtained by de Melo et al. (2016) in a 120-day experiment with 15dPGJ2-loaded SLNs, and by González et al. (2015) at the beginning of their experiment with poly (ethylene glycol)-nanoparticles containing geranium (an essential oil). However, the time-based analysis revealed that the SLN polydispersion index had increased after 60 days of storage (0.3 and $0.39 \mathrm{~nm}$; Figure 1SB - Supplementary Material), with significant differences between the timepoints $(\mathrm{P} \leq 0.005$ and $\mathrm{T}=0.0)$ and significant differences between $\mathrm{SLN}_{120}$ and $\mathrm{SLN}_{+} \mathrm{PYR}_{120}(\mathrm{P} \leq 0.005$ and $\mathrm{T}=0.0)$. These data indicate that there was a heterogeneous distribution of particle diameters, i.e., there was a greater aggregation of particles in the empty system (SLN). Particle aggregation and degradation occur in SLN formulations that increase and decrease particle size, respectively, due to the loss of a surfactant coating that protects the material (MULLER et al., 1996). 

0.4 and $-14 \pm 0.3 \mathrm{mV}$, respectively, for empty SLNs and $-9.7 \pm 0.2$ and $-18.2 \pm 0.3 \mathrm{mV}$, respectively, for SLN+PYR. There was a significant difference between the empty nanoparticles and those loaded with pyrethrum $\left(\mathrm{P} \leq 0.0001, \mathrm{~T}_{0 \mathrm{~d}}=8.989\right.$, and $\mathrm{T}_{120 \mathrm{~d}}=24.50$;

314 Table 1). After decreasing on the $30^{\text {th }}$ day $(-5.48 \pm 0.13 \mathrm{mV})$, the zeta potential of SLN+PYR 315 increased to $-12.2 \pm 0.18$ and $-18.2 \pm 0.35 \mathrm{mV}$ after 90 and 120 days, respectively (Figure 316 1SD- Supplementary Material). Similarly, the empty SLN zeta potential decreased after 15 $317(-4.85 \pm 0.19 \mathrm{mV})$ and $30(-6.27 \pm 0.18 \mathrm{mV})$ days, but increased on the $60^{\text {th }}$ day $(-15.43 \pm$ $3180.23 \mathrm{mV}$ ), indicating good stability until the end of the analysis time (Figure 1SD319 Supplementary Material). Zeta potential values greater than $30 \mathrm{mV}$ indicate excellent 320 electrostatic stabilization $(60 \mathrm{mV}$ is the ideal value), while values lower $15 \mathrm{mV}$ may result in 321 partial flocculation (SCHWARZ et al., 1994). Low zeta potentials were observed, but the 322 nanoparticle formulations were stable over time due to steric stabilization provided by the 323 PVA (LOURENÇO et al., 1996). Stabilizers can be used in nanoparticle formulations to 324 prevent particle aggregation (ABDELWAHED et al., 2006). In the present study, the 325 nonionic surfactant PVA was used to prepare the SLNs, which is absorbed onto surface 326 nanoparticles and promotes steric stabilization (ADITYA et al., 2013; OLIVEIRA et al., 327 2015). Therefore, unlike in previous studies, it was not superficial electrostatic repulsion that 328 provided stability to the system (PASQUOTO-STIGLIANI et al., 2017). Particles in 329 suspension are more stable if the zeta potential is greater than $20 \mathrm{mV}$, and $40 \mathrm{mV}$ indicates 330 excellent stability (ADITYA et al., 2013). Similar results were obtained by Oliveira et al. 331 (2018) in zein nanoparticles loaded with the essential oil citronella (geraniol and R332 citronellal), and by Kah et al. (2014) in a polymer-based nanoformulation of atrazine. 
Table 1: Characterization of empty SLN and SLN loaded with pyrethrum extract over a period from 0 to 120 days.

\begin{tabular}{|c|c|c|c|c|}
\hline PARAMETERS & $S L N_{0}$ & $S L N_{120}$ & $S L N+P Y R_{0}$ & $S L N+P Y R_{120}$ \\
\hline$M D_{D L S}(N M)$ & $290.0 \pm 5.0$ & $406.7 \pm 6.7^{\mathrm{a}, \mathrm{c}}$ & $264.9 \pm 2.8$ & $260.8 \pm 3.7$ \\
\hline$M D_{N T A}(N M)$ & $185.9 \pm 4.6^{\mathrm{c}}$ & $263.8 \pm 18.5^{\mathrm{a}, \mathrm{c}}$ & $161.5 \pm 2.7$ & $227.0 \pm 12.3^{\mathrm{b}}$ \\
\hline$P D I$ & $0.12 \pm 0.01$ & $0.39 \pm 0.12^{\mathrm{a}, \mathrm{c}}$ & $0.12 \pm 0.01$ & $0.15 \pm 0.02$ \\
\hline$Z P(-m V)$ & $13 \pm 0.4^{\mathrm{c}}$ & $14 \pm 0.3^{\mathrm{c}}$ & $9.7 \pm 0.2$ & $18.2 \pm 0.3^{b}$ \\
\hline $\begin{array}{c}C T\left(10^{13}\right. \\
\text { particles } / m L)\end{array}$ & $2.7 \pm 0.5$ & $3.8 \pm 0.2$ & $5.9 \pm 0.5$ & $2.0 \pm 0.1$ \\
\hline$p H$ & $4.9 \pm 0.04$ & $5,7 \pm 0.04^{\mathrm{a}, \mathrm{c}}$ & $5.0 \pm 0.02$ & $7.1 \pm 0.02^{\mathrm{b}}$ \\
\hline$E E(\%)$ & - & - & $>99 \%$ & $>99 \%$ \\
\hline
\end{tabular}

Legend - Mean diameter (MD) using dynamic light scattering (DLS) and nanoparticle tracking analysis (NTA) techniques; polydispersion index (PDI); zeta potential (ZP), concentration of nanoparticles(CT); hydrogenionic potential $(\mathrm{pH})$ and encapsulation efficiency $(\mathrm{EE})$. The values are expressed as the mean \pm standard error of six measurements. ${ }^{a}$ Significant difference between SLN group and times; ${ }^{b}$ Significant difference between SLN+PYR group and times; ' Significant difference between SLN and SLN+PYR group. Paired T Test for parametric test, and Mann Whitney $\mathrm{U}$ test for nonparametric test.

SLNs showed good stability for the encapsulated a.i, evidencing that physicochemical properties not changed over time. According to Naseri et al. (2015), SLNs are good nanocarriers and can be used to deliver drugs and agrochemicals. Their properties include great physicochemical stability during production and storage, a good release profile, the ability to solubilize lipophilic actives, and low toxicity (NASERI et al., 2015).

There was a significant difference in the $\mathrm{pH}$ of the empty SLN suspension between 0 and 120 days $(4.9 \pm 0.04$ and $5.7 \pm 0.04$, respectively; $\mathrm{P} \leq 0.0001$ and $\mathrm{T}=16.08)$, and of SLN+PYR $(5.0 \pm 0.02$ and $7.1 \pm 0.02$, respectively; $\mathrm{P} \leq 0.0001$ and $\mathrm{T}=10.04$; Table 1$)$. Only at 120 days was there a significant difference in $\mathrm{pH}$ between the treatment groups $(\mathrm{P} \leq 0.0001$ and $\mathrm{T}=107.9$ ) with SLN+PYR having a pH of $7.16 \pm 0.02$ (Figure $1 \mathrm{SC}-$ Supplementary Material), indicating that hydrolytic processes occurred during this period. Similar results were obtained by Oliveira et al. (2015). 
The NTA revealed that the empty SLNs contained $2.7 \pm 0.5 \times 10^{13}$ particles per $\mathrm{mL}$

355 with an initial size of $185.9 \pm 4.6 \mathrm{~nm}$, and SLN+PYR contained $5.9 \pm 0.5 \times 10^{13}$ particles per

$356 \mathrm{~mL}$ with an initial size of $161.5 \pm 2.7 \mathrm{~nm}$. Table 1 shows that there was a significant

357 difference among timepoints for empty SLNs $(\mathrm{P} \leq 0.02$ and $\mathrm{T}=3.65)$ and $\mathrm{SLN}+\mathrm{PYR}(\mathrm{P} \leq$ 3580.007 and $\mathrm{T}=4.92)$, as well as between empty SLNs and SLN+PYR at $0(\mathrm{P} \leq 0.0004$ and T $359=10.68)$ and $120(\mathrm{P} \leq 0.007$ and $\mathrm{T}=5.23)$ days. NTA counts the number of particles per $\mathrm{mL}$ 360 and is a complementary technique in the analysis of hydrodynamic diameters, and DLS and 361 NTA did not provide similar diameter values and particle concentrations. This difference 362 may have been caused by sample dilution during the NTA, which could have caused some 363 aggregates to rupture in suspension and result in smaller particles than the DLS 364 (MARUYAMA et al., 2016).

The encapsulation efficiency of pyrethrum into the SLNs was evaluated using an analytical curve of pyrethrum determined by HPLC (Peak area (a.u.) $=4.69442+$ $3671952.15769 *$ [pyrethrum concentration], $\mathrm{r}=0.99341)$. The encapsulation efficiency was as 368 high as $99 \%$, suggesting that the pyrethrum extract was efficiently encapsulated in this carrier 369 system. Nevertheless, is important verify the release profile of pyrethrum in field conditions 370 and it is expected that due the high encapsulation efficiency that the particles protect the a.i.

371 in order to increase its shelf life in field conditions. A high encapsulation efficiency has also 372 been reported in polymeric nanocapsules and SLNs loaded with carbendazim and 373 tebuconazole (CAMPOS et al., 2015), in chitosan nanoparticles carrying the herbicides 374 imazapic and imazapyr (MARUYAMA et al., 2016), and in microcapsules containing 375 dementholized peppermint oil (ZHAO et al., 2016). The high encapsulation value indicates 376 the affinity of the biocide to the lipid matrix (de MELO et al., 2016) due to its low solubility 377 in water $\left(<10 \mathrm{mg} . \mathrm{L}^{-1}\right)$ and high solubility in organic solvents (USEPA, 2006). 
379 3.2. Differential scanning calorimetry (DSC) DSC thermograms for SLN+PYR, empty SLNs, tripalmitin, and pyrethrum extract

381 are presented in Figure 1. The DSC analyzes in this study were carried out with the objective 382 of demonstrating that the pyrethrum interacts with nanocarriers components. There were no 383 endothermic peaks for the pyrethrum extract. Tripalmitin's lowest peak was observed at $38461^{\circ} \mathrm{C}$, which agrees with the melting point described in the literature (CHEN et al., 2006). 385 Analysis of the empty SLNs and SLN+PYR revealed that the melting points for tripalmitin 386 were 65 and $64^{\circ} \mathrm{C}$, respectively, indicating that tripalmitin in the SLNs was solid, and that 387 the pyrethrum did not change the lipid core organization of the SLNs. Similar results were 388 obtained by Oliveira et al. (2015), who found that the herbicides simazine and atrazine were 389 dispersed on a nanoparticle matrix; as well as, Nasseri et al. (2016), verified that SLNs 390 containing Zataria multiflora essential oil (ZEO) not showed DSC pick of Zanataria 391 multiflora, and authors suggested that essential oil was incorporated and dissolved in the lipid 392 matrix. Analysis of the empty and encapsulated SLNs revealed two peaks, one indicating a 393 tripalmitin peak and the other possibly indicating PVA. Thermal studies of PVA have 394 reported an $88.1^{\circ} \mathrm{C}$ peak, probably due to moisture evaporation (GUIRGUIS; MOSELHEY, 395 2012). 


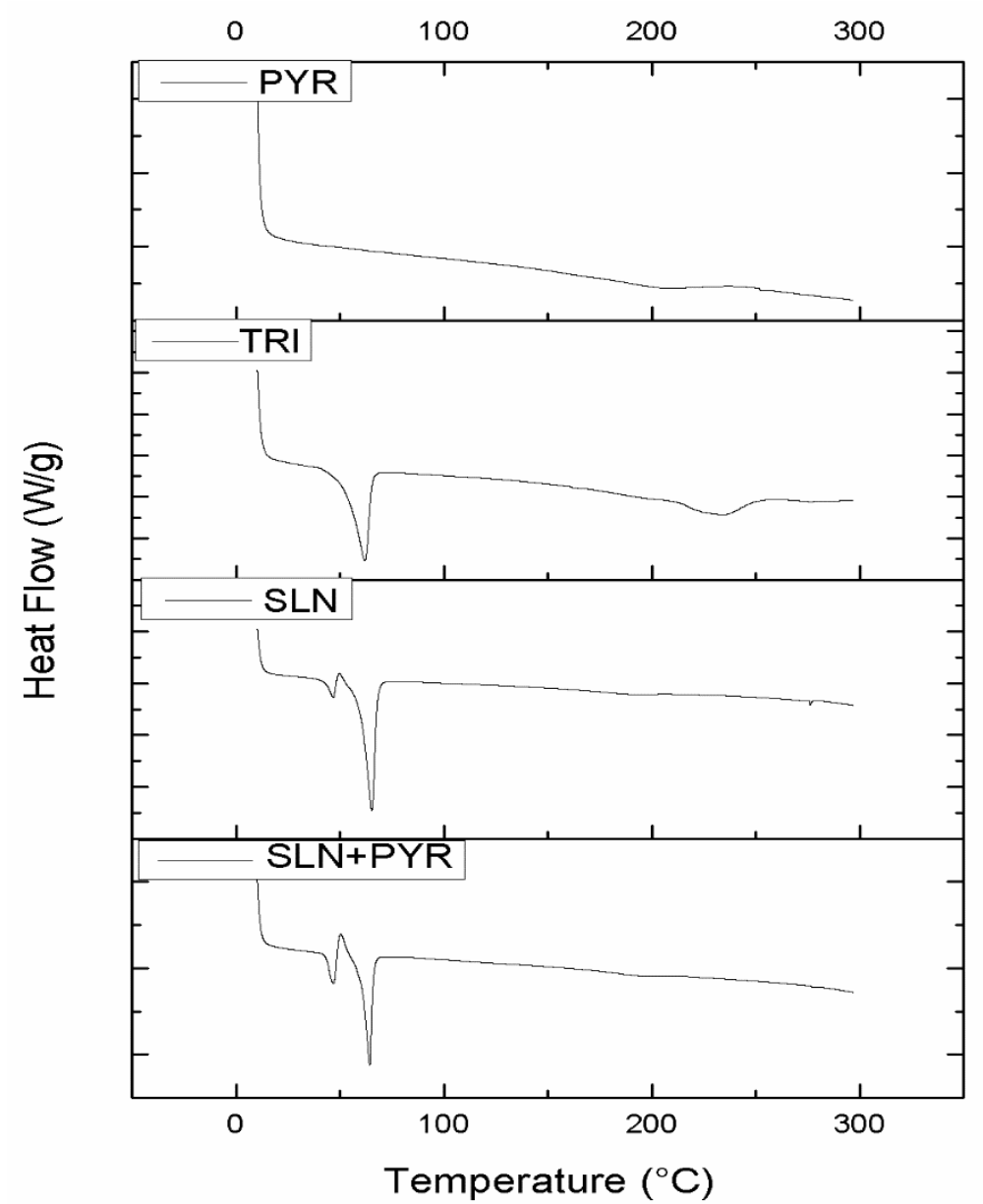

Figure 1 - Differential scanning calorimetry evaluation of interaction between pyrethrum extract and components of the SLN formulation: Thermograms for (PYR) Pyrethrum extract, (TRI) Tripalmitin, (SLN) Solid lipid nanoparticles, (SLN+PYR) Pyrethrum loaded in solid lipid nanoparticles. Conditions: $\mathrm{N}_{2}$ flow $-50 \mathrm{~mL} /$ minute, heating ramp of 10 to $300^{\circ} \mathrm{C}$ at a rate of $10^{\circ} \mathrm{C}$ per minute.

\subsection{Fourier Transform Infrared Spectroscopy (FTIR)}

The physical mixture had three specific bands at 2914, 2368, and $1654 \mathrm{~cm}^{-1}$ (Figure 2), which corresponded with tripalmitin $\left(2914 \mathrm{~cm}^{-1}\right)$; and pyrethrum extract bands at 2368 and $1654 \mathrm{~cm}^{-1}$, corresponding with peak $\mathrm{CO}_{2}$ (OLIVEIRA and PASSOS, 2013) and a stretching of the $-\mathrm{C}=\mathrm{C}$ group, respectively. The infrared spectra of PVA, empty SLNs, and SLN+PYR exhibited similar specific bands at $3335 \mathrm{~cm}^{-1}$ (Figure 2), which suggests the presence of an $-\mathrm{O}-\mathrm{H}$ group in the formulations. These groups were probably derived from the water and PVA used in the preparation of the nanoparticles (ZAIN et al., 2011). The 
411 specific bands at 2914 and $2848 \mathrm{~cm}^{-1}$ that were observed in the nanoparticles indicates a

412 stretching of the $-\mathrm{C}-\mathrm{H}$ group (Figure 2), corresponding to tripalmitin (CAMPOS et al., 2015).

413 It was also possible to observe bands at $1735 \mathrm{~cm}^{-1}$, corresponding to a stretching of the $414 \mathrm{C}=\mathrm{O}$ group, at $1470 \mathrm{~cm}^{-1}$, corresponding to a bending of the $-\mathrm{C}-\mathrm{H}_{2}$ group, and at $1178 \mathrm{~cm}^{-1}$, 415 corresponding to a stretching of the $-\mathrm{C}-\mathrm{O}$ group.

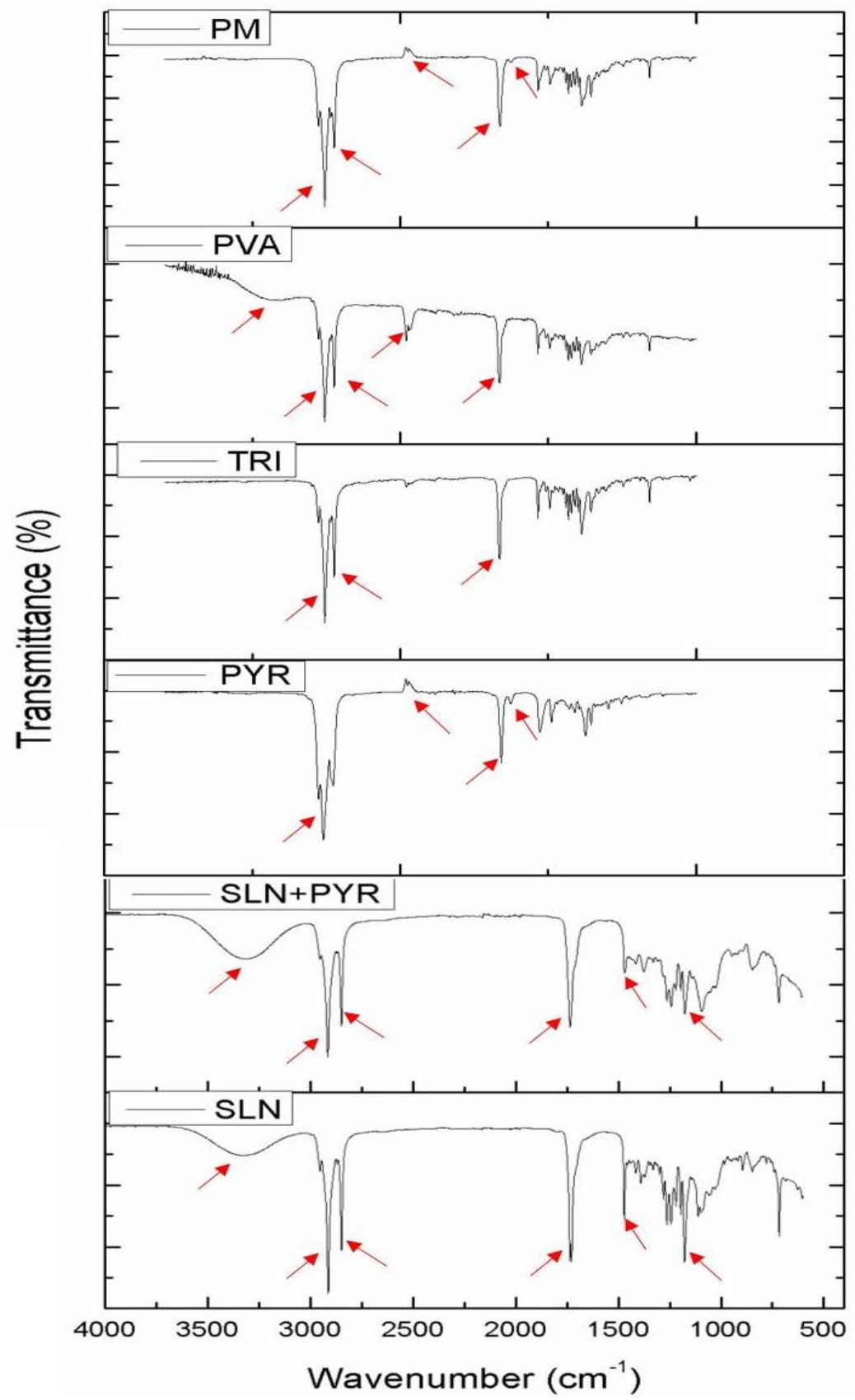


417

418

419

420

421

422

423

424

425

426

427

428

429

430

431

432

433

434

435

436

437

438

439

440

441

442

443

Figure 2 - Infrared spectroscopic evaluation of interaction between pyrethrum extract and components of the SLN formulation: FTIR spectra for (PM) Physical mixture (PVA) Surfactant - polyvinyl alcohol; (TRI) Tripalmitin; (PYR) Pyrethrum extract; (SLN+PYR) Pyrethrum loaded in solid lipid nanoparticles; (SLN) Solid lipid nanoparticles. Arrows indicate the main characteristic absorption bands in each spectrum. Conditions: infrared spectrophotometer with a range of 400 to $4000 \mathrm{~cm}^{-1}, 128$ scans per sample and $2 \mathrm{~cm}^{-1}$ resolutions.

\subsection{Toxicological bioassay}

Exposure to deltamethrin or pyrethrum extract $\left(10 \mathrm{ng} \cdot \mu \mathrm{L}^{-1}\right)$ affected the longevity of bees, reducing their life span. Bees exposed to pyrethrum extract $(\mathrm{P}<0.01 ; 141.18 \pm 21.3$ hours) and pyrethroid $(\mathrm{P}<0.001 ; 25.33 \pm 0.93 \mathrm{~h})$ presented shorter longevity than those in the control group $(257.83 \pm 21.79 \mathrm{~h})$. There is not significant difference between control and other experimental groups (ACN; PVA; SLN; SLNP ${ }_{1 \mathrm{ng}} ; \mathrm{SLNP}_{10 \mathrm{ng}}$ and PYR $\mathrm{SH}_{1 \mathrm{ng}} ; \mathrm{P}>0.05$ ). The ACN $(252.7 \pm 25.03 \mathrm{~h})$ data was similar to control group, as well as $\operatorname{SLNP}_{1 \mathrm{ng}}(256.24 \pm$ $21.00 \mathrm{~h})$ and $\mathrm{SLNP}_{10 \mathrm{ng}}(241.33 \pm 18.81 \mathrm{~h})$. The mean survival time of PVA $(171.16 \pm 18.09$ h), SLN (196.54 $\pm 11.38 \mathrm{~h})$ and $\mathrm{PYR}_{1 \mathrm{ng}}(175.33 \pm 28.12 \mathrm{~h})$ groups was lower than the control group, but not significant $(\mathrm{P}>0.05)$. The data of survival analysis were showed in Supplementary Material (Figure 2S).

Pyrethroids can be dangerous to honeybees (JOHNSON et al., 2010), for example, they interfere in the behavior (PALMQUIST et al., 2012), learning and memory performance (LIAO et al., 2018). In addition, exposure to Lambda-Cyhalothrin negatively affects the life span (LIAO et al., 2018; DOLEZAL et al., 2016). In line with these data, the pyrethrum extract and deltamethrin also reduced survival of Africanized Apis mellifera.

The sublethal doses of $1 \mathrm{ng} \cdot \mu \mathrm{L}^{-1}(1 \mathrm{ppm})$ and $10 \mathrm{ng} \cdot \mu \mathrm{L}^{-1}(10 \mathrm{ppm})$ of biocide free or encapsulated that were administered to the bees, induced short-term responses, at morphological level, in the midguts of newly emerged workers. 
444

445

446

447 448

The bee midgut is mainly responsible for food digestion and nutrient absorption, and is composed of three cell types: digestive, endocrine, and regenerative cells. Digestive cells are responsible for the production of digestive enzymes and nutrient absorption, endocrine cells produce hormones, and regenerative cells, which are within nests, are responsible for cell renewal of the epithelium (MARTINS et al., 2006).

Histological analysis of the bee midguts revealed morphological alterations in the epithelium (Figure 3), specifically in the digestive cells, whereas the regenerative cell nests maintained their normal morphological pattern. An increase in the elimination of digestive cells to the intestinal lumen was observed in some treatment groups (empty SLNs, SLNP ${ }_{1 n g}$, and $\mathrm{PYR}_{10 \mathrm{ng}}$; Figure $3 \mathrm{D}, 3 \mathrm{E}$, and $3 \mathrm{H}$ ) in comparison to the control groups (CTL, ACN, and PVA), which was significant in the empty SLN group (Figure 4A and Table 3S Supplementary Material).

Therefore, sublethal concentrations of pyrethrum extract in both non-encapsulated and encapsulated form in nanoparticles, as well as in empty nanoparticles (SLN), caused changes in digestive cells. Digestive cells have many microvilli close to the peritrophic matrix in the lumen, and among these cells, nests of small regenerative cells are in the intestinal epithelium (NEVES et al., 2002). These undifferentiated cells that remain in the nest are a source for cell renewal in epithelium of bee midgut (CAVALCANTE and CRUZLANDIM, 2004). Thus, regenerative cells replace dead digestive cells, which were released into the lumen, for new epithelial digestive cells by differentiation process (CRUZ et al., 2011). In this study, regenerative nests were observed in midgut epithelium, but histological alterations indicative of cytotoxicity were not found in these cells, such as pyknotic nuclei. If the regenerative cells from nests had presented nuclear pyknosis, which is an indicative of cell death in undifferentiated cells, this alteration would have a "severe pathological 
468

469

470

471

472

473

474

475

476

477

478

479

480

481

482

483

484

485

486

487

488

489

490

491 importance" because regenerative cells in adults does not suffer mitosis (CRUZ et al., 2011), and consequently epithelial renewal of midgut would be compromised, resulting to partial or total loss of the organ function.

Digestive cells are eliminated by cell degeneration under natural conditions, meanwhile this process can be accelerated and/or intensified in response to xenobiotic exposure (e.g., SLNs; Table 3S - Supplementary Material). Therefore, cell renewal is an important process in maintaining the organ function, because the differentiation process from regenerative cells can replace dead digestive cells and to renew the midgut epithelium.

There was less elimination of digestive cells to the intestinal lumen in bees exposed to pyrethrum-loaded nanoparticles than in those exposed to empty nanoparticles (SLN). Probably, the reduced cell-to-lumen liberation has been due to the interaction of the pyrethrum with the active sites in the nanoparticle, providing greater stability of the colloidal system over the time (0-120d) and high encapsulation efficiency (>99\% along 120d), as evidenced in the physicochemical characterization data. On the contrary, empty SLNs are more reactive and form aggregates more easily over time. Therefore, reactive empty SLNs could interact with the epithelial cells of the midgut (oral exposure) and induce cytotoxicity in digestive cells, which would trigger their elimination to the organ's lumen. The compounds used in nanoparticle formulations, and the colloidal instability of the system, can affect interactions with cell membranes and trigger cytotoxicity (NAFEE et al., 2009). Whereas the worker honeybee has lifetime of 45 days, and considering the acute exposure to the nanopesticide during its application, probably the whole SLNP will remain stable during its life span. Associating this information with the survival analysis, it can be noted that encapsulated pyrethrum kept the survival time $(256.24 \pm 21.00 \mathrm{~h}$ and $241.33 \pm 18.81 \mathrm{~h}$, $\mathrm{SLNP}_{1 \mathrm{ng}}$ and $\mathrm{SLNP}_{1 \mathrm{ng}}$, respectively) of the bees similar to the control group $(257.83 \pm 21.79$ 
492 h). Given that $10 \mathrm{ng}$ of pyrethrum extract and pyrethroid (deltamethrin) reduced life span of 493 the bees, it may be noted that pyrethrum-loaded in nanoparticle is more safe for honeybees, 494 probably because of the stability of the encapsulated pyrethrum and its release as a function 495 of time.

Another important process that we observed was increased apocrine secretions from 497 the midgut epithelium onto the apical surfaces of midgut digestive cells (Figure 3SD and 3SE 498 - Supplementary Material). These epithelial cells secrete digestive enzymes and peritrophic 499 matrix substances normally by means of apocrine secretion. Therefore, an increase in 500 secretion may be a protective compensatory response to xenobiotic exposure. Increased 501 apocrine secretion occurred in both the empty nanoparticle-exposed and $1 \mathrm{ng} . \mu \mathrm{L}^{-1}$ of 502 pyrethrum-loaded nanoparticle-exposed groups (SLN and $\mathrm{SLNP}_{1 \mathrm{ng}}$; Table 3S and Figure 503 4B). A previous study reported an increase in apocrine secretion of midgut digestive cells in 504 bees exposed to sublethal doses of thiamethoxam insecticide $\left(0.428 \mathrm{ng} \cdot \mu \mathrm{L}^{-1}\right.$ and 0.0428 505 ng. $\mu \mathrm{L}^{-1}$ per day for 18 days), as well as the increase in both cell vacuolization and cell 506 elimination from the epithelium to the midgut lumen over the exposure period (OLIVEIRA 507 et al., 2014).

Higher frequency of eliminated digestive cells and release of apocrine secretion

509 (Figure 4) were considered reversible alterations in the bee midgut and that did not affect 510 survival of bees in empty SLNs or encapsulated pyrethrum (SLNPs) groups. In normal 511 physiological situations, there is low frequency of senescent or dead cells eliminated to the 512 lumen (CAVALCANTE; CRUZ-LANDIM, 1999), and releasing of digestive enzymes from 513 cells to the peritrophic matrix in the lumen, usually by apocrine secretion (TERRA; 514 FERREIRA, 2012). Therefore, these alterations were classified as importance factor 1 in the 515 semi-quantitative analysis, because normally they are reversible, i.e., damage recovery in 
516 epithelium occurs through the differentiation of regenerative cells from their nests in order

517 to have new digestive cells. Thus, there is a compensatory response to the potential 518 physiological stress triggered by agrochemicals or nanocarriers that can lead to the 519 elimination of cells and/or intensification of apocrine secretion. Soares et al. (2012) reported 520 an elimination of cells into the lumen, increased apocrine secretion, and pyknotic nuclei in 521 the epithelial cells of the Scaptotrigona postica midgut after applying sublethal doses of the 522 insecticide imidacloprid. Similarly, Rossi et al. (2011) exposed Africanized A. mellifera to 523 sublethal doses of imidacloprid and observed an increase in both cell elimination and 524 apocrine secretion in the midgut.

525 Aljedani (2017) evaluated the effects of acute exposure to deltamethrin on foraging 526 worker honeybees (A. mellifera jemenatica). The bees that were fed a sugary solution 527 containing $2.5 \mathrm{ppm}$ of pyrethroid presented morphological changes in the midgut. In our 528 study, sublethal concentrations of pyrethrum extract (1 and $\left.10 \mathrm{ng} . \mu \mathrm{L}^{-}\right)$did not induce 529 histopathological effects on midguts' honeybees when the cell biomarkers were analyzed 530 separately, but the total organ index analysis showed alterations in $10 \mathrm{ng} . \mu \mathrm{L}^{-1}$ pyrethrum 531 extract that could potentially impair midgut function, since there was a decrease in the 532 longevity of the bees, demonstrating the relevance of evaluation of total organ index in bees 533 exposed to pesticides coupled to survival analysis. 

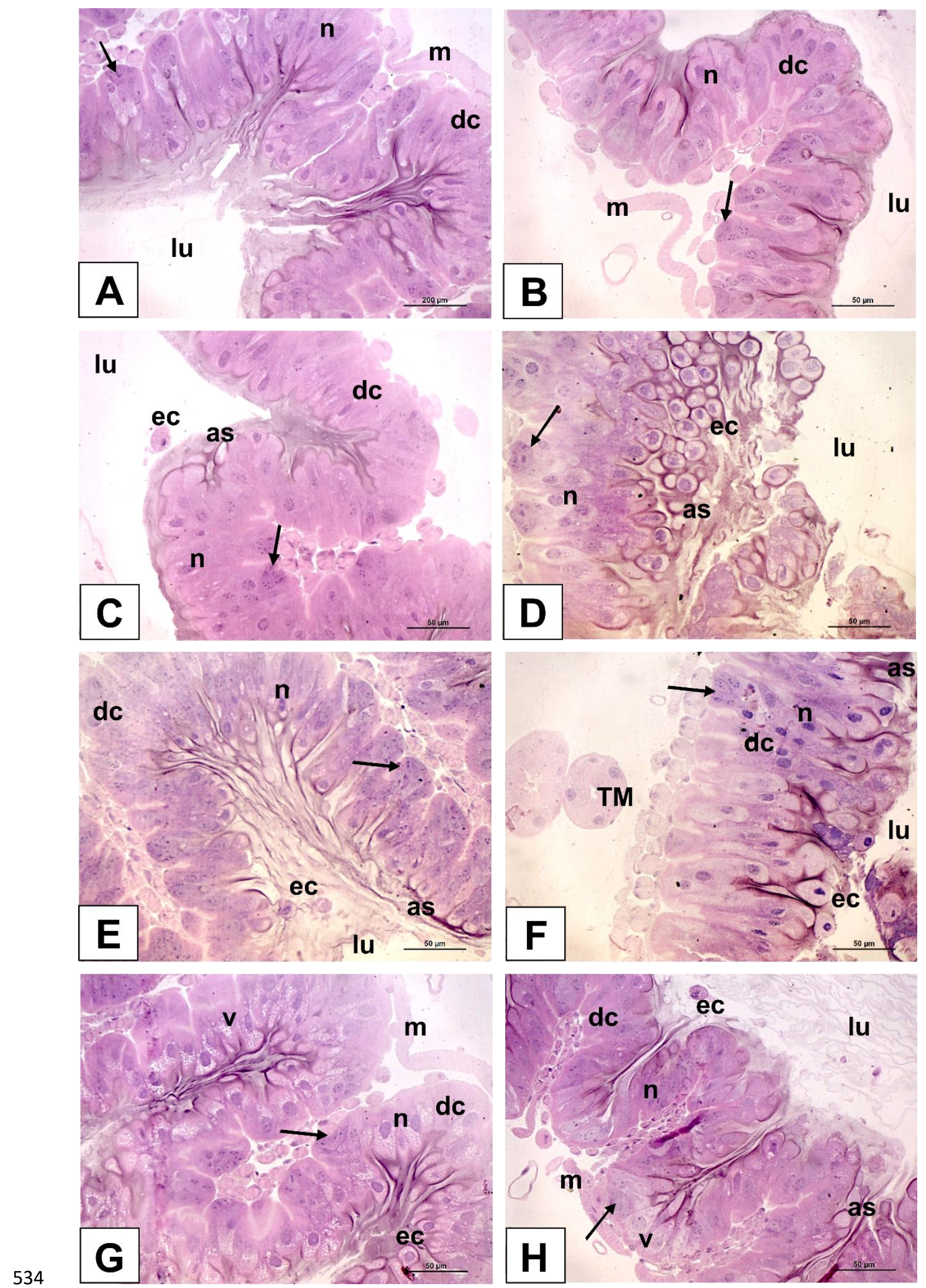
535

536

537

538

539

540

541

542

543

544

545

546

547

548

549

550

551

552

553

554

555

556

557

558

559

560

561

562

Figure 3 - Honeybees (Africanized A. mellifera) midguts after $48 \mathrm{~h}$ of acute exposure. A) CTL - syrup control; B) ACN - acetone control; C) PVA - surfactant control; D) SLN - Solid lipid nanoparticles; E) $\mathrm{SLNP}_{1 \mathrm{ng}}-1 \mathrm{ng} \cdot \mu \mathrm{L}^{-1}$ of pyrethrum loaded in solid lipid nanoparticles;

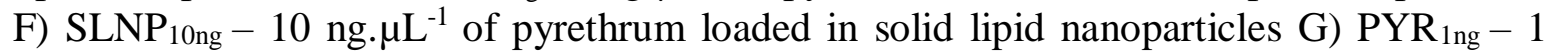
ng. $\mu \mathrm{L}^{-1}$ of pyrethrum extract; H) PYR $10 \mathrm{ng}-10 \mathrm{ng} . \mu \mathrm{L}^{-1}$ of pyrethrum extract. Legend: $\mathrm{dc}=$ digestive cell; ec = eliminated cell in the lumen; $\mathrm{lu}=$ lumen; $\mathrm{n}=$ nucleus, $\mathrm{v}=$ vacuolization; as $=$ apocrine secretion; Black arrow $=$ Regenerative cell; $\mathrm{TM}=$ Malpighi's tubes; $\mathrm{m}=$ muscle. Staining: Hematoxylin-Eosin. Bars: $50 \mu \mathrm{m}$.

Although vacuolization can be present in bee midgut cells as a physiological process of autophagy for intracellular turnover, their increased level frequently has been associated to side-effects of xenobiotics, especially in bees exposed to pesticides. For example, Cruz et al. (2010) reported cytoplasmic vacuolization and cell elimination in A. mellifera larvae midguts exposed to fipronil $\left(0.1\right.$ and $\left.1 \mu \mathrm{g} \cdot \mathrm{g}^{-1}\right)$ and boric acid $\left(1.0,2.5\right.$, and $\left.7.5 \mathrm{mg} \cdot \mathrm{g}^{-1}\right)$. Kakamand et al. (2008) observed an increase in the vacuolization of midgut cells in honeybees exposed to deltamethrin $\left(1,2.5,5\right.$, and $\left.10 \mathrm{mg} \cdot \mathrm{L}^{-1}\right)$ and the degeneration of the midgut epithelium of bees exposed to the highest concentration of this compound.

Histochemical analysis of vacuolization areas in digestive cells (Figure 4S Supplementary Material) showed that they are negative for proteins or neutral glycoconjugates, but had positive labelling for lipids that could indicate multivesicular bodies, because newly emerged honeybees have no spherocrystals yet. Multivesicular bodies are frequently found in midgut cells of insects (SERRAO; CRUZ-LANDIM, 1996), and are formed from early endosomes due to an inward budding of its membrane resulting in intralumenal vesicles whose main function is "collecting" plasma membrane receptors to be degraded into the lysosomes. Multivesicular bodies and autophagy are closely related (FADER; COLOMBO, 2009).

At the present study, intensification of cytoplasm vacuolization was considered a morphological alteration indicative of cytoplasmic loss, which is of greater pathological 
563 importance than the other alterations analyzed because, especially in insects, autophagy may 564 act as a pro-death process at the cellular/organ level (MALAGOLI et al., 2010), although its 565 effects at the organismal level can still be considered as fundamental for survival.

566 Cell vacuolization increased in both groups exposed to pyrethrum extract (Figure 3G 567 and $3 \mathrm{H}$, Figure $3 \mathrm{SG}$ and $3 \mathrm{SH}$, and Table $3 \mathrm{~S}$ ), but there was no significant difference due to 568 the highly variable degree of vacuolization among individuals exposed to pyrethrum extract 569 (Figure 4C). However, when the organ index was calculated, vacuolization accounted for a 570 higher total index under $10 \mathrm{ng} \cdot \mu \mathrm{L}^{-1}$ of pyrethrum extract (Figure 4D), as this alteration was 571 classified as importance factor 2 in the semi-quantitative analysis (Table $3 \mathrm{~S}$ ) because of the 572 loss of cytoplasmic material and the severity level.

573 In the total organ index analysis, the empty nanoparticles and $10 \mathrm{ng} \cdot \mathrm{LL}^{-1}$ of pyrethrum 574 extract caused more significant changes than the other experimental groups (Table 3S). In 575 contrast, nanoparticles loaded with 1 ng. $\mu \mathrm{L}^{-1}$ pyrethrum extract did not increase cell 576 alterations more than the other groups (nanoparticles and pyrethrum extract). The SLNP 577 groups exhibited a decrease in short-term cell alterations, so in this respect was considered 578 safer for bees over short exposure times. 

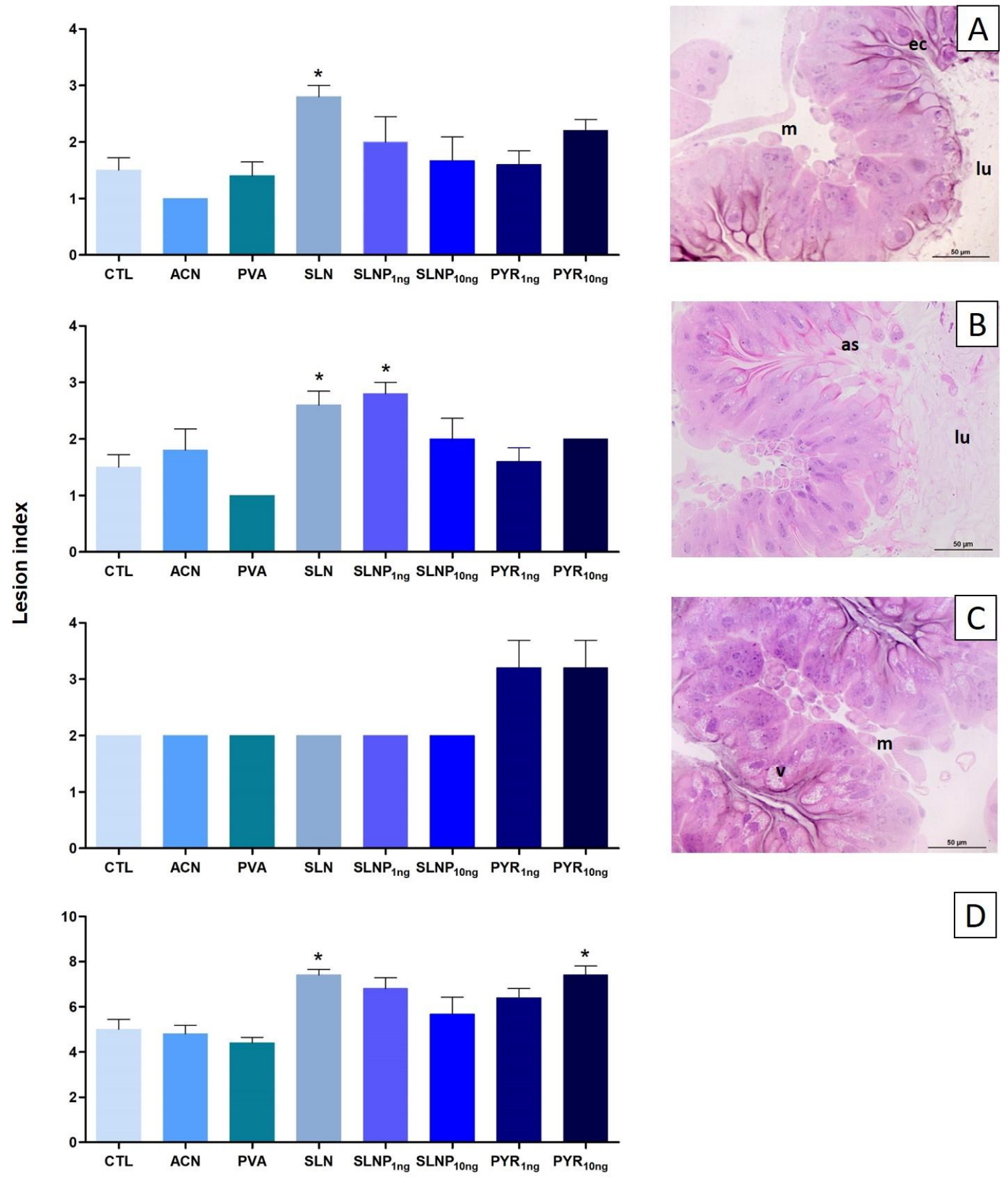

\section{Treatments}

Figure 4 - Alterations and organ index in honeybee (Africanized A. mellifera) midguts. a) Eliminated cell index; b) Apocrine secretion index; c) Vacuolization index; d) Total organ index. Legend: CTL - syrup control; ACN - acetone control; PVA - surfactant control; SLN - Solid lipid nanoparticles; SLNP 1 ng -1 ng. $\mu L^{-1}$ of pyrethrum loaded in solid lipid nanoparticles; $\mathrm{SLNP}_{10 \mathrm{ng}}-10 \mathrm{ng} . \mu \mathrm{L}^{-1}$ of pyrethrum loaded in solid lipid nanoparticles PYR $\mathrm{R}_{1 \mathrm{ng}}$ $-1 \mathrm{ng} . \mu \mathrm{L}^{-1}$ of pyrethrum extract; $\mathrm{PYR}_{10 \mathrm{ng}}-10 \mathrm{ng} \cdot \mu \mathrm{L}^{-1}$ of pyrethrum extract. Kruskal Wallis One-way ANOVA, followed by Dunn's multiple comparison test. *represent significant differences between groups. 
At the lowest sublethal doses $\left(1 \mathrm{ng} . \mu \mathrm{L}^{-1}\right)$, the biocide did not evidence significant

589 histopathological changes in the total lesion index, indicating that could be applied on crops.

590 A carrier system could be developed to improve pyrethrum extract stability, thus allowing its

591 use as nanopesticides. Besides, when the pyrethrum extract was encapsulated in nanocarriers

592 and demonstrated lower toxicity when compared with pyrethrum only. Therefore,

593 nanocarriers are an alternative to conventional pesticide applications. Nanotechnology

594 applied in the agricultural sector could increase agricultural production and crop protection,

595 contribute to sustainable agriculture and eco-friendly carrier systems, and reduce

596 environmental effects and toxicity to organisms (GRILLO et al., 2016). Oliveira et al. (2018)

597 found that zein nanoparticles loaded with citronella effectively controlled the pest species

598 Tetranychus urticae with low toxicity.

599 The empty SLNs showed effects onto honeybee, for example, in the total lesion index,

600 with the increase the eliminated cells and apocrine secretion. Therefore, nanocarrier system

601 itself may have reactive sites capable of changing their biological system because it has no

602 active ingredient encapsulated. These reactive sites could interact with organic molecules of

603 the organism, inducing negative effects that indirectly decreased the mean survival time of

604 the bees $(196.54 \pm 11.38 \mathrm{~h} ; \mathrm{P}>0.05)$. By the way, further studies need to be performed in

605 order to evaluate these hypotheses.

606 Nanopesticides can be able to increase the efficiency of agrochemicals and biocides,

607 because it is possible that in the field low doses of the active ingredients can be used.

608 However, in the case of pyrethrum and SLNs this fact will be confirmed with biological 609 assays in target organisms that will be run in the future. In addition, they increase production 610 and reduce damage to the environment (PRASAD et al., 2017). However, there are still many 611 gaps in information to be filled, normative instructions to be written, and legislation to be 
612 made before they can be extensively and safely employed in agriculture (KAH; HOFMANN,

613 2014; KOOKANA et al., 2014). According Kah et al. (2018), further studies that investigate

614 the efficacy of nanopesticides in crop farming are needed, in order to elucidate their effects

615 on biodiversity and human health, and their benefits and costs compared with conventional 616 formulations.

617

618

\section{CONCLUSION}

It is important to develop and analyze carrier systems as they have many potential benefits in comparison to synthetic and natural agrochemicals, such as reducing the amount 621 of biocide in the environment and greater stability. However, nanotoxicological studies 622 should be undertaken to evaluate the effects of nanoparticles on non-target organisms. In 623 conclusion, this study demonstrates that nanoparticles loaded with pyrethrum extract at 624 sublethal dose (1 or $\left.10 \mathrm{ng} \cdot \mathrm{LL}^{-1}\right)$ are relatively safe for honeybees, because they do not cause 625 morphological changes in digestive cells. In contrast, empty nanoparticles and $10 \mathrm{ng} . \mu \mathrm{L}^{-1}$ of 626 pyrethrum extract caused changes in digestive cells during acute exposure. The concentration 627 of $1 \mathrm{ng} \cdot \mu \mathrm{L}^{-1}$ of pyrethrum extract could be used for pest control. These data reflect the effects 628 of a sublethal and acute exposure, and more studies are needed to check if a chronic exposure 629 to these compounds would have different effects on bees. Our results added information for 630 subsidizing future decision making, regulatory framework creation, risk assessments, and 631 legislation development, and improve food security. In addition, based on the results we are 632 planning to run biological assays in order to investigate the efficacy of the nanopesticide 633 against target organisms. 
673

674

675

676

677

\section{ACKNOWLEDGMENTS}

Authors would like to thank the grant of São Paulo Research Foundation (\#2017/21004-5). Hellen Maria Soares-Lima and Rafaela Tadei for assisting in the toxicity bioassays, and Edson Sampaio keeping the colonies of honeybees for experiments. Authors thanks Profa. Dra. Leticia S. Souto from LADIVE by the availability of the microtome (FAPESP 2015/01424-4).

\section{CONFLICT OF INTEREST}

The authors declare there are no conflicts of interest in the present study.

\section{REFERENCES}

Abdelwahed, W.; Degobert, G.; Stainmesse, S.; Fessi, H. 2006. Freeze-drying of nanoparticles: formulation, process and storage considerations. Adv. Drug Delivery Rev. 58 (15), 1688-1713. https://doi.org/10.1016/j.addr.2006.09.017

About NIFA, 2018. National Institute of Food and Agriculture (NIFA) - United States Department of Agriculture (USDA). White House Office of Science and Technology Policy: Alexandria, VA, 2018. https://nifa.usda.gov/about-nifa (accessed Mar 04, 2018).

Aditya, N.P.; Shim, M.; Lee, I.; Lee, Y.; Im, M.H.; Ko, S. 2013. Curcumin and gnistein coloaded nanostructured lipid carriers: in vitro digestion and antiprostate cancer activity. $J$. Agri. Food Chem. 61 (8), 1878-1883. doi: 10.1021/jf305143k.

Aljedani, D.M. 2017. Effects of Abamectin and Deltamethrin to the foragers honeybee workers of Apis mellifera jemenatica (Hymenoptera: Apidae) under laboratory conditions. Saudi J. Biol. Sci. 24 (5), 1007-1015. doi: http://dx.doi.org/10.1016/j.sjbs.2016.12.007.

Anderson, W.; Kozak, D.; Coleman, V.A.; Jämting, Å.K.; Trau, M. 2013. A comparative study of submicron particle sizing platforms: Accuracy, precision and resolution analysis of polydisperse particle size distributions. J. Colloid Interface Sci. 405, 322-330. https://doi.org/10.1016/j.scienta.2007.11.013

Anjali, C.H.; Sudheer Khan, S.; Margulis-Goshen, K.; Magdassi, S.; Mukherjee, A.; Chandrasekaran, N. 2010. Formulation of water-dispersible nanopermethrin for larvicidal applications. Ecotoxicol. Environ. Saf. $73 \quad$ (8), 1932-1936. doi: 10.1016/j.ecoenv.2010.08.039.

Bernet, D.; Schmidt, H.; Meier, W.; Burkhardt-Holm, P.; Wahli, T. 1999. Histopathology in fish: Proposal for a protocol to assess aquatic pollution. J. Fish Dis., 22 (1), 25-34. https://doi.org/10.1046/j.1365-2761.1999.00134.x 
678

679

680

681

682

683

684

685

686

687

688

689

690

691

692

693

694

695

696

697

698

699

700

701

702

703

704

705

706

707

708

709

710

711

712

713

714

715

716

717

718

719

720

721

722

723
Campos, E.V.R.; de Oliveira, J.L.; da Silva, C.M.; Pascoli, M.; Pasquoto, T.; Lima, R.; Abhilash, P.C.; Fraceto, L.F. 2015. Polymeric and Solid Lipid Nanoparticles for Sustained Release of Carbendazim and Tebuconazole in Agricultural Applications. Sci Rep. 5, 13809. doi: $10.1038 /$ srep13809

Cavalcante, V.M.; C. Cruz-Landim. 1999. Types of cells present in the midgut of the insects: A review. Naturalia (Rio Claro) 24, 19-40.

Cavalcante, V.M.; Cruz-Landim, C. 2004. Padrão eletroforético de proteínas e atividade de fosfatase ácida em extratos do intestino médio de Apis mellifera L. durante a metamorfose. Neotrop. $\quad$ Entomol. $33 \quad$ (2), 169-172. http://dx.doi.org/10.1590/S1519$566 \times 2004000200007$.

Chen, H; Chang, X.; Du, D.; Liu, W.; Liu, J.; Weng, T.; Yang, Y.; Xu, H.; Yang, X. 2006. Podophyllotoxin-loaded solid lipid nanoparticles for epidermal targeting. J. Controlled Release 110 (2), 296 - 306. doi: 10.1016/j.jconrel.2005.09.052

Chen, H., Yada, R. 2011. Nanotechnologies in agriculture: new tools for sustainable development. Trends Food Sci. Technol 22, 585-594. https://doi.org/10.1016/j.tifs.2011.09.004

Cruz, A.S.; da Silva-Zacarin, E.C.; Bueno, O.C.; Malaspina, O. 2010. Morphological alterations induced by boric acid and fipronil in the midgut of worker honeybee (Apis mellifera L.) larvae. Cell Biol. Toxicol. 26 (2), 165-176. doi: 10.1007/s10565-009-9126-X.

Cruz, L.C.; Araújo, V.A.; Dolder, H.; Araújo, A.P.; Serrão, J.E.; Neves, C.A. 2011. Morphometry of the midgut of Melipona quadrifasciata anthidioides (Lepeletier) (Hymenoptera: Apidae) during metamorphosis. Neotrop. Entomol. 40 (6), 677-681. http://dx.doi.org/10.1590/S1519-566X2011000600007.

de Melo, N.F.S.; Araújo, D.R.; Grillo, R.; Moraes, C.M.; Matos, A.P.; Paula, E.; Rosa, A.H.; Fraceto, L.F. 2012. Benzocaine-loaded polymeric nanocapsules: Study of the anesthetic activities. J. Pharm. Sci. 101, 1157-1165.

de Melo, N.F.; de Macedo, C.G.; Bonfante, R.; Abdalla, H.B.; da Silva, C.M.; Pasquoto, T.; de Lima, R.; Fraceto, L.F.; Clemente-Napimoga, J.T.; Napimoga, M.H. 2016. 15d-PGJ $2^{-}$ Loaded Solid Lipid Nanoparticles: Physicochemical Characterization and Evaluation of Pharmacological Effects on Inflammation. PLoS One 11 (8), e0161796. https://doi.org/10.1371/journal.pone.0161796

Dolezal, A.G.; Carrillo-Tripp, J.; Miller, W.A.; Bonning, B.C.; Toth, A.L. 2016. Pollen Contaminated with Field-Relevant levels of Cyhalothrin affects Honey Bee Survival, Nutritional Physiology, and Pollen Consumption Behavior. J. Econ, Entomol. 109 (1), 41-8. https://doi.org/10.1093/jee/tov301. 
Fader, C.M.; Colombo, M.I. 2009. Autophagy and multivesicular bodies: two closely related partners. Cell Death Differ. 16 (1), p. 70-78. doi: 10.1038/cdd.2008.168.

Gamisans, F.; Lacoulonche, F.; Chauvet, A.; Espina, M.; García, M.L.; Egea, M.A. 1999. Flurbiprofen-loaded nanospheres: analysis of the matrix structure by thermal methods. Int. J. Pharm. 179 (1), 37-48. https://doi.org/10.1016/S0378-5173(98)00381-0

Giannini, T.C.; Cordeiro, G.D.; Freitas, B.M.; Saraiva, A.M. Imperatriz-Fonseca, V.L. 2015. The dependence of crops for pollinators and the economic value of pollination in Brazil. $J$. Econ. Entomol. 108, 1-9. doi: 10.1093/jee/tov093.

Gopal, M.; Kumar, R.; Goswami, A. 2012. Nano-pesticides - A recent approach for pest control. The J. Plant Protec. Sci. 4 (2), 1-7.

Goulson, D.; Nicholls, E.; Botías, C.; Rotheray, E.L. 2015.Bee declines driven by combined stress from parasites, pesticides, and lack of flowers. Science. 347 (6229), 1255957. Doi: $10.1126 /$ science. 1255957

Grillo, R.; Abhilash, P.C.; Fraceto, L.F. 2016. Nanotechnology applied to Bio-encapsulation of pesticides. J. Nanosci. Nanotechnol. 16, 1231-1234. https://doi.org/10.1166/jnn.2016.12332

Guirguis, O.W.; Moselhey, M.T.H. 2012. Thermal and structural studies of poly(vinyl alcohol) and hydroxypropyl cellulose blends. Natural Sci. 4 (1), 57-67. http://dx.doi.org/10.4236/ns.2012.41009

Jacques, M.T.; Oliveira, J.L.; Campos, E.V.; Fraceto, L.F.; Ávila, D.S. 2017. Safety assessment of nanopesticides using the roundworm Caenorhabditis elegans. Ecotoxicol. Environ. Saf. 139, 245-253. doi: 10.1016/j.ecoenv.2017.01.045

Johnson, R.M.; Ellis, M. D.; Mullin, C. A.; Frazier, M. 2010. Pesticides and honey bee toxicity - USA. Apidologie 41, 312-331. doi: 10.1051/apido/2010018

Kah, M.; Machinski, P.; Koerner, P.; Tiede, K.; Grillo, R.; Fraceto, L.F. 2014. Hofmann T.Analysing the fate of nanopesticides in soil and the applicability of regulatory protocols using a polymer-based nanoformulation of atrazine. Environ. Sci. Pollut. Res. 21 (20), 11699707. doi: 10.1007/s11356-014-2523-6.

Kah, M.; Hofmann, T. 2014. Nanopesticide research: Current trends and future priorities. Environ. Int. 63, 224-235. doi: 10.1016/j.envint.2013.11.015.

Kah, M.; Kookana, R.S.; Gogos, A.; Bucheli, T.D. 2018. A critical evaluation of nanopesticides and nanofertilizers against their conventional analogues. Nat. Nanotechnol. 13, 677-684. doi: 10.1038/s41565-018-0131-1. 
Kakamand, F.A.K.; Mahmoud, T. T.; Amin, A.M. 2008. The role of three insecticides in disturbance the midgut tissue in honey bee Apis mellifera L. Workers. J. Dohuk Univ. 11 (1), 144-151.

Kearns, C.A.; Inouye, D. W. 1997. Pollinators, Flowering Plants, and Conservation Biology. BioScience 47 (5), 297-307.

Kilic, A. C.; Capan, Y.; Vural, I.; Gursoy, R.N.; Dalkara, T.; Cuine, A.; Hincal, A.A. 2005. Preparation and characterization of PLGA nanospheres for the targeted delivery of NR2Bspecific antisense oligonucleotides to the NMDA receptors in the brain. $J$. Microencapsulation 22, 633-641.

Kim, D.Y.; Kadam, A.; Shinde, S.; Saratale, R.G.; Patra, J.; Ghodake, G. 2018. Recent developments in nanotechnology transforming the agricultural sector: a transition replete with opportunities. J. Sci. Food Agric. 98 (3), 849-864. doi: 10.1002/jsfa.8749.

Kookana, R.S.; Boxall, A.B.; Reeves, P.T.; Ashauer, R.; Beulke, S.; Chaudhry, Q.; Cornelis, G.; Fernandes, T.F.; Gan, J.; Kah, M.; Lynch, I.; Ranville, J.; Sinclair, C.; Spurgeon, D.; Tiede, K.; Van den Brink, P.J. 2014. Nanopesticides: guiding principles for regulatory evaluation of environmental risks. J. Agric. Food. Chem. 62 (19), 4227-4240. doi: $10.1021 /$ jf500232f

Liao, C.H.; He, X.J.; Wang, Z.L.; Barron, A.B.; Zhang, B.; Zeng, Z.J.; Wu, X.B. 2018. ShortTerm Exposure to Lambda-Cyhalothrin Negatively Affects the Survival and MemoryRelated Characteristics of Worker Bees Apis mellifera. Arch. Environ. Contam. Toxicol. 75 (1), 59-65. doi: 10.1007/s00244-018-0514-1.

Liu, Y.; Tong, Z.; Prud'homme, R.K. 2008. Stabilized polymeric nanoparticles for controlled and efficient release of bifenthrin. Pest. Manag. Sci. 64 (8), 808-812. doi: 10.1002/ps.1566.

Lourenço, C.; Teixeira, M.; Simões, S.; Gaspar, R. 1996. Steric stabilization of nanoparticles: Size and surface properties. Int. J. Pharm. 138 (1), 1-12. https://doi.org/10.1016/03785173(96)04486-9

Malagoli, D.; Abdalla, F.C.; Cao, Y.; Feng, Q.; Fujisaki, K.; Gregorc, A.; Matsuo, T.; Nezis, I.P.; Papassideri, I.S.; Sass, M.; Silva-Zacarin, E.C.; Tettamanti, G.; Umemiya-Shirafuji, R. 2010. Autophagy and its physiological relevance in arthropods: current knowledge and perspectives. Autophagy. 6 (5), 575-88. doi: 10.4161/auto.6.5.11962.

Martins, G.F.; Neves, C.A.; Campos, L.A.; Serrão, J.E. 2006. The regenerative cells during the metamorphosis in the midgut of bees. Micron 37 (2), 161-168. https://doi.org/10.1016/j.micron.2005.07.003

Maruyama, C.R.; Guilger, M.1.; Pascoli, M.; Bileshy-José, N.; Abhilash, P.C.; Fraceto, L.F.; de Lima, R. 2016. Nanoparticles Based on Chitosan as Carriers for the Combined Herbicides Imazapic and Imazapyr. Sci. Rep. 6 (19768). Doi: 10.1038/srep19768 
816

817

818

819

820

821

822

823

824

825

826

827

828

829

830

831

832

833

834

835

836

837

838

839

840

841

842

843

844

845

846

847

848

849

850

851

852

853

854

855

856

857

858

859

860

861

862
Masarudin, M.J.; Cutts, S.M.; Evison, B.J.; Phillips, D.R.; Pigram, P. J. 2015. Factors determining the stability, size distribution, and cellular accumulation of small, monodisperse chitosan nanoparticles as candidate vectors for anticancer drug delivery: application to the passive encapsulation of $\left[{ }^{14} \mathrm{C}\right]$-doxorubicin. Nanotechnol. Sci. Appl. 8, 67-80. http://doi.org/10.2147/NSA.S91785

Mishra, S.; Keswani, C.; Abhilash, P.C.; Fraceto, L.F.; Singh, H.B. 2017. Integrated Approach of Agri-nanotechnology: Challenges and Future Trends. Front. Plant. Sci. 8, 1-12.

Montanha, F.P.; Pimpão, C.T. 2012. Efeitos toxicológicos de piretróides (cipermetrina e deltametrina) em peixes. Rev. Cient. Elet. Med. Vet. 9 (18), 1-58.

Mukhopadhyay, S.S. 2014. Nanotechnology in agriculture: prospects and constraints. Nanotechnol., Sci. Appl. 7, 63-71. doi: 10.2147/NSA.S39409

Muller, R. H.; Rühl, D.; Runge, S.A. 1996. RungeBiodegradation of solid lipid nanoparticles as a function of lipase incubation time. Int. J. Pharm. 144 (1), 115-121.

Muller, H.R.; Mäder, K.; Gohla, S. 2000. Solid lipid nanoparticles (SLN) for controlled drug delivery: a review of the state of the art. Eur. J. Pharm. Biopharm. 50 (1), 161-177. https://doi.org/10.1016/S0939-6411(00)00087-4

Muller, H.; Shegokar, R.; Keck, C.M. 2011. 20 Years of Lipid Nanoparticles (SLN \& NLC): Present State of Development \& Industrial Applications. Curr. Drug. Discov. Technol. 8, 207-227. https://doi.org/10.2174/157016311796799062

Nafee, N.; Schneider, M.; Schaefer, U.F.; Lehr, C.M. 2009. Relevance of the colloidal stability of chitosan/PLGA nanoparticles on their cytotoxicity profile. Int. J. Pharm. 381 (2, 3), 130-139. https://doi.org/10.1016/j.ijpharm.2009.04.049

Naseri, N.; Valizadeh, H.; Zakeri-Milani, P. 2015. Solid Lipid Nanoparticles and Nanostructured Lipid Carriers: Structure, Preparation and Application. Adv. Pharm. Bull. 5 (3), 305-313. http://doi.org/10.15171/apb.2015.043

Nasseri, M.; Golmohammadzadeh, S.; Arouiee, H.; Jaafari, M.R.; Neamati, H. 2016. Antifungal activity of Zataria multiflora essential oil-loaded solid lipid nanoparticles in-vitro condition. Iran. J. Basic Med. Sci. 19 (11), 1231-1237. Doi: 10.22038/ijbms.2016.7824

Neves, C.A.; Bhering, L.L.; Serrão, J.E.; Gitirana, L.B. 2002. FMRFamide-like midgut endocrine cells during the metamorphosis in Melipona quadrifasciata anthidioides (Hymenoptera Apidae). Micron 33 (5), 453-460. https://doi.org/10.1016/S09684328(01)00043-9

Oliveira, J.L.; Campos, E.V.; Gonçalves da Silva, C.M.; Pasquoto, T.; Lima, R.; Fraceto, L.F. 2015. Solid Lipid Nanoparticles Co-loaded with Simazine and Atrazine: Preparation, Characterization, and Evaluation of Herbicidal Activity. J. Agric. Food Chem. 63, 422-432. Doi: $10.1021 /$ jf5059045 
863

864

865

866

867

868

869

870

871

872

873

874

875

876

877

878

879

880

881

882

883

884

885

886

887

888

889

890

891

892

893

894

895

896

897

898

899

900

901

902

903

904

905

906

907

908

909
Oliveira, J.L.; Campos, E.V.R.; Pereira, A.E.S.; Pasquoto, T.; Lima, R.; Grillo, R.; Andrade, D.J.; Santos, F.A.D.; Fraceto, L.F. 2018. Zein Nanoparticles as Eco-Friendly Carrier Systems for Botanical Repellents Aiming Sustainable Agriculture. J. Agric. Food Chem. 66, 13301340. doi: 10.1021/acs.jafc.7b05552.

Oliveira, R.A.; Roat, T.C.; Carvalho, S.M.; Malaspina, O. 2014. Side-effects of thiamethoxam on the brain and midgut of the africanized honeybee Apis mellifera (Hymenopptera: Apidae). Environ. Toxicol. 29 (10), 1122-33. doi: 10.1002/tox.21842.

Oliveira, R.L.; Passos, F.B. 2013. Estudo da oxidação parcial do etanol em catalisadores de Rh por DRIFTS. Quim. Nova 36 (3), 375-381.

Palmquist, K.; Salatas, J.; Fairbrother, A. 2012. Pyrethroid insecticides: use, environmental fate, and ecotoxicology, in: Perveen, F. (Ed.), Insecticides: Advances in Integrated Pest Management, InTech, Rijeka: Croatia, cap. 11, pp. 251-278.

Pasquoto-Stigliani, T.; Campos, E.V.R.; Oliveira, J.L.; Silva, C.M.G.; Bilesky-José, N.; Guilger, M.; Troost, J.; Oliveira, H.C.; Stolf-Moreira, R.; Fraceto, L.F.; de Lima, R. 2017. Nanocapsules Containing Neem (Azadirachta Indica) Oil: Development, Characterization, And Toxicity Evaluation. Sci. Rep. 7 (5929). doi:10.1038/s41598-017-06092-4

Peay, S.; Hiley, P.D.; Collen, P.; Martin, I. 2006. Biocide treatment of ponds in Scotland to eradicate signal crayfish. Bull. Fr. Pêche Piscic. 380-381, 1363-1379. https://doi.org/10.1051/kmae:2006041

Perez-de-Luque, A.; Rubiales, D. 2009. Nanotechnology for parasitic plant control. Pest Manage. Sci. 65 (5), 540-545. https://doi.org/10.1002/ps.1732

Polleto, F.S.; Jäger, E.; Ré, M.I.; Guterres, S.S.; Pohlmann, A.R. 2007. Rate modulating PHBHV/PCL microparticles containing weak acid model drugs. Int. J. Pharm. 345, 70-80. https://doi.org/10.1016/j.ijpharm.2007.05.040

Potts, S.G.; Biesmeijer, J.C.; Kremen, C.; Neumann, P.; Schweiger, O.; Kunin, W.E. 2010. Global pollinator declines: trends, impacts and drivers. Trends Ecol. Evol. 25 (6), 345-353. https://doi.org/10.1016/j.tree.2010.01.007

Prasad, R., Bhattacharyya, A.; Nguyen, Q.D. 2017. Nanotechnology in Sustainable Agriculture: Recent Developments, Challenges, and Perspectives. Front. Microbiol. 20; 8:1014. https://doi.org/10.3389/fmicb.2017.01014

Rossi, C.A., Roat, T.C.; Tavares, D.A.; Cintra-Socolowski, P.; Malaspina, O. 2011. Effects of sublethal doses of imidacloprid in malpighian tubules of africanized Apis mellifera (Hymenoptera, Apidae). Microsc. Res. Tech. 76 (5), 552-558. https://doi.org/10.1002/jemt.22199 
910

911

912

913

914

915

916

917

918

919

920

921

922

923

924

925

926

927

928

929

930

931

932

933

934

935

936

937

938

939

940

941

942

943

944

945

946

947

948

949

950

951

952

953

954

955

956
Santos, M.A.T.; Areas, M.A.; Reyes, F.G. 2007. Piretróides - uma visão geral. Alim. Nutr. 18 (3), 339-349.

Sarangi, M.J.; Padhi, S. Solid lipid nanoparticles - A Review. J. Crit. Rev. 2016, 3 (3), 5-12.

Sarlak, N.; Taherifar, A.; Salehi, F. 2014. Synthesis of Nanopesticides by Encapsulating Pesticide Nanoparticles Using Functionalized Carbon Nanotubes and Application of New Nanocomposite for Plant Disease Treatment._J. Agric. Food Chem 62 (21), 4833-483. doi.10.1021/jf404720d

Schaffazick, S.R.; Guterres, S.S.; Freitas, L.L.; Pohlmann, A.R. 2003. Caracterização e estabilidade físico-química de sistemas poliméricos nanoparticulados para administração de fármacos. Quím. Nova $26 \quad$ (5), 726-737. http://dx.doi.org/10.1590/S010040422003000500017.

Schleier, J.J.; Peterson, R.K.D. 2011. Pyrethrins and Pyrethroid Insecticides, in: López, O.; Fernández-Bolaños, J.G. (Eds.), Green Trend. Insect Cont, J. Publishing. London: Burlington House, cap. 3, pp. 94-131.

Schwarz, C.; Mehnert, W.; Lucks, J.S.; Müller, R.H. 1994. Solid lipid nanoparticles (SLN) for controlled drug delivery. I. Production, characterization and sterilization. J. Controlled Release. 30 (1), 83-96. https://doi.org/10.1016/0168-3659(94)90047-7

Serrão, J. E., C. Cruz-Landim. 1996. Ultrastructure of digestive cells in stingless bees of various ages (Hymenoptera, Apidae, Meliponinae). Cytobios 88, 161-171.

Scott, N.; Chen, H. 2012. Nanoscale Science and Engineering for Agriculture and Food Systems. Ind. Biotechnol. 9 (1), 17-18. https://doi.org/10.1089/ind.2013.1555

Sekhon, B.S. 2014. Nanotechnology in agri-food production: an overview. Nanotechnol., Sci. Appl. 7, 31-53. http://doi.org/10.2147/NSA.S39406

Silva-Zacarin, E.C.M.; Chauzat, M.P.; Zeggane, S.; Drajnudel, P.; Schurr, F.; Faucon, J.P.; Malaspina, O.; Engler, J.A. 2012. Protocol for optimization of histological, histochemical and immunohistochemical analyses of larval tissues: application in histopathology of honey bee. In: Méndez-Vilas, A. (Ed.), Current microscopy contributions to advances in science and technology, Formatex Research Center: Badajoz, 5. ed., v. 1, pp. 696-703.

Silva, M. dos S. Cocenza, D. S. Grillo, R. de Melo, N. F. S. Tonello, P. S. Oliveira, L. C. de Cassimiro, D. L. Rosa, A. H. Fraceto, L. F. 2011. Paraquat-loaded alginate/chitosan nanoparticles: preparation, characterization and soil sorption studies. J. Hazard. Mater. 190 (1-3), 366-374.

Soares, H.M. Avaliação dos efeitos do inseticida imidacloprido para abelhas sem ferrão Scaptotrigona postica Latreille, 1807 (Hymenoptera, Apidae, Meliponini). Dissertação de Mestrado, Universidade Estadual Paulista - campus Rio Claro/SP, 2012. 
957

958

959

960

961

962

963

964

965

966

967

968

969

970

971

972

973

974

975

976

977

978

979

980

981

982

983

984

985

986

987

988

989

990

991

992

993

994

995

996

997

998

999

1000

1001

1002

1003
Soares-Lima, H.M.; Silva-Zacarin, E.C.M.; Camargo, I; Nocelli, R.C.F.; Malaspina, O. Histopathological alterations on honeybees midgut infected by Nosema ceranae and exposed to imidacloprid. In: Society of Environmental Toxicology and Chemistry Asia-Pacific Conference, Daegu, Korea, Sep 16-19, 2018; SETAC AP, Eds.; SETAC: Korea, 2018.

Terra, W.R.; Ferreira, C. 2012. Biochemistry and molecular biology of digestion. In, Gilbert, L.I. (Ed.), Insect Molecular Biology and Biochemistry, Academic Press: San Diego, pp. 365418. https://doi.org/10.1016/C2009-0-62118-8

U.S. Department of Agriculture, National Institute of Food and Agriculture (USDA/NIFA) 2018; National Nanotechnology Initiative (NANO). White House Office of Science and Technology Policy: Alexandria, VA, 2018. https://www.nano.gov/node/137 (accessed Mar 04, 2018).

Data Evaluation Record - Pyrethrum extract 1991; U.S. Environmental Protection Agency (USEPA). White House Office of Science and Technology Policy: Philadelphia, PA, 1991. https://www3.epa.gov/pesticides/chem_search/cleared_reviews/csr_PC-069001_3-Sep-

91_a.pdf (accessed Mar 14, 2018).

Reregistration Eligibility Decision for Pyrethrins 2006; U.S. Environmental Protection Agency (USEPA). White House Office of Science and Technology Policy: Philadelphia, PA, 2006. http://www.epa.gov/oppsrrd1/REDs/pyrethrins_red.pdf (accessed Mar 14, 2018).

Venkatraman, S. S. 2005. Micelle-like nanoparticles of PLA-PEG-PLA triblock copolymer as chemotherapeutic carrier. Int. J. Pharm. 298, 219-232. https://doi.org/10.1016/j.ijpharm.2005.03.023

Vitorino, C.; Carvalho, F.A.; Almeida, A.J.; Sousa, J.J.; Pais, A.A. 2011. The size of solid lipid nanoparticles: An interpretation from experimental design. Colloids Surf., B. 84 (1), 117-130. https://doi.org/10.1016/j.colsurfb.2010.12.024

Walker, G.W.; Kookana, R.S.; Smith, N.E.; Kah, M.; Doolette, C.L.; Reeves, P.T.; Lovell, W.; Anderson, D.J.; Turney, T.W.; Navarro, D.A. 2017. Ecological risk assessment of nanoenabled pesticides: A perspective on problem formulation. J. Agric. Food Chem. 66 (26), 6480-6486. https://doi: 10.1021/acs.jafc.7b02373

Wang, Q.; Guan, Y.X.; Yao, S.J.; Zhu, Z.Q. 2010. Microparticle formation of sodium cellulose sulfate using supercritical fluid assisted atomization introduced by hydrodynamic cavitation mixer. Chem. Eng. J. 159(1-3), 220-229. https://doi.org/10.1016/j.cej.2010.02.004

Zain, N.A.M.; Suhaimi, M.S.; Idris, A. 2011. Development and modification of PVAalginate as a suitable immobilization matrix. Process Biochem. 46 (11), 2122-2129. https://doi.org/10.1016/j.procbio.2011.08.010

Zhao, D.; Jiao, X.; Zhang, M.; Ye, K.; Shi, X.; Xihua, Lu. Qiu, G.; Sheac, K.J. 2016. Preparation of high encapsulation efficiency fragrance microcapsules and their application in textiles. $R S C A d v$. 84, 80924-80933. doi: 10.1039/C6RA16030A 
1004

1005 Zhou, T.; Zhou, W.; Wanga, Q.; Dai, P.L.; Feng, L.; Zhang, Y.L; Sun, J.H. 2011. Effects of 1006 pyrethroids on neuronal excitability of adult honeybees Apis mellifera. Pestic. Biochem. 1007 Physiol. 100 (1), 35-40. https://doi.org/10.1016/j.pestbp.2011.02.001

1008 


\title{
Nanopesticide based on botanical insecticide pyrethrum and its potential effects on honeybees
}

Cristiane R. Oliveira, ${ }^{\mathrm{a}, \mathrm{b}}$; Caio E. C. Domingues ${ }^{\mathrm{c}}$; Nathalie F. S. de Melo ${ }^{\mathrm{d}}$; Thaisa C. Roat $^{\mathrm{c}}$; Osmar Malaspina ${ }^{\mathrm{c}}$; Monica Jones-Costa ${ }^{\mathrm{b}}$; Elaine C. M. Silva-Zacarin ${ }^{\mathrm{b}}$ and Leonardo F. Fraceto ${ }^{\mathrm{a}} *$

\footnotetext{
a Universidade Estadual Paulista (UNESP) - "Júlio de Mesquita Filho", Instituto de Ciência e Tecnologia de Sorocaba, Laboratório de Nanotecnologia Ambiental, Av. Três de Março, 511, Alto da Boa Vista, 18087-180, Sorocaba, SP, Brazil.

${ }^{\mathrm{b}}$ Universidade Federal de São Carlos (UFSCar), Campus Sorocaba, Departamento de Biologia (CCHB), Laboratório de Fisiologia da Conservação e Laboratório de Ecotoxicologia e Biomarcadores em Animais, Rodovia João Leme dos Santos km 110, Itinga, 18052-780, Sorocaba, SP, Brazil.

' Universidade Estadual Paulista (UNESP) - "Júlio de Mesquita Filho", Campus Rio Claro, Departamento de Biologia, Centro de Estudos de Insetos Sociais (CEIS), Av. 24 A, 1515, Jardim Bela Vista, 13506-900, Rio Claro, SP, Brazil.

d Faculdade de Medicina São Leopoldo Mandic, Campus Araras. Av. Dona Renata, 71, Santa Cândida, 13600-001, Araras, SP, Brazil.
}

\begin{abstract}
Nanotechnology has the potential to overcome the challenges of sustainable agriculture, and nanopesticides can control agricultural pests and increase farm productivity with little environmental impact. However, it is important to evaluate their toxicity on nontarget organisms, such as honeybees (Apis mellifera) that forage on crops. The aims of this study were to develop a nanopesticide that was based on solid lipid nanoparticles (SLNs) loaded with pyrethrum extract (PYR) and evaluate its physicochemical properties and short-term toxicity on a non-target organism (honeybee). SLN+PYR was physicochemically stable after 120 days. SLN+PYR had a final diameter of $260.8 \pm 3.7$ $\mathrm{nm}$ and a polydispersion index of $0.15 \pm 0.02 \mathrm{~nm}$, in comparison with SLN alone that had a diameter of $406.7 \pm 6.7 \mathrm{~nm}$ and a polydispersion index of $0.39 \pm 0.12 \mathrm{~nm}$. SLN+PYR had an encapsulation efficiency of $99 \%$. The survival analysis of honeybees indicated that $\mathrm{PYR}_{10 \mathrm{ng}}$ presented shorter longevity than those in the control group $(\mathrm{P} \leq$ 0.01). Empty nanoparticles and $\mathrm{PYR}_{10 \mathrm{ng}}$ caused morphological alterations in the bees' midguts, whereas pyrethrum-loaded nanoparticles had no significant effect on digestive cells, so are considered safer, at least in the short term, for honeybees. These results are important in understanding the effects of nanopesticides on beneficial insects and may decrease the environmental impacts of pesticides.
\end{abstract}

KEYWORD: Nanopesticide; Biocide; Sustainable agriculture, Solid lipid nanoparticles; Bees.

\section{Corresponding Authors}

* Elaine C. M. Silva Zacarin - Universidade Federal de São Carlos (UFSCar), Campus Sorocaba, Departamento de Biologia (Dbio, CCHB), Laboratório de Fisiologia da Conservação e Laboratório de Ecotoxicologia e Biomarcadores em Animais, Rodovia João Leme dos Santos km 110, Itinga, 18052-780, Sorocaba, SP, Brazil. Email: elaine@ufscar.br

*Leonardo Fernandes Fraceto - Universidade Estadual Paulista (UNESP), Instituto de Ciência e Tecnologia de Sorocaba, Av. Três de Março, 511, Alto da Boa Vista, 18087-180, Sorocaba, SP, Brazil. Email - leonardo.fraceto@unesp.br 

Supplementary Material
Click here to download S

Click here to download Supplementary Material: Supplementary Information_OLIVEIRA et al_2019_review_.docx Click here to downoad Supplementary Material: Supplementary Information_oLIVETRA .

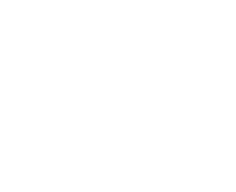

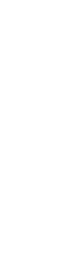
西 西 西 西 . . . . . . 


\section{Language Edited Manuscript}

\section{CERTIFICATE OF \\ ENGLISH EDITING}

This document certifies that the paper listed below has been edited to ensure that the language is clear and free of errors. The edit was performed by professional editors at Editage, a division of Cactus Communications. The intent of the author's message was not altered in any way during the editing process. The quality of the edit has been guaranteed, with the assumption that our suggested changes have been accepted and have not been further altered without the knowledge of our editors.

\section{Title Of The PAPER}

Can a nanopesticide based on solid lipid nanoparticles loaded with the botanical insecticide pyrethrum be toxic to honeybees?

\section{Authors}

Cristiane Ronchi de Oliveira; Caio Eduardo C. Domingues; Nathalie Ferreira S. de Melo; Thaisa Cristina Roat; Osmar Malaspina; Monica Jones-Costa; Elaine Cristina M. Silva-Zacarin; Leonardo Fernandes Fraceto.
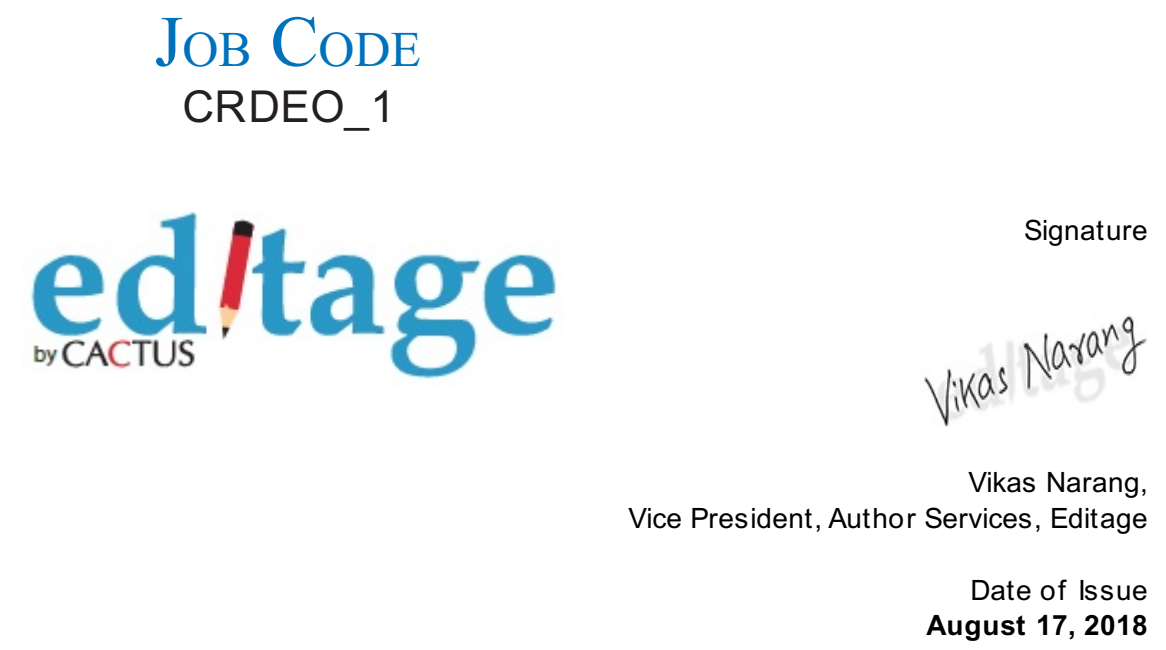

Editage, a brand of Cactus Communications, offers professional English language editing and publication support services to authors engaged in over 500 areas of research. Through its community of experienced editors, which includes doctors, engineers, published scientists, and researchers with peer review experience, Editage has successfully helped authors get published in internationally reputed journals. Authors who work with Editage are guaranteed excellent language quality and timely delivery.

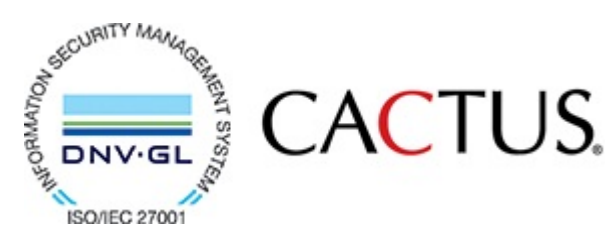

Taiwan

submitjobs@editage.com

0226570306

www.editage.com.tw 


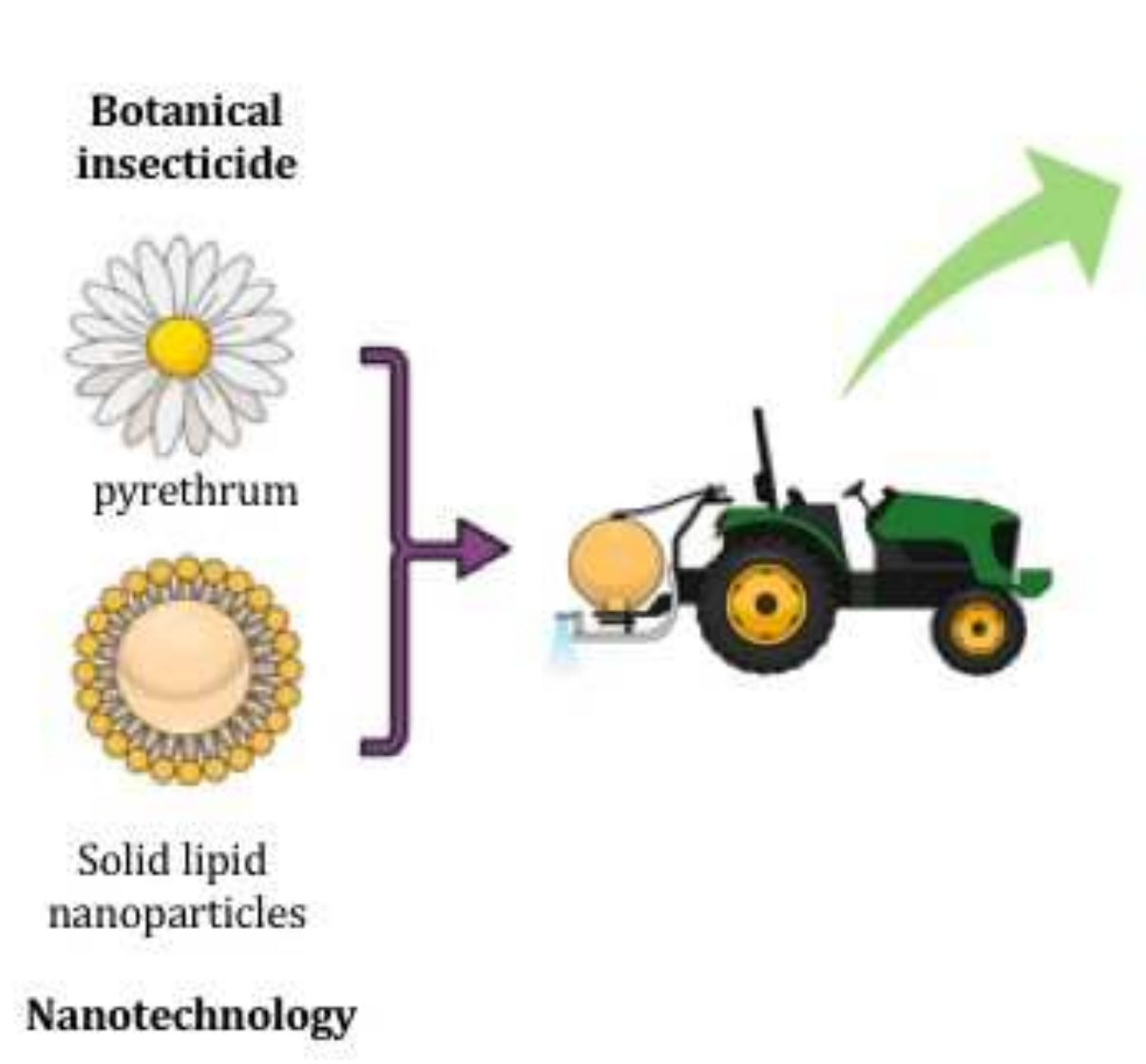

Solid lipid nanoparticles

\section{Nanotechnology} gy

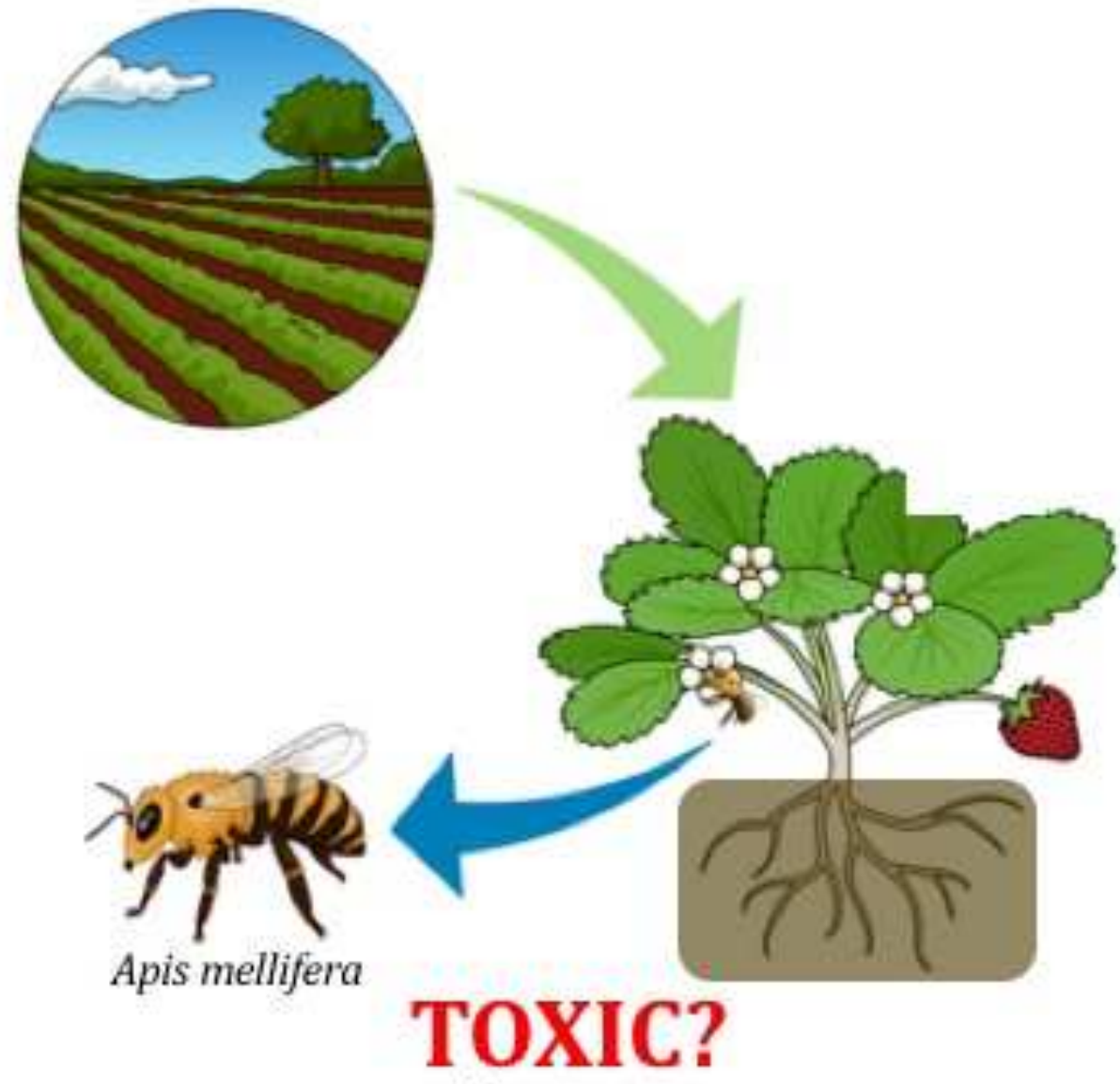

TOXIC?

Non-target

$$
\text { organism }
$$

